\title{
WIPP Gas-Generation Experiments
}

\author{
Frank S. Felicione \\ Steven M. Frank \\ Dennis D. Keiser
}

May 2007

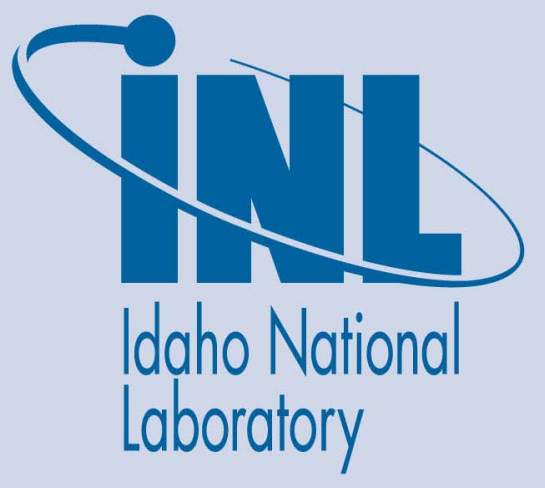

The INL is a U.S. Department of Energy National Laboratory operated by Battelle Energy Alliance 
INL/EXT-07-12631

\section{WIPP Gas-Generation Experiments}

Frank S. Felicione

Steven M. Frank

Dennis D. Keiser

May 2007

\section{Idaho National Laboratory \\ Idaho Falls, Idaho 83415}

http://www.inl.gov

Prepared for the U.S. Department of Energy

Assistant Secretary for Environmental Management

Carlsbad Field Office

Under DOE Idaho Operations Office

Contract DE-AC07-05ID14517 



\section{ABSTRACT}

An experimental investigation was conducted for gas generation in contact-handled transuranic (CH-TRU) wastes subjected for several years to conditions similar to those expected to occur at the Waste Isolation Pilot Plant (WIPP) should the repository eventually become inundated with brine. Various types of actual CH-TRU wastes were placed into 12 corrosion-resistant vessels. The vessels were loosely filled with the wastes, which were submerged in synthetic brine having the same chemical composition as that in the WIPP vicinity. The vessels were also inoculated with microbes found in the Salado Formation at WIPP. The vessels were sealed, purged, and the approximately $750-\mathrm{ml}$ headspace in each vessel was pressurized with nitrogen gas to approximately 146 atmospheres to create anoxic conditions at the lithostatic pressure estimated in the repository were it to be inundated. The temperature was maintained at the expected $30^{\circ} \mathrm{C}$. The test program objective was to measure the quantities and species of gases generated by metal corrosion, radiolysis, and microbial activity. These data will assist in the specification of the rates at which gases are produced under inundated repository conditions for use in the WIPP Performance Assessment computer models.

These experiments were very carefully designed, constructed, instrumented, and performed. Approximately 6-1/2 years of continuous, undisturbed testing were accumulated. Several of the vessels showed significantly elevated levels of generated gases, virtually all of which was hydrogen. Up to $4.2 \%$ hydrogen, by volume, was measured. Only small quantities of other gases, principally carbon dioxide, were detected.

Gas generation was found to depend strongly on the waste composition. The maximum hydrogen generation occurred in vessels containing carbon steel. Visual examination of carbon-steel coupons confirmed the correspondence between the extent of observable corrosion and hydrogen generation. Average corrosion penetration rates in carbon-steel of up to 2.3 microns per year were deduced. Conversion of carbon to carbon dioxide was calculated to be as high as $4.7 \mu \mathrm{g}-\mathrm{mol} / \mathrm{yr} / \mathrm{g}$-carbon. Carbon monoxide was detected in only two waste compositions, and methane was detected in only one. In all three of these cases, the concentrations of these lesser gases detected were barely above the detection limits. No hydrogen sulfide was ever detected.

Initial rates of hydrogen generation measured in the carbon-steel-bearing wastes during the first year of testing did not always correspond to rates measured over the longer term. Compared to the long-term trends, the initial gasgeneration rates for some waste types were higher, for some lower, and for others remained constant. Although carbon-steel corrosion was clearly the dominant hydrogen generator, the rates of generation were found to be reduced in test vessels where the same quantity of carbon steel was co-mingled with other waste types. This is a beneficial phenomenon relative to performance of the WIPP repository. Statistical analyses of the results were made to quantify these negative interaction effects.

Electron microscopy analyses of the carbon-steel coupons revealed that corrosion products were predominantly iron chlorides and oxides. Iron, chlorine, 
oxygen, uranium, magnesium, calcium, aluminum, silicon were all present in the corrosion products. No americium nor neptunium, both present in the wastes, were detected in any of the corrosion products. All actinides found in the brine were fully solubilized, indicating no particulate or colloidal transport of actinides from the solids to the brine. 


\section{CONTENTS}

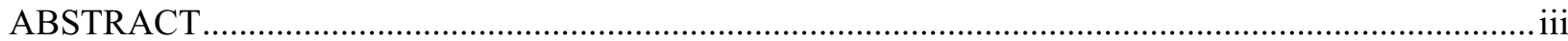

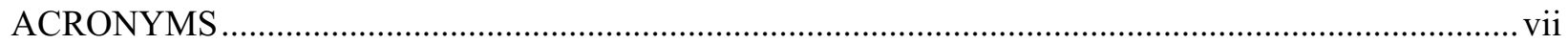

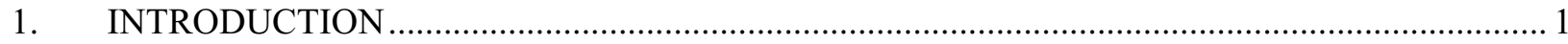

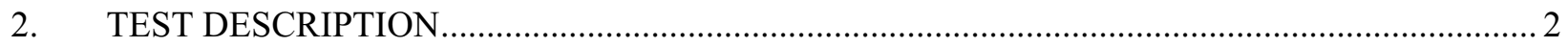

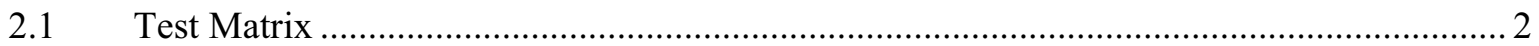

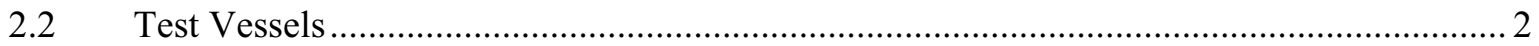

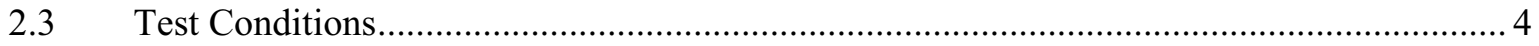

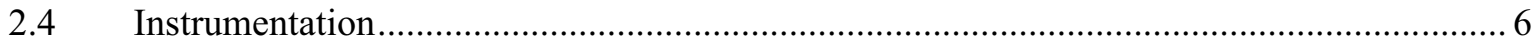

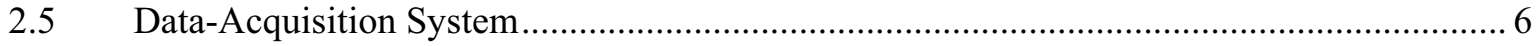

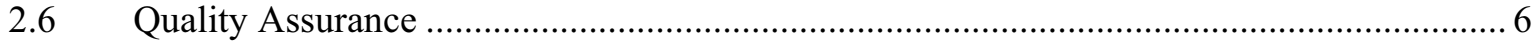

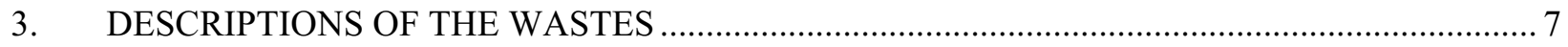

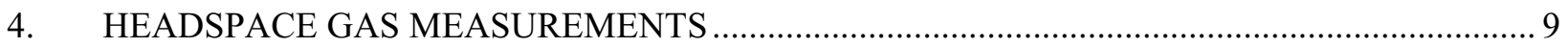

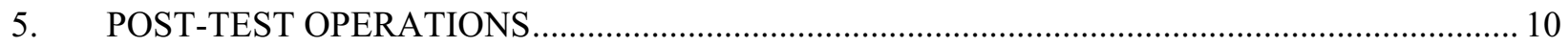

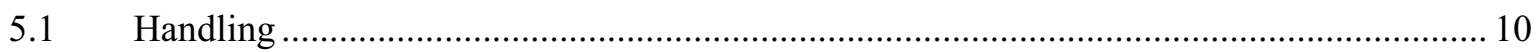

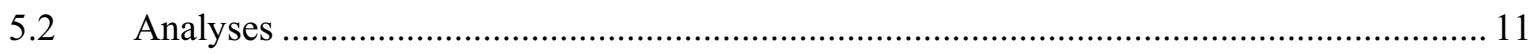

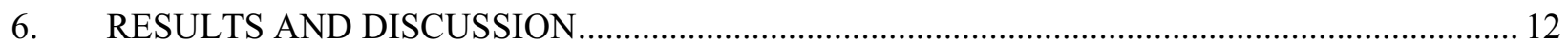

6.1 Analyses of Headspace-Gas Samples ........................................................................... 12

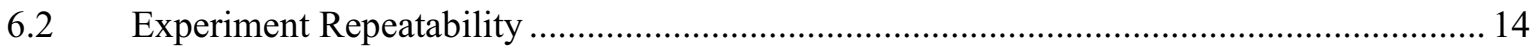

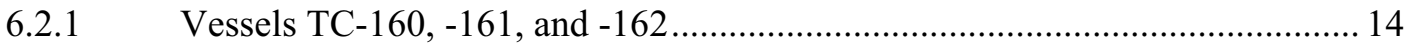

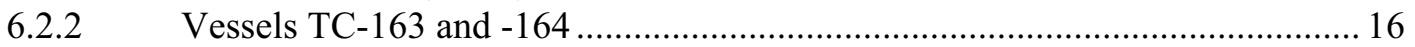

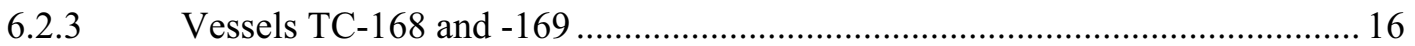

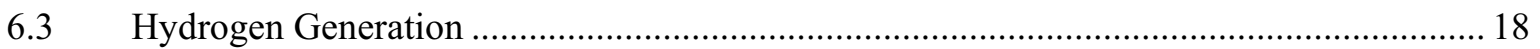

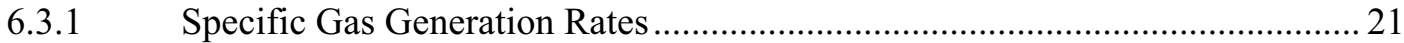

6.3.2 Hydrogen-Generation Temporal Profiles ........................................................ 23

6.3.3 Hydrogen Generation in TC-166 vs. Other Carbon-Steel-Bearing

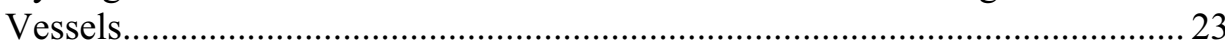

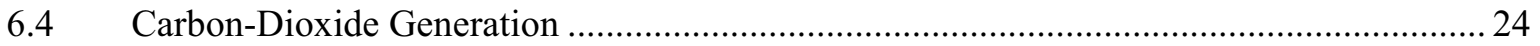




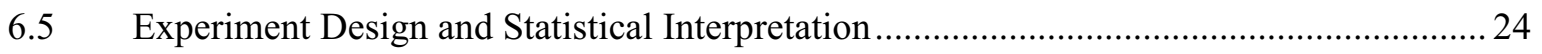

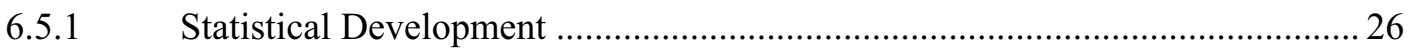

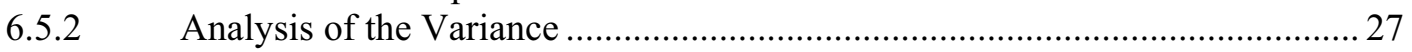

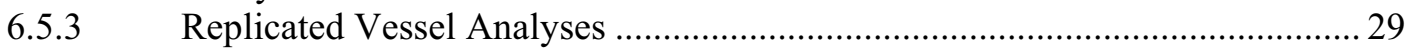

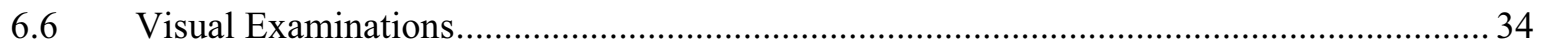

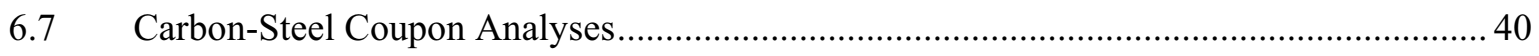

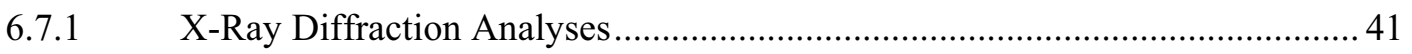

6.7.2 Scanning Electron Microscopy Analyses..................................................... 42

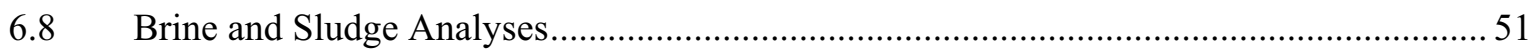

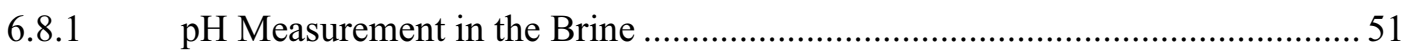

6.8.2 Radionuclide Leaching into the Brine............................................................. 52

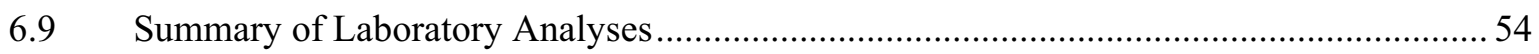

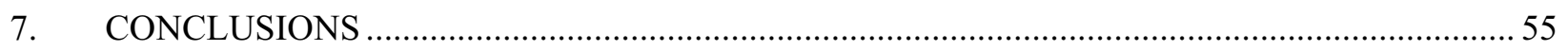

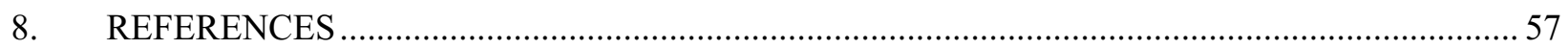

\section{FIGURES}

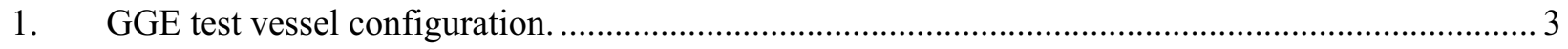

2. Transparent mockup of a GGE vessel with typical waste. ......................................................... 4

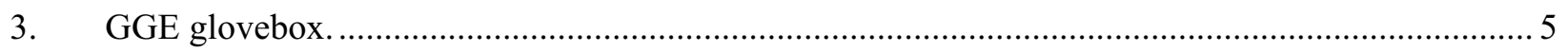

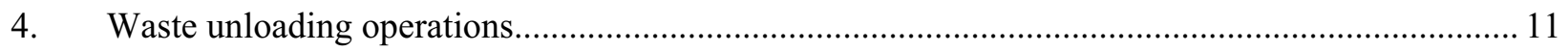

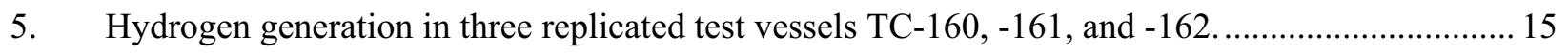

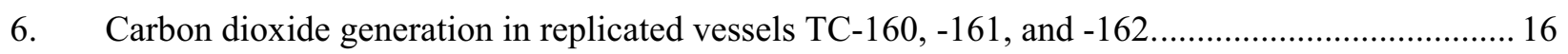

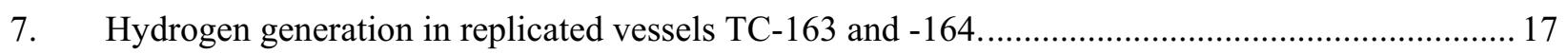

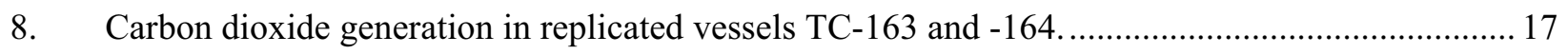

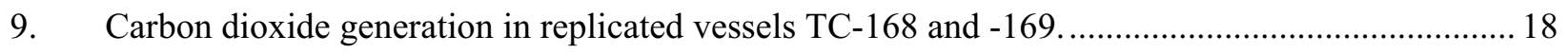

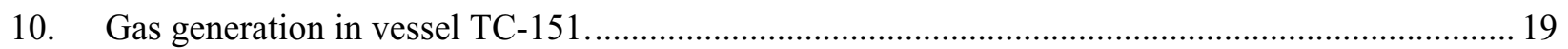

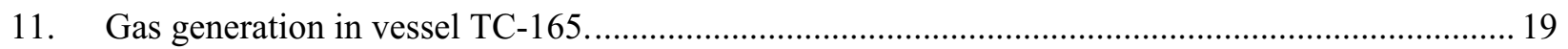

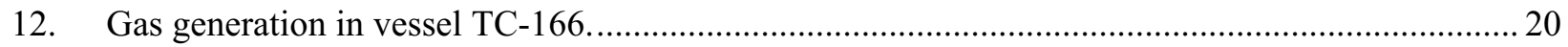

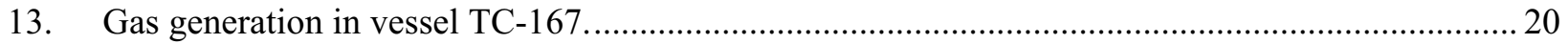




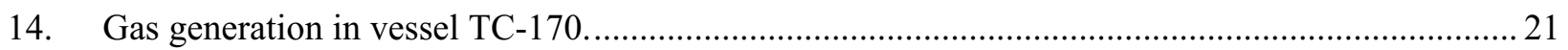

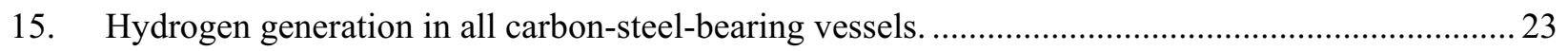

16. Statistical confidence limits for final hydrogen measurements................................................2

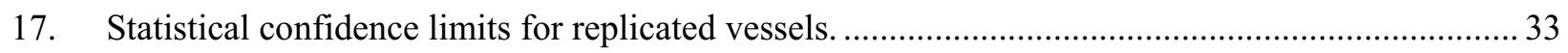

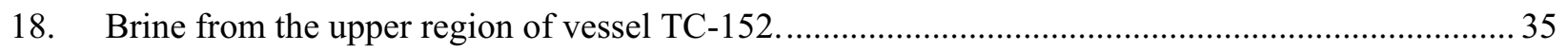

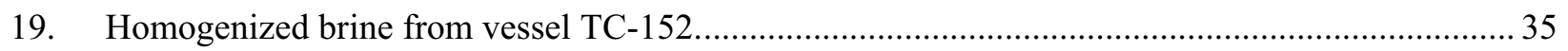

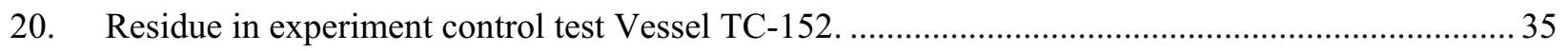

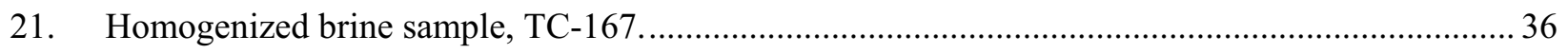

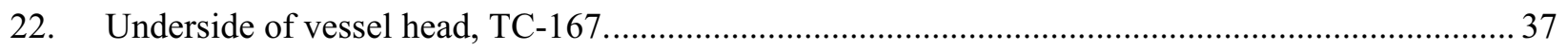

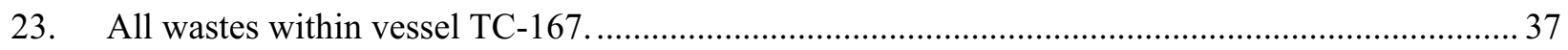

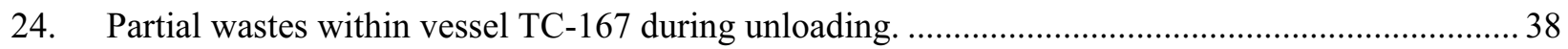

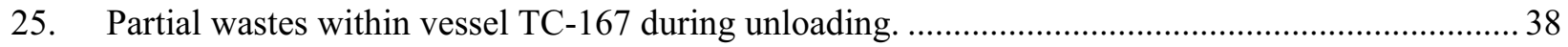

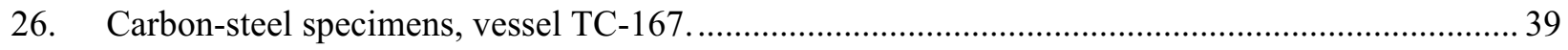

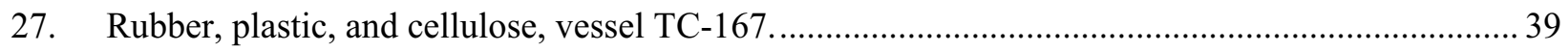

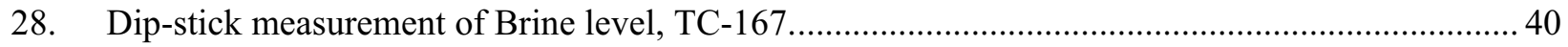

29. Sludge-covered carbon-steel coupons immediately after removal and separation, TC-166........... 40

31. Montage of backscattered electron micrographs for the carbon-steel specimen, TC-160 .............. 42

30. X-ray diffraction pattern of the carbon-steel corrosion coupon, TC-166..................................... 42

32. Backscattered electron images of the surface of the carbon-steel coupon, TC-160..................... 43

33. (a) Backscattered electron micrograph of bright-contrast phase; and

(b) EDS spectrum of a box scan of the area depicted in view $a$

34. (a) Backscattered electron image of corrosion products observed on carbon-steel coupon, TC-160 (X-ray maps for Iron (View $b$ ), Uranium $($ View $c$ ), and Oxygen $($ View $d$ )) . ............................... 45

35. Montage of carbon-steel-coupon surface backscattered electron micrographs, TC-166................ 46

36. Carbon-steel-coupon surface backscattered electron images, TC-166 ....................................... 47

37. Backscattered electron images of specific corrosion products, carbon-steel-coupon surface, TC-166. 
38. EDS spectra for the phases shown in Figure 37a (the largest peak in $(a)$ is U, and the palladium $(\mathrm{Pd})$ is from the coating process).

39. (a) Carbon-steel coupon backscattered electron image of corrosion products, TC-160.

$\mathrm{X}$-ray maps for Iron (view $b$ ), Uranium (view $c$ ), and Oxygen (view $d$ ).

40. Sample cross-section backscattered electron images, (a) TC-160 and (b) TC-166.

41. Comparison of the Uranium, Neptunium, Plutonium, and Americium distributions in the Brine and the solid Sludge.

\section{TABLES}

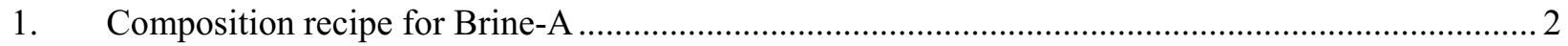

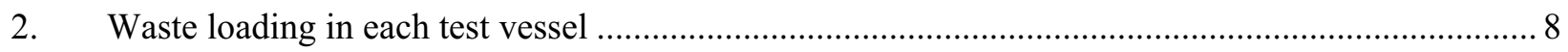

3. Headspace gas analyses after approximately 6-1/2 yr testing (Fall 2002 samples)........................ 13

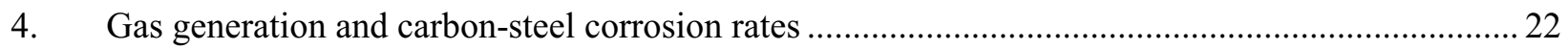

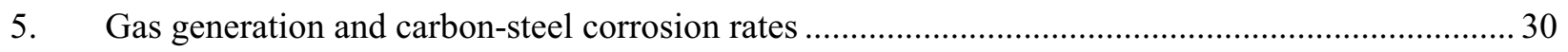

6. Statistical analyses of hydrogen generation in replicated vessels............................................... 31

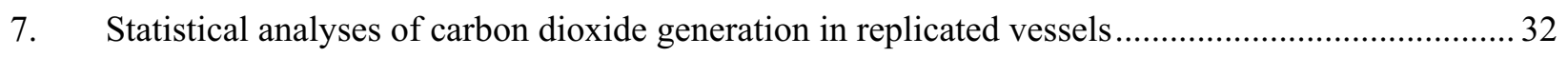

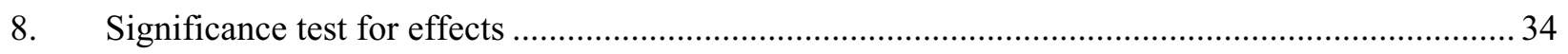

9. $\mathrm{pH}$ values of Sludge/Brine mixtures (measurement uncertainty $\pm 1 \mathrm{pH}$ unit)............................ 52

10. Actinide isotopic concentrations in the filtered Brine solutions $(0.7-\mu \mathrm{m}$ and $0.005-\mu \mathrm{m}$ filter) and the solid Sludge samples (measurement uncertainty $\pm 10 \%$ relative standard deviation)

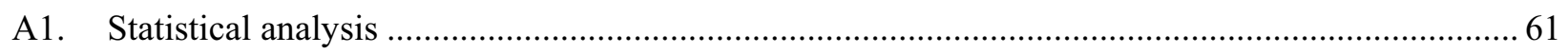

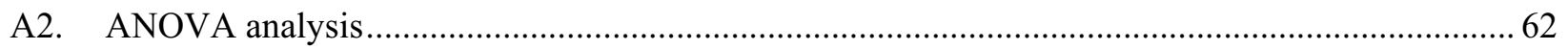




\section{ACRONYMS}

ANL Argonne National Laboratory

ANL-W Argonne National Laboratory-West

ANOVA Analysis of Variance

ASME American Society of Mechanical Engineers

BNL Brookhaven National Laboratory

CBFO Carlsbad Field Office

CH-TRU contact-handled transuranic

DOE Department of Energy

DOT Department of Transportation

EDS energy dispersive spectrometer (spectra)

GGE Gas Generation Experiments

ICP-MS inductively coupled plasma - mass spectrometry

INL Idaho National Laboratory

LANL Los Alamos National Laboratory

NIST National Institute of Standards and Technology

PNNL Pacific Northwest National Laboratory

QA Quality Assurance

RTD resistance temperature detector

SEM scanning electron microscopy

SNL Sandia National Laboratory

STP standard temperature and pressure

STTP Source-Term Waste Test

TC test container

WIPP Waste Isolation Pilot Plant

XRD $\quad$-ray diffraction 


\section{WIPP Gas-Generation Experiments}

\section{INTRODUCTION}

Sandia National Laboratory (SNL) has the responsibility during the preclosure operations phase of the Waste Isolation Pilot Plant (WIPP) for periodically predicting the long-term performance of the repository to satisfy licensing requirements. Eventual inundation of the repository by brine from the Salado Formation has been identified as an anticipated occurrence. Gases would be generated from the wastes stored within carbon-steel drums as a result of corrosion of both containers and metal wastes, radiolysis of the brine and wastes, and from the activities of aerobic and anaerobic micro-organisms that are known to populate the brine. The resulting pressure developed within the WIPP storage rooms has a strong influence on the rate at which brine can enter and transport soluble and suspended actinide materials. Computer models of the WIPP for the Performance Assessment must include conservative, but realistic, account for gas generation.

Generation of gases is a complex process, given the plethora of waste materials and conditions that can be expected in the repository. Corrosion of metals in an aqueous environment liberates hydrogen as the metals oxidize. Other reactions among the waste materials can also influence the quantity of gases liberated from the wastes. Radioactive contaminants in the waste can produce hydrogen by radiolysis of the brine and organic materials. Finally, carbon-rich wastes can provide a healthy environment for aerobic and anaerobic microbe colonies. Microbes feeding on wastes can liberate hydrogen as well as produce metabolic gases such as carbon dioxide and carbon monoxide, and certain of the microbe types found in the Salado Formation are known to produce methane and hydrogen sulfide.

Several test programs, sponsored by the Carlsbad, New Mexico field office of the Department of Energy (DOE), have been established within the SNL Gas-Generation Program Department to better understand the potential for mobilizing radionuclides in WIPP. For example, gas generation by metal corrosion, at low to moderate pressures, in both humid and inundated conditions, was investigated at the Pacific Northwest National Laboratory (PNNL) (1). Gas generation via microbial processes was investigated at Brookhaven National Laboratory (2). Testing at Los Alamos National Laboratory (LANL) examined the extent to which actinide materials become mobilized (dissolved or suspended) in brine (3).

As a further benchmark and confirmation of gas generation measured in the other programs, a fully integrated test program was initiated in 1994 at Argonne National Laboratory (ANL). Technical requirements were established by SNL (4), (5). The ANL program subjected actual, contact-handled transuranic (CH-TRU) wastes of various types to long-term testing with prototypic, inoculated brine at the conditions expected in WIPP. Environmental conditions matched the $30-^{\circ} \mathrm{C}$ temperature and the 146-atm lithostatic pressure expected at the 656-m (2150-ft) depth of the repository. The oxygen levels were maintained very low to mimic the anaerobic conditions that will develop after the first few years following the consumption of free oxygen initially within the storage rooms by chemical reactions, radiolysis, and microbial processes. The ANL Gas Generation Experiments (GGE) program would account for synergistic as well as antagonistic gas-generation mechanisms. Testing at ANL began in early 1996 and continued through the Fall of 2002. Thus, approximately 6-1/2 years of continuous testing under very realistic conditions were achieved. The test data obtained represent a valuable basis for future improvements to repository performance modeling.

This report describes the program, the experiments, the gas-generation results, and results from the post-test activities and analyses of the wastes directed by the DOE Carlsbad Field Office (CBFO). 


\section{TEST DESCRIPTION}

\subsection{Test Matrix}

CH-TRU wastes generated at the Rocky Flats Plant were tested. The wastes selected consisted of various materials known to comprise a large percentage of the wastes destined for the WIPP. These included several heterogeneous materials: carbon steel, paper, cloth, plastic, rubber, and leaded rubber. A homogeneous, inorganic "waste-water" sludge was also a constituent. Isotopic distributions of actinides were determined for each waste category. Various combinations of the waste materials, constructed per a two-level, fractional factorial experiment design, were loaded into 12 vessels. Measurements of the longterm gas-generation behavior of these materials to obtain data for refining computer models comprised the experiment (5). Although the overall proportions of wastes destined for the WIPP are reasonably well known, the proportions within any of the approximately 124 repository rooms can vary significantly (6). The proportions of wastes tested in the GGE were not intended to mimic the overall WIPP distributions, but, rather, to include those waste types and combinations known to be plentiful and that are susceptible to the generation of gases.

The wastes were immersed in simulated brine, referred to as Brine-A, which was chemically representative of the brine from the Carlsbad, New Mexico Salado formation. The brine consisted of numerous salts that had been carefully proportioned in accordance with analyses of natural brine samples from the WIPP area. Table 1 lists the Brine-A constituents and their proportions. Microbes collected from lakes and sediment beds in the Nash Draw, adjacent to the WIPP, and from the underground workings were inoculated into the brine. In addition to the 12 waste-bearing vessels, two identical experimentcontrol vessels contained inoculated brine, but no wastes, for a total of 14 test vessels.

Table 1. Composition recipe for Brine-A.

\begin{tabular}{|c|c|}
\hline Constituent & Quantity \\
\hline $\mathrm{MgCl}_{2} \cdot 6 \mathrm{H}_{2} \mathrm{O}$ & $5.311 \mathrm{~kg}$ \\
\hline $\mathrm{NaCl}$ & $1.820 \mathrm{~kg}$ \\
\hline $\mathrm{KCl}$ & $1.036 \mathrm{~kg}$ \\
\hline $\mathrm{Na}_{2} \mathrm{SO}_{4}$ & $0.113 \mathrm{~kg}$ \\
\hline $\mathrm{Na}_{2} \mathrm{~B}_{4} \mathrm{O}_{7} \cdot 10 \mathrm{H}_{2} \mathrm{O}$ & $35.46 \mathrm{~g}$ \\
\hline $\mathrm{CaCl}_{2}$ & $30.18 \mathrm{~g}$ \\
\hline $\mathrm{NaHCO}_{3}$ & $17.46 \mathrm{~g}$ \\
\hline $\mathrm{NaBr}$ & $9.46 \mathrm{~g}$ \\
\hline $\mathrm{LiCl}$ & $2.27 \mathrm{~g}$ \\
\hline $\mathrm{RbCl}$ & $0.4965 \mathrm{~g}$ \\
\hline $\mathrm{SrCl}_{2} \cdot 6 \mathrm{H}_{2} \mathrm{O}$ & $0.2736 \mathrm{~g}$ \\
\hline $\mathrm{K} 1$ & $0.2392 \mathrm{~g}$ \\
\hline $\mathrm{FeCl}_{3} \cdot 6 \mathrm{H}_{2} \mathrm{O}$ & $0.2397 \mathrm{~g}$ \\
\hline $\mathrm{CsCl}$ & $0.0302 \mathrm{~g}$ \\
\hline Conc. $\mathrm{HCl}$ & $0.23 \mathrm{ml}$ \\
\hline De-ionized Water $(\geq 1 \mathrm{M} \Omega)$ & 18.201 \\
\hline
\end{tabular}




\subsection{Test Vessels}

Identical vessels were used for all of the tests. The 14 test vessels were vertical cylinders, approximately $400 \mathrm{~mm}$ (16 in) deep and $152 \mathrm{~mm}$ (6 in) diameter, and each had a total volume of approximately 7.3 liters (1.92 gal). A full-diameter top closure facilitated the introduction of large waste items. These vessels were manufactured from Hastelloy-C276 to minimize any potential chemical reactions between brine and vessel. The vessels were constructed to the American Society of Mechanical Engineers (ASME) Boiler and Pressure Vessel Code specifications and so stamped, with a working pressure rating of $20 \mathrm{MPa}(2900 \mathrm{psig})$ at $30^{\circ} \mathrm{C}(86 \mathrm{~F})$. Empty weight of each vessel was approximately $55 \mathrm{~kg}(120 \mathrm{lb})$.

Figure 1 shows the outer view and a schematic cross-section of the test vessels. An instrument tree that consisted of isolation valves, pressure transducer, and pressure transmitter was attached to the top of the vessel, but is not shown in this figure.
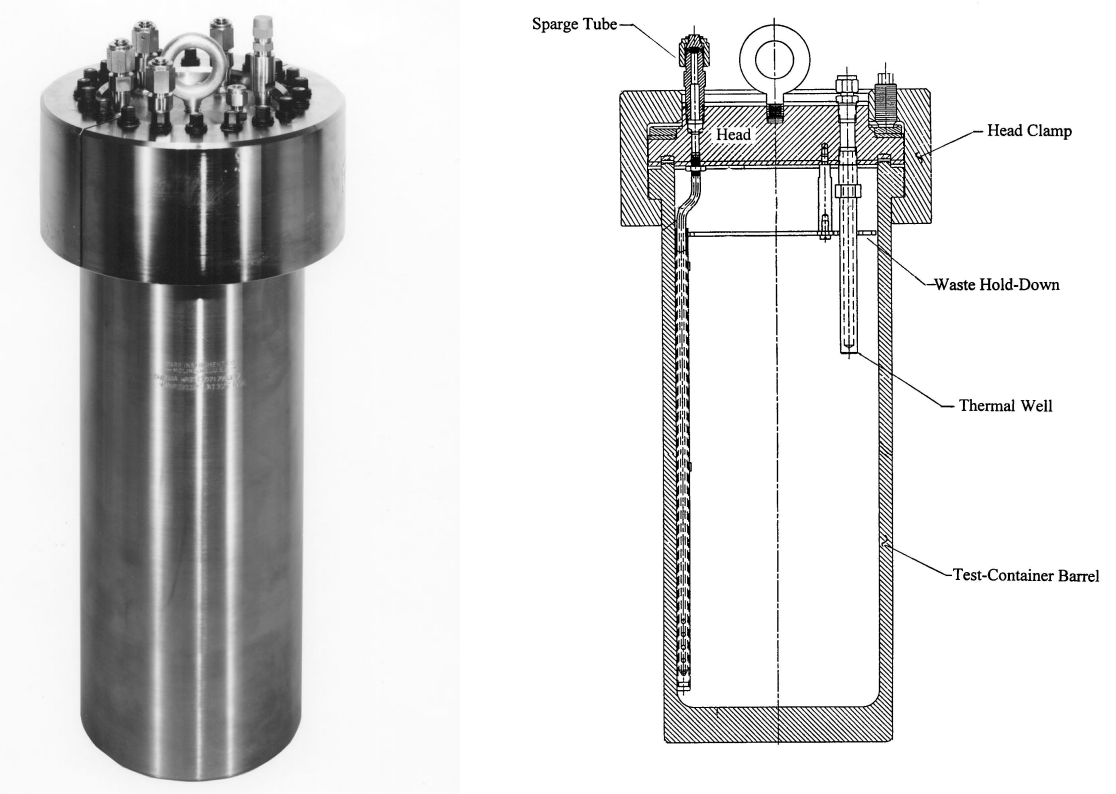

Figure 1. GGE test vessel configuration.

Carefully measured wastes were loosely loaded in layers into the vessels. Brine and the inoculum were then added to fill approximately $90 \%$ of the volume and to completely submerge the wastes. A holddown screen fastened to the underside of the vessel lid ensured that the wastes remained fully submerged after the vessel was closed. The free, or headspace, volume that remained above the brine level was typically about $750 \mathrm{ml}\left(46 \mathrm{in}^{3}\right)$. Several penetrations through the top lid provided access for initial gas sparging, brine filling, gas sampling, instrumentation, and an over-pressure-relief rupture disk. Figure 2 shows a transparent plastic container mockup of the vessel with wastes. 


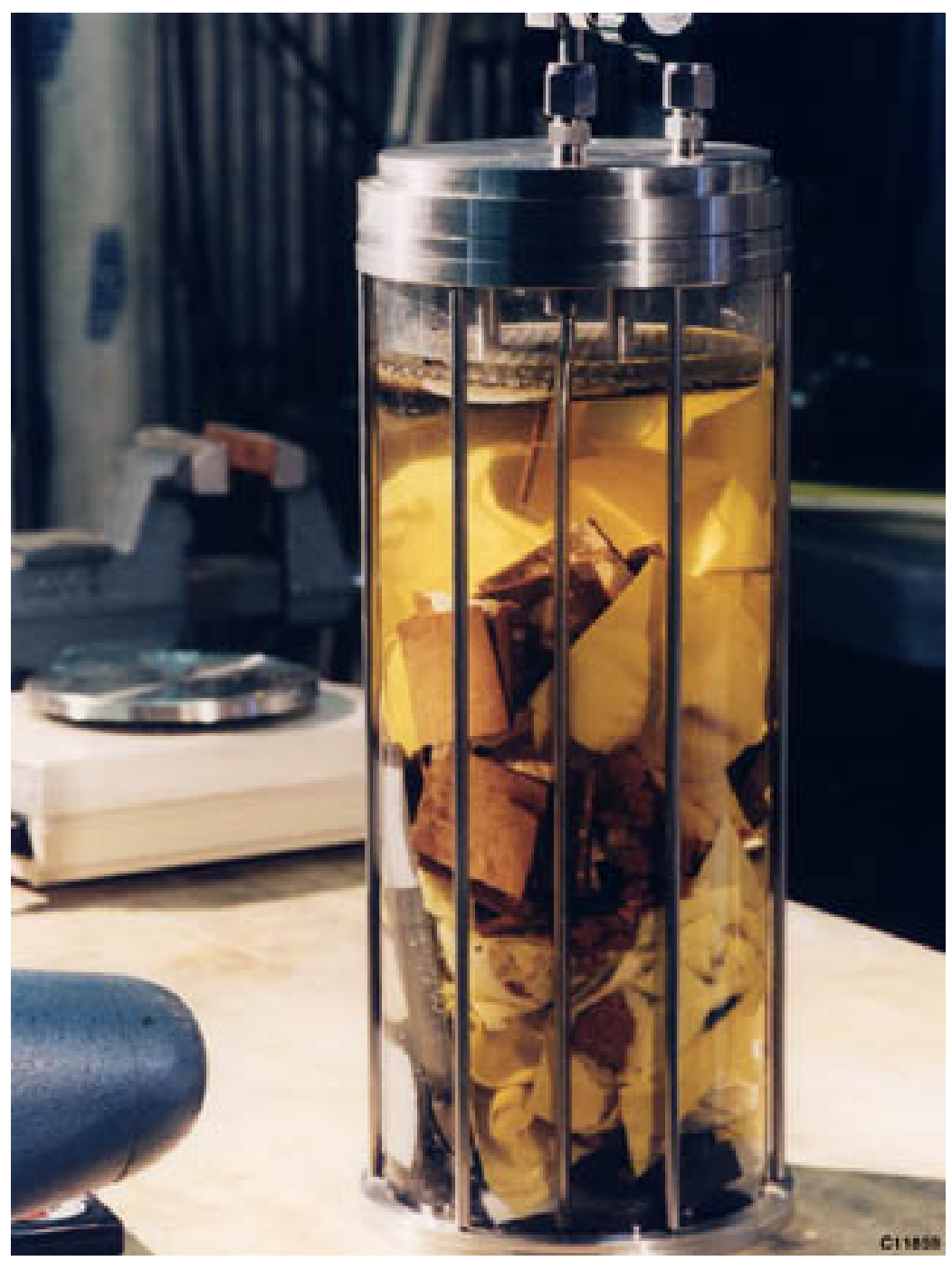

Figure 2. Transparent mockup of a GGE vessel with typical waste.

\subsection{Test Conditions}

The headspaces in all 14 vessels were pressurized to approximately $146 \mathrm{~atm}$ (14.8 MPa, or $2145 \mathrm{psig}$ ) with dry, high purity nitrogen gas to provide the required test pressure. Approximately $1 \%$ helium was added to the nitrogen gas for use as a tracer during leak testing. The temperature within each test vessel was maintained at $30 \pm 2^{\circ} \mathrm{C}$, well within the $30 \pm 5^{\circ} \mathrm{C}$ test specifications. An individual, proportional, integral, and derivative controller regulated an electric heater band that surrounded, but did not contact, each vessel. A safety concern required the vessel heaters to be turned off during the final $1-1 / 2$ years of the tests, but the temperature remained very close to $30^{\circ} \mathrm{C}$. However, an unrelated programmatic requirement materialized during the final few months of the experiment that reduced the host facility temperature (and therefore, that of the no-longer-heated GGE vessels, as well) to approximately $17.5-20^{\circ} \mathrm{C}$.

The vessels were placed in an argon-gas-inerted glovebox, Figure 3, for the duration of the testing. A gas-cleaning system ensured that the oxygen concentration within the glovebox remained less than the $100-\mathrm{ppm}$, by volume, test specification as a precaution against corrupting the gas-samples. 


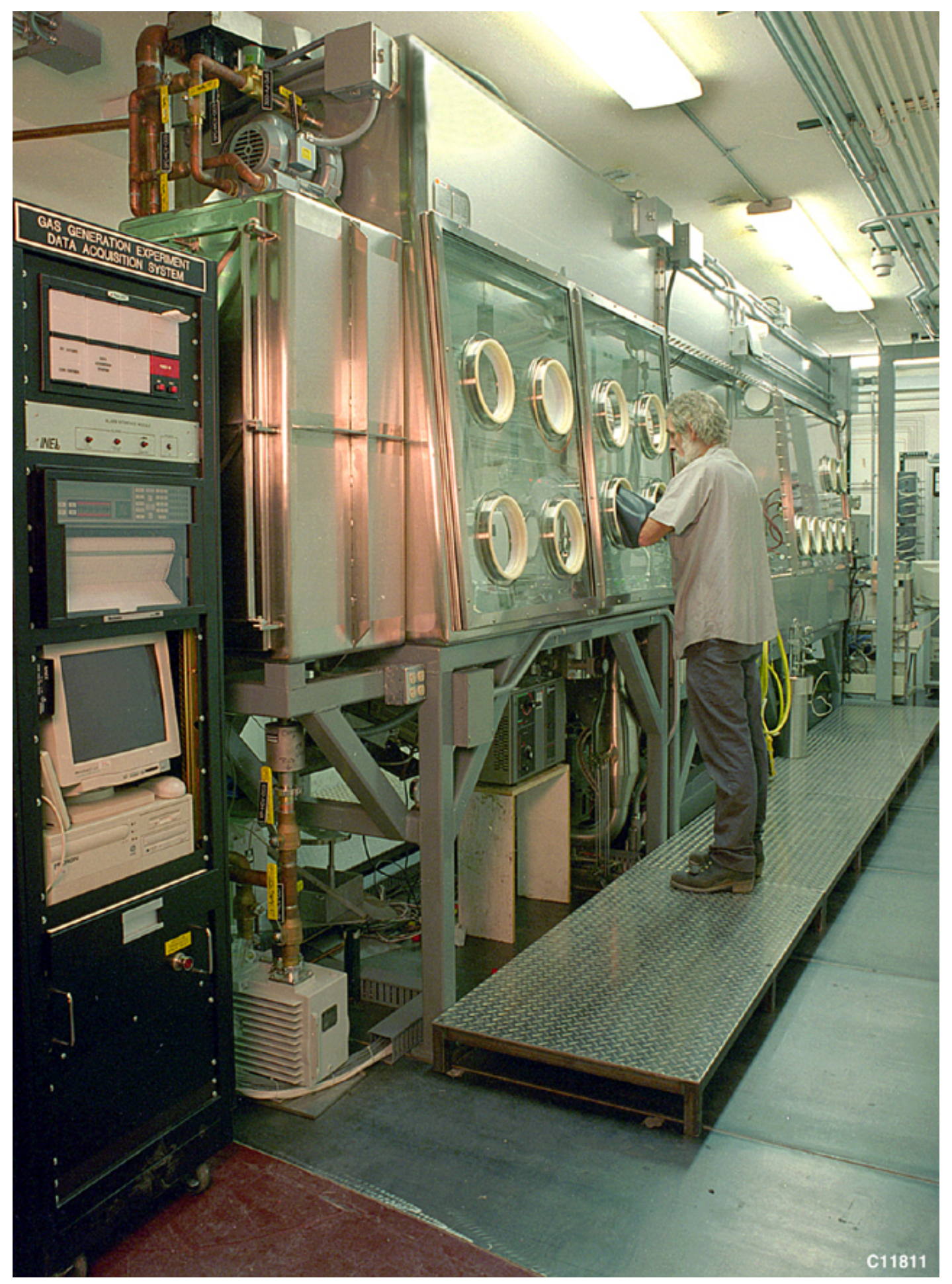

Figure 3. GGE glovebox. 


\subsection{Instrumentation}

Instrumentation on each vessel consisted of a resistance temperature detector (RTD) in a thermal well immersed approximately $75 \mathrm{~mm}$ (2.95 in) deep in the brine; a highly sensitive and stable pressure sensor (Mensor Corporation) for the headspace gas; and a single RTD that measured the glovebox temperature. The $\mathrm{RTD}=\mathrm{s}$ and pressure sensors were calibrated against National Institute of Standards and Technology (NIST) traceable standards every 6 months for the initial four years of testing. Curtailed funding during the final 2-1/2 yr, however, allowed calibrations to be performed only just prior to sampling the headspace gases.

\subsection{Data-Acquisition System}

Temperature and pressure data for each vessel and the glovebox temperature were measured and displayed on a computer monitor. The temperatures and pressures existing at the beginning of each hour were recorded on a computer hard disk throughout the duration of the experiments. High and low temperature and pressure alarms monitored the operation continuously.

\subsection{Quality Assurance}

The program was conducted during the first four years of testing in accordance with the WIPP Quality Assurance (QA) Program Plan and a project-specific QA Implementation Plan. Although a hiatus in funding over the final 2-1/2 yr prevented strict adherence to every aspect of the QA plan, there is very high confidence in the data that was acquired during this period. 


\section{DESCRIPTION OF THE WASTES}

Waste materials were selected from waste drums that originated at the Rocky Flats Plant (now designated the Rocky Flats Environmental Technology Site) and which were stored at the Idaho National Engineering and Environmental Laboratory. The wastes were confirmed by measurement to be transuranic, i.e., having activities greater than $100 \mathrm{nCi} / \mathrm{g}$. Isotopic measurements of the contaminants were made, yielding gravimetric distributions for ${ }^{238} \mathrm{Pu},{ }^{239} \mathrm{Pu},{ }^{240} \mathrm{Pu},{ }^{241} \mathrm{Pu},{ }^{242} \mathrm{Pu}$, and ${ }^{241} \mathrm{Am}$ in each test vessel. Waste loadings for a given vessel were carefully formulated. These formulations comprised wastes from the following categories:

- $\quad$ Carbon steel. Strips approximately $51 \times 178$-mm $(2 \times 7$-in $)$ cut from the lids of standard Department of Transportation (DOT) 7A 208-liter (55-gal) drums.

- Sludge. Aqueous, inorganic “waste-water" type, moist and sticky when loaded.

- $\quad$ Lead. Leaded neoprene-rubber glovebox gloves, chopped to pieces approximately $60 \times 60 \mathrm{~mm}$ $(2.4 \times 2.4$ in $)$.

- $\quad$ Rubber. 5-mm-diameter (cross-section) neoprene o-rings, chopped to various lengths.

- $\quad$ Plastic. High-density polyethylene bottles, chopped into approximately $60 \times 60 \mathrm{~mm}(2.4 \times 2.4 \mathrm{in})$ pieces.

- $\quad$ Cellulose. Paper (brown fiber carton pieces) approximately $60 \times 60 \times 3$-mm thick $(2.4 \times 2.4 \times 0.125$ in) and cloth (cotton anti-contamination clothing pieces).

Because of the difficulty in obtaining the required quantity of contaminated carbon steel with enough uniformity to conduct comparative tests, a decision was made to use uncontaminated lids from new DOT-7A drums. Paint and other surface protective coatings were removed. Carbon steel was quantified by the exposed area (two sides plus edges). The other waste types were quantified by their masses. Table 2 lists the waste types and loadings for each vessel. The actinide contents in each vessel are shown on the right-hand side of the table.

The experiment design required nominally identical quantities of each waste type in each vessel where this particular waste type was specified. For example, all vessels that contained carbon steel had nominally $900 \mathrm{~cm}^{2}\left(139.5 \mathrm{in}^{2}\right)$ of surface area; those containing plastic were loaded with nominally $90 \mathrm{~g}$ $(0.2 \mathrm{lb})$ of the polyethylene bottle pieces; etc. The small variations that occurred in the actual waste loadings were carefully noted and recorded. Several pieces of each heterogeneous waste material were required to make up the waste loadings specified, e.g., 5 pieces of the steel specimens were placed in the carbon-steel-bearing vessels.

The mass fractions of carbon estimated for each waste category are shown at the bottom of Table 2 . When these fractions are multiplied by the waste mass the result is the mass of carbon in that waste component. Carbon fractions for rubber and leaded rubber include both the carbon within the neoprene molecule plus the large quantity of carbon-black filler that is added to this material (7). 
Table 2. Waste loading in each test vessel.

\begin{tabular}{|c|c|c|c|c|c|c|c|c|c|c|c|c|c|}
\hline \multirow{3}{*}{$\begin{array}{c}\text { Test Vessel } \\
\text { Number }\end{array}$} & \multicolumn{7}{|c|}{ Waste Type } & \multicolumn{6}{|c|}{ Radionuclide Content } \\
\hline & \multicolumn{2}{|c|}{$\begin{array}{c}\text { Carbon } \\
\text { Steel }\end{array}$} & \multirow{2}{*}{$\begin{array}{c}\text { Sludge } \\
\mathrm{g}\end{array}$} & \multirow{2}{*}{$\begin{array}{c}\text { Leaded } \\
\text { Rubber } \\
\text { g }\end{array}$} & \multirow{2}{*}{$\begin{array}{c}\text { Rubber } \\
\mathrm{g}\end{array}$} & \multirow{2}{*}{$\begin{array}{c}\text { Plastic } \\
\mathrm{g}\end{array}$} & \multirow{2}{*}{$\begin{array}{c}\text { Cellulose } \\
\mathrm{g}\end{array}$} & \multirow{2}{*}{$\begin{array}{c}{ }^{238} \mathrm{Pu} \\
\mathrm{mg}\end{array}$} & \multirow{2}{*}{$\begin{array}{c}{ }^{239} \mathrm{Pu} \\
\mathrm{mg}\end{array}$} & \multirow{2}{*}{$\begin{array}{c}{ }^{240} \mathrm{Pu} \\
\mathrm{mg}\end{array}$} & \multirow{2}{*}{$\begin{array}{c}{ }^{241} \mathrm{Pu} \\
\mathrm{mg}\end{array}$} & \multirow{2}{*}{$\begin{array}{c}{ }^{242} \mathrm{Pu} \\
\mathrm{mg}\end{array}$} & \multirow{2}{*}{$\begin{array}{c}{ }^{241} \mathrm{Am} \\
\mu \mathrm{g}\end{array}$} \\
\hline & $\mathrm{cm}^{2}$ & $\left(i^{2}\right)$ & & & & & & & & & & & \\
\hline TC-151 & 859.29 & 133.19 & & 129.98 & & & & $9.45 \mathrm{E}-03$ & $8.87 \mathrm{E}+01$ & $5.43 \mathrm{E}+00$ & 3.21E-01 & 1.89E-02 & $1.58 \mathrm{E}+02$ \\
\hline \multicolumn{14}{|l|}{ TC-152 } \\
\hline \multicolumn{14}{|l|}{ TC-153 } \\
\hline TC-160 & 926.52 & 143.61 & 269.10 & 124.72 & 44.83 & 91.84 & 344.24 & 1.44E-02 & $1.35 \mathrm{E}+02$ & $8.27 E+00$ & 4.89E-01 & $2.88 \mathrm{E}-02$ & $2.12 \mathrm{E}+03$ \\
\hline TC-161 & 904.39 & 140.18 & 273.68 & 125.96 & 43.64 & 86.38 & 344.35 & $1.25 \mathrm{E}-02$ & 1.17E+02 & $7.19 \mathrm{E}+00$ & $4.25 \mathrm{E}-01$ & $2.50 \mathrm{E}-02$ & $1.62 E+03$ \\
\hline TC-162 & 929.74 & 144.11 & 267.56 & 123.36 & 45.00 & 86.90 & 343.85 & $1.75 \mathrm{E}-02$ & $1.64 \mathrm{E}+02$ & $1.01 \mathrm{E}+01$ & 5.95E-01 & 3.50E-02 & $1.32 \mathrm{E}+03$ \\
\hline TC-163 & & & 271.62 & 125.52 & & & 345.22 & 1.10E-02 & $1.03 E+02$ & $6.32 \mathrm{E}+00$ & 3.74E-01 & $2.20 \mathrm{E}-02$ & $2.05 E+03$ \\
\hline TC-164 & & & 269.87 & 127.41 & & & 343.72 & 1.13E-02 & $1.06 \mathrm{E}+02$ & $6.47 E+00$ & 3.83E-01 & $2.25 \mathrm{E}-02$ & $1.73 E+03$ \\
\hline TC-165 & & & 285.10 & & 43.77 & 88.47 & & 1.15E-02 & $1.08 \mathrm{E}+02$ & $6.62 \mathrm{E}+00$ & 3.91E-01 & 2.30E-02 & $1.36 \mathrm{E}+03$ \\
\hline TC-166 & 902.58 & 139.90 & 275.63 & & & & & $3.76 \mathrm{E}-03$ & $3.53 E+01$ & $2.16 \mathrm{E}+00$ & $1.28 \mathrm{E}-01$ & $7.51 \mathrm{E}-03$ & $2.21 \mathrm{E}+03$ \\
\hline TC-167 & 905.36 & 140.33 & & & 42.52 & 88.43 & 345.56 & $6.52 \mathrm{E}-02$ & $6.12 \mathrm{E}+02$ & $3.75 E+01$ & $2.22 \mathrm{E}+00$ & $1.30 \mathrm{E}-01$ & $1.00 \mathrm{E}+03$ \\
\hline TC-168 & & & & & & & 345.90 & $2.60 \mathrm{E}-04$ & $2.44 \mathrm{E}+00$ & 1.49E-01 & $8.83 \mathrm{E}-03$ & $5.20 \mathrm{E}-04$ & $4.58 \mathrm{E}+00$ \\
\hline TC-169 & & & & & & & 341.83 & 3.35E-04 & $3.15 \mathrm{E}+00$ & 1.93E-01 & 1.14E-02 & $6.71 \mathrm{E}-04$ & $7.52 \mathrm{E}+00$ \\
\hline TC-170 & & & & 123.03 & 42.48 & 88.80 & & 1.81E-02 & $1.70 \mathrm{E}+02$ & $1.04 \mathrm{E}+01$ & $6.16 \mathrm{E}-01$ & 3.63E-02 & 2.67E+02 \\
\hline \multicolumn{2}{|c|}{ Chemical Composition } & N/A & $\mathrm{N} / \mathrm{A}$ & $\mathrm{Pb}, \mathrm{C},\left[\mathrm{C}_{4} \mathrm{H}_{5} \mathrm{Cl}\right]_{n}$ & $\mathrm{C},\left[\mathrm{C}_{4} \mathrm{H}_{5} \mathrm{Cl}\right]_{\mathrm{n}}$ & {$\left[\mathrm{CH}_{2}-\mathrm{CH}_{2}\right]_{\mathrm{n}}$} & {$\left[\mathrm{C}_{6} \mathrm{H}_{10} \mathrm{O}_{5}\right]_{\mathrm{n}}$} & & & & & & \\
\hline \multicolumn{2}{|c|}{ Carbon Mass Fraction } & 0 & 0 & 0.45 & 0.90 & 0.875 & 0.444 & & & & & & \\
\hline
\end{tabular}




\section{HEADSPACE GAS MEASUREMENTS}

Gas samples consisted of a small, 3.05-ml $\left(0.19-\mathrm{in}^{3}\right)$ volume of the headspace gas at near full vessel pressure, obtained by slightly expanding the approximately $750-\mathrm{ml}$ headspace gas. This sample was then further expanded into the measurement instrument. The gas species were identified and their concentrations quantified using thermal-conductivity gas chromatography. Certified gas standards were used to calibrate the gas chromatograph prior to each gas-sampling session. Gas species measured were argon, carbon dioxide, carbon monoxide, helium, hydrogen, hydrogen sulfide, methane, and oxygen. The argon was a residual contaminant from the argon atmosphere during the waste loading and during sampling. The helium originated from the approximately $1 \%$ helium that was deliberately added to the nitrogen fill gas for use in detecting any leakage from the vessels. These are the same gas species measured in the Actinide Source-Term Waste Test (STTP) program, but gas measurements were not made in the high-pressure tests in that program (3).

After the initial 6-month period, gas measurements were made sparingly, since even the small volumes extracted tended to reduce the test vessel pressure by approximately 55 to $70 \mathrm{kPa}(8-10 \mathrm{psi})$ each time a sample was drawn. Over the entire duration of the experiment, up to 10 gas samples were withdrawn from each vessel. 


\section{POST-TEST OPERATIONS}

\subsection{Handling}

Following completion of the testing in the late fall, 2002, the experiment was disassembled. The DOE-CBFO authorized and funded the post-test examination of the six vessels that contained the steel specimens. No funding was provided for examination of the remaining six vessels, however, on the basis of what was believed to be an adequate understanding of the roles of microbes and radiolysis in gas generation from other test programs. Instrumentation systems were deactivated and all of the vessels were slowly depressurized, leaving approximately $140 \mathrm{kPa}$, absolute, (8 psig) of nitrogen in the vessels' headspaces to preserve the anoxic conditions. The rate of pressure decrease from the normal operating level of $14.8 \mathrm{MPa}(2,150 \mathrm{psi}$, abs) to the residual level was limited to approximately $70 \mathrm{kPa} / \mathrm{min}$ (10 psi/min). This was done to minimize foaming in the vessels caused by the release of any dissolved gases. To gain some insight to the quantity of dissolved gases, the pressures in the 6 vessels that contained steel specimens were reduced in two steps: first to about $3.5 \mathrm{MPa}$ (508 psia), at which point the vessel remained for 3-5 days to allow gases to diffuse out of solution; another headspace gas sample was then drawn, and the vessel pressure was then slowly reduced to the residual level.

The vessels were disconnected from the instrumentation systems and withdrawn from the glovebox. Care was used to avoid tipping or jostling the vessels during the handling. The vessels were placed into standard, 208-1 (55-gal) DOT-7A drums, for which special spacer structures had been inserted, accommodating three GGE vessels per drum. These drums were transported to another ANL facility for examination of the wastes and preparation for disposal. Because of the radioactive and/or mixed-waste nature of the remnants, disposal of the wastes needed to be controlled. Free liquids needed to be prepared to meet the waste-acceptance criteria at the INL's Radioactive Waste Management Complex.

After approximately six weeks of interim storage, the waste-bearing vessels were individually introduced into a contaminated-equipment repair area for opening. Working in bubble suits with supplied breathing air, two technicians carefully opened each vessel and removed the contents. From each vessel samples of each waste constituent were extracted for possible analysis and the remaining liquid content was absorbed into generous quantities of vermiculite. Samples were taken from all of the vessels, and visual observations were made. However, detailed examinations were planned only for the brine and steel specimens from the six steel-bearing vessels. The two nonradioactive, experiment-control vessels that did not contain waste were recovered for possible future use in other programs. No attempts were made to recover the waste-bearing vessels because of the difficulty in decontaminating these.

Materials were removed from the vessels in the following manner. The solid waste articles were removed using a long-handled set of forceps. The brine was removed using a suction-bulb device (an ordinary, kitchen-type "turkey baster" was used). Two 1,000-ml (34 oz) brine aliquots were taken. The first was extracted from the relatively clear liquid near the surface of the brine upon first opening the vessel. The second sample was taken after all of the brine had been removed and mixed to uniformly distribute any sediment. All waste materials were removed from the vessels. One sample of each type of waste material present was taken, with the exception that all steel coupons were removed and preserved. These were placed, wet, into "zip-lock" bags and labeled. The steel-coupon-bearing bags were vented of as much air as possible before the bags were sealed. Photographs of the operation, vessel internals, and waste materials were made. After all the brine was returned to the vessel, a depth measurement was made using a ruler. This was a crude measurement, at best, because some of the brine would have been removed with the wastes, particularly the cloth and fiber board. The volume of brine was used to infer the performance of the entire vessel from the sample analyses, described below. The collected solutions and corrosion coupons were then transferred to the ANL-W analytical laboratory for analysis. Figure 4 shows a view of the vessel-opening operation. 


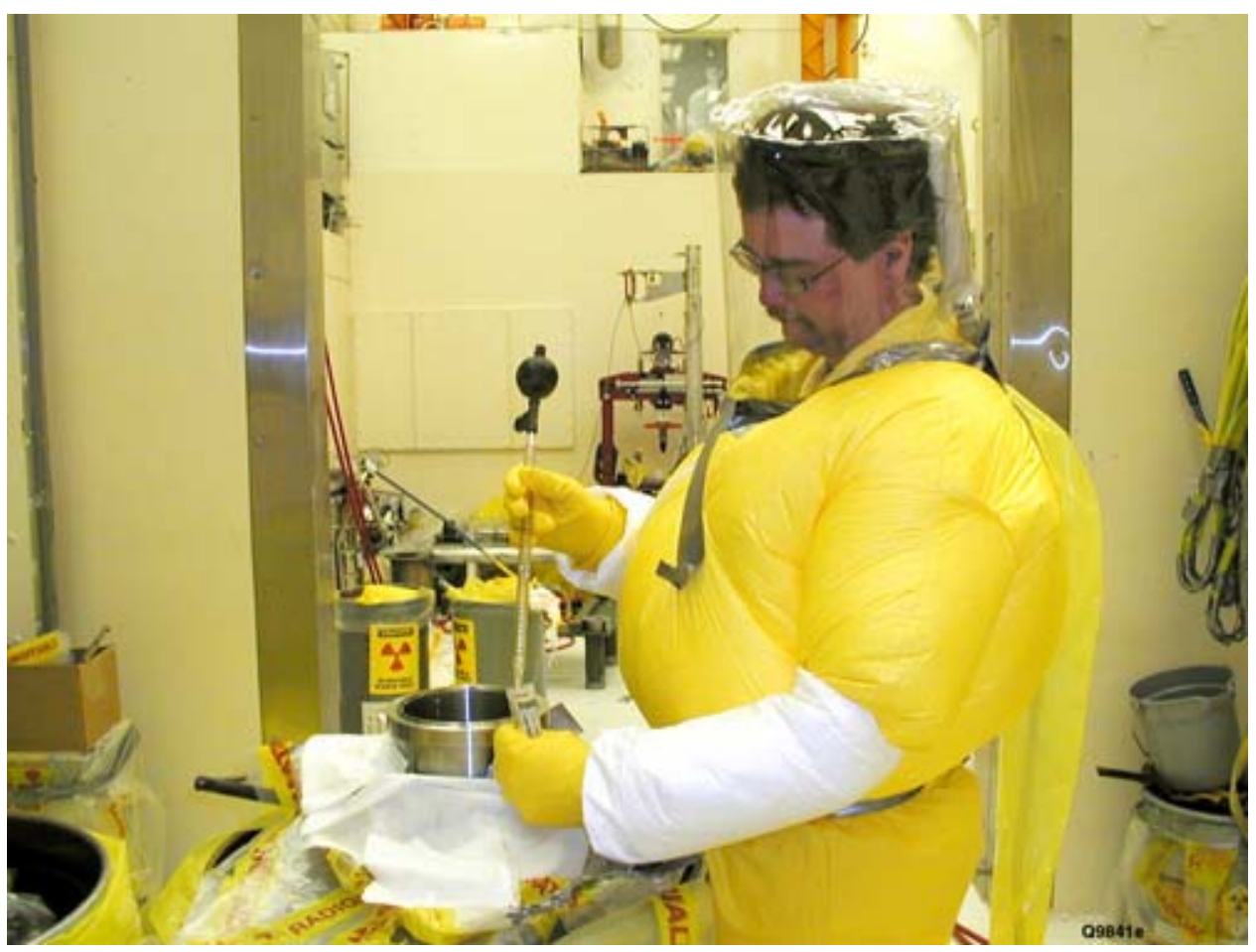

Figure 4. Waste unloading operations.

\subsection{Analyses}

Review of the headspace gas analyses was continued. These analyses, in combination with analyses made throughout the experiment period, provide a complete history of gas generation from the respective wastes over the $6-1 / 2$ years of immersion in the brine.

Per DOE-CBFO directions, only limited analyses of the waste materials were conducted. The brine was examined for $\mathrm{pH}$ and radionuclide content. The ANL-W analytic laboratory researched the best way to make the $\mathrm{pH}$ measurements. Because of the high ionic strength of the brine, measurements of the $\mathrm{pH}$ using reference electrodes are unreliable or ambiguous. Funding limitations restricted $\mathrm{pH}$ measurements to available methods. $\mathrm{pH}$ paper was therefore used to make these determinations.

Steel specimens were examined for corrosion product identification. Investigation of selected carbon-steel corrosion coupons was performed by x-ray diffraction (XRD) and scanning electron microscopy (SEM). The steel coupons analyzed were chosen from test containers (TC) TC-160 and -166. Brine and/or sludge solutions from TC-151, -160, -161, -162, -166 and -167 were measured for actinide content by inductively coupled plasma mass spectrometry (ICP-MS). Actinide transport into the brine is a key parameter in the potential for radionuclide migration from the repository. 


\section{RESULTS AND DISCUSSION}

Observations, measurements, and analyses of the GGE tests are presented in this section. These results comprise the following categories: (a) analyses of headspace-gas samples throughout the course of the tests; (b) visual observations of the wastes upon opening the vessels at the conclusion of the tests; (c) pH analyses of the brine; (d) gross alpha activity in the brine samples; (e) radionuclide content in the brine; and (f) x-ray diffraction, energy dispersive $\mathrm{x}$-ray, and scanning electron microscopy examination of selected carbon-steel samples.

\subsection{Analyses of Headspace-Gas Samples}

Table 3 lists the gas concentrations measured from the final full-pressure gas samples, taken in late October and early November, 2002 just prior to depressurization of the vessels. Detection limits and twostandard-deviation uncertainties for each gas specie measurement are shown in the table, along with the waste types loaded into each vessel. In general, the quantity of each gas measured in the headspace increased throughout the course of the experiment, reaching the values shown in this table after approximately $6-1 / 2 \mathrm{yr}$ of testing. However, there was a reduction in the quantity of carbon dioxide found in the final gas measurements taken in Fall 2002 in all vessels that had detectable carbon dioxide in the headspace. This probably resulted from the increased gas solubility into the brine induced by the lowered temperatures that occurred over the last few months of the experiment. The total quantities of generated gases measured in the samples agreed reasonably well with total pressure trends over the course of the testing, after appropriate adjustments were made for temperature effects (8).

The gas concentrations measured in the headspace gas do not reveal the actual quantities of gases generated, of course, nor do they necessarily support accurate vessel-to-vessel comparisons, for several reasons. In addition to the slight variation in the actual waste loadings among the test vessels, there were some non-trivial variations in the headspace volumes and in the quantities of specific radionuclides in the wastes. Another possible aspect is that the vessels remained undisturbed for the entire duration of the experiment (in contrast, for example, to testing done in the STTP at LANL, in which the vessels were periodically agitated (3)). This may have caused some generated gases to remain trapped close to their point of origin in submerged bubbles. The high pressures maintained in the present experiments would have kept bubble diameters extremely small, limiting the buoyant forces that cause bubbles to rise to the surface. Gases trapped within these bubbles would not have been detected in gas samples extracted from the vessel headspace. Furthermore, carbon dioxide and hydrogen sulfide are both highly soluble in water and in brine. This, too, would reduce the concentrations of these gases in the headspace. It is also noted that gases such as oxygen, carbon dioxide, or carbon monoxide may have been generated but subsequently reacted chemically, e.g., with anti-oxidants in the plastic or rubber. Despite these caveats, the table is useful for a general overview.

The most obvious observation from Table 3 is that only hydrogen and, to a much lesser extent carbon dioxide, was present in the headspace in measurable quantities. Carbon monoxide was detectable in only two vessels, and methane was detectable in only one vessel. The concentrations of both carbon monoxide and methane gases were only slightly above the detection limits. Neither hydrogen sulfide nor oxygen was ever detected in the headspace of any vessel, indicating only low activity by the sulfurreducing microbes. However, because hydrogen sulfide is both very soluble and chemically very active, it cannot be certain from the headspace-gas analyses that this gas was never generated. Biological activity by fermentative microbes appeared to taper off quickly, and it would appear that there was, at best, very limited methanogenesis microbe activity. Evidence of denitrifying microbe activity in these experiments would have been obscured in the headspace gas samples by the nitrogen pressurizing gas. 
Table 3 . Headspace gas analyses after approximately 6-1/2 yr testing (fall 2002 samples).

\begin{tabular}{|c|c|c|c|c|c|c|c|c|c|c|c|c|c|c|c|}
\hline \multicolumn{8}{|c|}{ Waste Types } & \multicolumn{8}{|c|}{$\begin{array}{l}\text { Gas Analyses (ppm by volume), } \\
\text { With Detectability Limits and 2-Sigma Uncertainties }\end{array}$} \\
\hline $\begin{array}{l}\text { Vessel } \\
\text { Number }\end{array}$ & $\begin{array}{l}\text { Waste } \\
\text { Free }\end{array}$ & $\begin{array}{c}\text { Carbon } \\
\text { Steel }\end{array}$ & Sludge & $\begin{array}{l}\text { Leaded } \\
\text { Rubber }\end{array}$ & Rubber & Plastic & Cellulose & $\begin{array}{c}\text { Argon } \\
-- \\
\pm 20 \%\end{array}$ & $\begin{array}{c}\text { Carbon } \\
\text { Dioxide } \\
50 \mathrm{ppm} \\
\pm 10 \% \\
\end{array}$ & 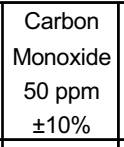 & $\begin{array}{c}\text { Helium } \\
-- \\
\pm 15 \% \\
\end{array}$ & \begin{tabular}{|c|} 
Hydrogen \\
$50 \mathrm{ppm}$ \\
$\pm 10 \%$ \\
\end{tabular} & $\begin{array}{c}\text { Hydrogen } \\
\text { Sulfide } \\
500 \mathrm{ppm} \\
--\end{array}$ & $\begin{array}{c}\text { Methane } \\
50 \mathrm{ppm} \\
\pm 10 \% \\
\end{array}$ & $\begin{array}{c}\text { Oxygen } \\
50 \text { ppm } \\
-- \\
\end{array}$ \\
\hline 151 & & $x$ & & $x$ & & & & 1584 & $<\mathrm{d}$ & $<\mathrm{d}$ & 11850 & 5800 & $<\mathrm{d}$ & $<\mathrm{d}$ & $<d$ \\
\hline 152 & $x$ & & & & & & & 1743 & $<\mathrm{d}$ & $<\mathrm{d}$ & 11820 & $<d$ & $<\mathrm{d}$ & $<\mathrm{d}$ & $<d$ \\
\hline $153^{*}$ & $\mathrm{x}$ & & & & & & & 2872 & $<\mathrm{d}$ & $<\mathrm{d}$ & 12050 & $<\mathrm{d}$ & $<\mathrm{d}$ & $<\mathrm{d}$ & $<d$ \\
\hline 160 & & $x$ & $\mathrm{x}$ & $x$ & $x$ & $\mathrm{x}$ & $\mathrm{x}$ & 1444 & 187 & $<\mathrm{d}$ & 11060 & 9553 & $<\mathrm{d}$ & $<\mathrm{d}$ & $<d$ \\
\hline 161 & & $x$ & $x$ & $x$ & $x$ & $\mathrm{x}$ & $\mathrm{x}$ & 1252 & 154 & $<\mathrm{d}$ & 11060 & 11480 & $<\mathrm{d}$ & $<\mathrm{d}$ & $<d$ \\
\hline 162 & & $x$ & $x$ & $x$ & $x$ & $x$ & $x$ & 5270 & 110 & $<\mathrm{d}$ & 11910 & 3038 & $<\mathrm{d}$ & $<\mathrm{d}$ & $<d$ \\
\hline 163 & & & $x$ & $\mathrm{x}$ & & & $\mathrm{x}$ & 1522 & 418 & $<\mathrm{d}$ & 11190 & 1107 & $<\mathrm{d}$ & $<\mathrm{d}$ & $<d$ \\
\hline $164^{*}$ & & & $x$ & $x$ & & & $x$ & 1586 & 698 & $<\mathrm{d}$ & 12060 & 938 & $<\mathrm{d}$ & $<\mathrm{d}$ & $<d$ \\
\hline 165 & & & $x$ & & $x$ & $x$ & & 1245 & 455 & $<\mathrm{d}$ & 11150 & 1808 & $<\mathrm{d}$ & $<\mathrm{d}$ & $<d$ \\
\hline 166 & & $x$ & $x$ & & & & & 1945 & $<\mathrm{d}$ & $<\mathrm{d}$ & 11340 & 42040 & $<\mathrm{d}$ & $<\mathrm{d}$ & $<d$ \\
\hline 167 & & $x$ & & & $x$ & $\mathrm{x}$ & $\mathrm{x}$ & 1795 & 134 & 223 & 11030 & 14010 & $<\mathrm{d}$ & 118 & $<d$ \\
\hline 168 & & & & & & & $\mathrm{x}$ & 1812 & 134 & $<\mathrm{d}$ & 11870 & $<\mathrm{d}$ & $<\mathrm{d}$ & $<\mathrm{d}$ & $<d$ \\
\hline 169 & & & & & & & $\mathrm{x}$ & 1742 & 127 & $<\mathrm{d}$ & 11890 & $<\mathrm{d}$ & $<\mathrm{d}$ & $<\mathrm{d}$ & $<d$ \\
\hline 170 & & & & $x$ & $x$ & $x$ & & 1901 & $<\mathrm{d}$ & 107 & 11980 & 2017 & $<\mathrm{d}$ & $<\mathrm{d}$ & $<d$ \\
\hline
\end{tabular}


The vessels that generated significant hydrogen all contained carbon steel in their waste formulations, indicating that steel corrosion was the predominant source of headspace gases. Among the carbon-steel-bearing vessels even the lowest hydrogen generator (vessel no. TC-162) still measured over $50 \%$ more hydrogen than the non-carbon-steel-bearing vessel that produced the highest quantity of hydrogen (TC-170). On average, the carbon-steel-bearing wastes generated over 13 times more hydrogen than the non-carbon-steel-bearing wastes.

Vessels No. 152 and 153 were the experiment controls, containing inoculated brine, but no wastes. There were no detectable gases (besides nitrogen, argon, and helium) in either of these vessels for any of the headspace-gas samples taken over the entire course of the experiment. This established that no significant chemical reactions occurred between the brine and the vessel material, and that any microbial activity with the brine, e.g., sulfate reduction, did not result in measurable generation of gases.

Results are presented in the following sections in terms of volumes of generated gases by applying the measured concentrations by volume (i.e., volume fractions) to the actual headspace volume in each vessel. The volumes of the specific gas species are shown in liters, adjusted to standard temperature and pressure (STP) of $0^{\circ} \mathrm{C}$ and $1 \mathrm{~atm}$. These gas volumes can be further converted to moles of gas by use of an equation of state. However, since the partial pressures of hydrogen and carbon dioxide are quite low their compressibility factors are very nearly unity, implying that the gases can be considered ideal with very high accuracy. This allows the gas quantities to be obtained by dividing the volumes shown in this report by the perfect-gas constant of $22.42 \mathrm{l} / \mathrm{g}$-mol at STP. It also follows that the volume fractions, mol fractions, and partial pressure fractions are all essentially equal.

\subsection{Experiment Repeatability}

The repeatability of the experiments can be qualitatively judged by comparing the gas generation in vessels having nominally the same waste loadings, as discerned from Table 3. Vessels TC-160, -161, and -162 comprise such a group. Vessels TC-163 and -164, likewise, had common wastes and nominal quantities, and vessels TC-168 and -169 formed another replicate pair. Although not expected to be significant, the slight variation in waste loadings as well as the differences in actinide quantities are potential sources of variation among the replicate vessels. Comparisons within each of these three replicate groups are discussed below, and a more quantitative analysis is presented in Section 6.5.

\subsubsection{Vessels TC-160, -161 , and -162}

Vessels TC-160, -161 , and -162 each contained all of the waste constituents tested. Hydrogen generated in these vessels is shown in Figure 5 for gas samples taken throughout the course of the experiment.

Hydrogen generated in vessels TC-160 and -161 show very good agreement, both in magnitude and trend. The hydrogen concentration in vessel TC-162 is markedly lower than that in the other two vessels. Interestingly, the rate of hydrogen generation in this vessel toward the end of the experiment is similar to that observed in vessels TC-161. On a gas-generation rate basis toward the end of the experiment, TC-160 would appear to be the odd one, but, within some reasonable error band, the latter trends for all three vessels would have about the same slope. Some variation is inherent and should be expected in the experiment: the wastes were not arranged in an orderly configuration (as was done in other experiments, e.g. those reported in Reference 1). There may have been a partial masking of the carbon steel, where two, or more, of the flat steel specimens may have been in full or partial contact. The steel strips were too long to lie flat on the bottom of the test vessel, but the random vessel loading may have inadvertently allowed some specimens to be "stacked" in a leaning position. After a very long period of time, this masking effect would become increasingly insignificant. Visual observations of the steel specimens in 


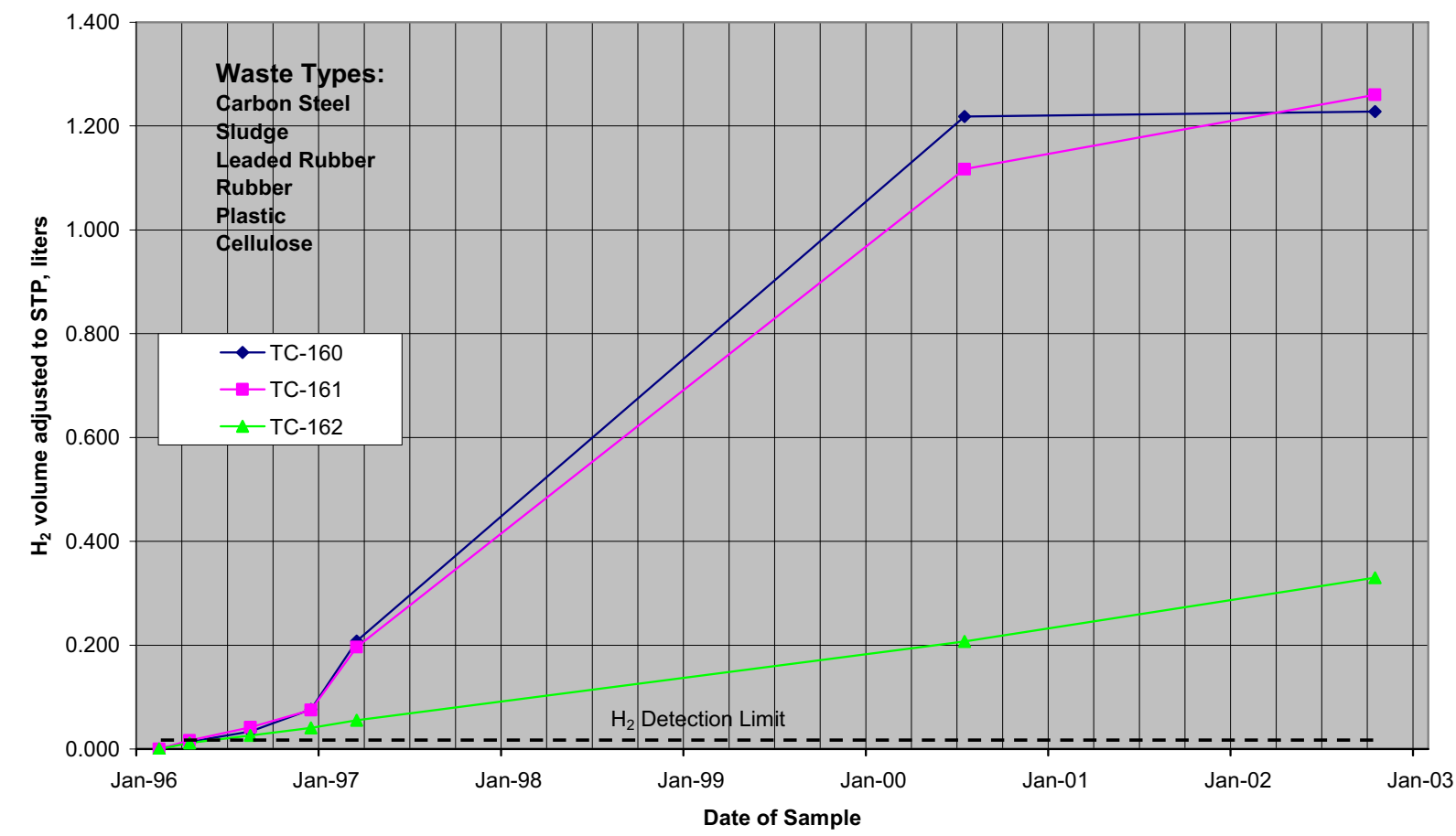

Figure 5. Hydrogen generation in three replicated test vessels TC-160, -161, and -162.

these vessels are discussed in Section 6.6. It appears from photographs made looking down into Vessel TC-162 during the waste-unloading operation (see Appendix B) that this effect may have been responsible for the discrepancy.

Another observation is how the rate of hydrogen gas generated varied over the course of the experiment. Compared to the first year of the experiment the rate of hydrogen generated increased noticeably over the next three-year period before dropping to a lower rate.

Carbon-dioxide production in these three vessels is shown in Figure 6. Interestingly, there is, again, very good agreement for two of the three replicate vessels, as was the case for hydrogen. Now, however, the outlier is vessel TC-160, which was also the outlier on the basis of rate of hydrogen generation over the final two years of the experiment. All three vessels showed a very similar behavior in the carbondioxide fraction: a rapid rise over the first year of testing, but little increase thereafter. 


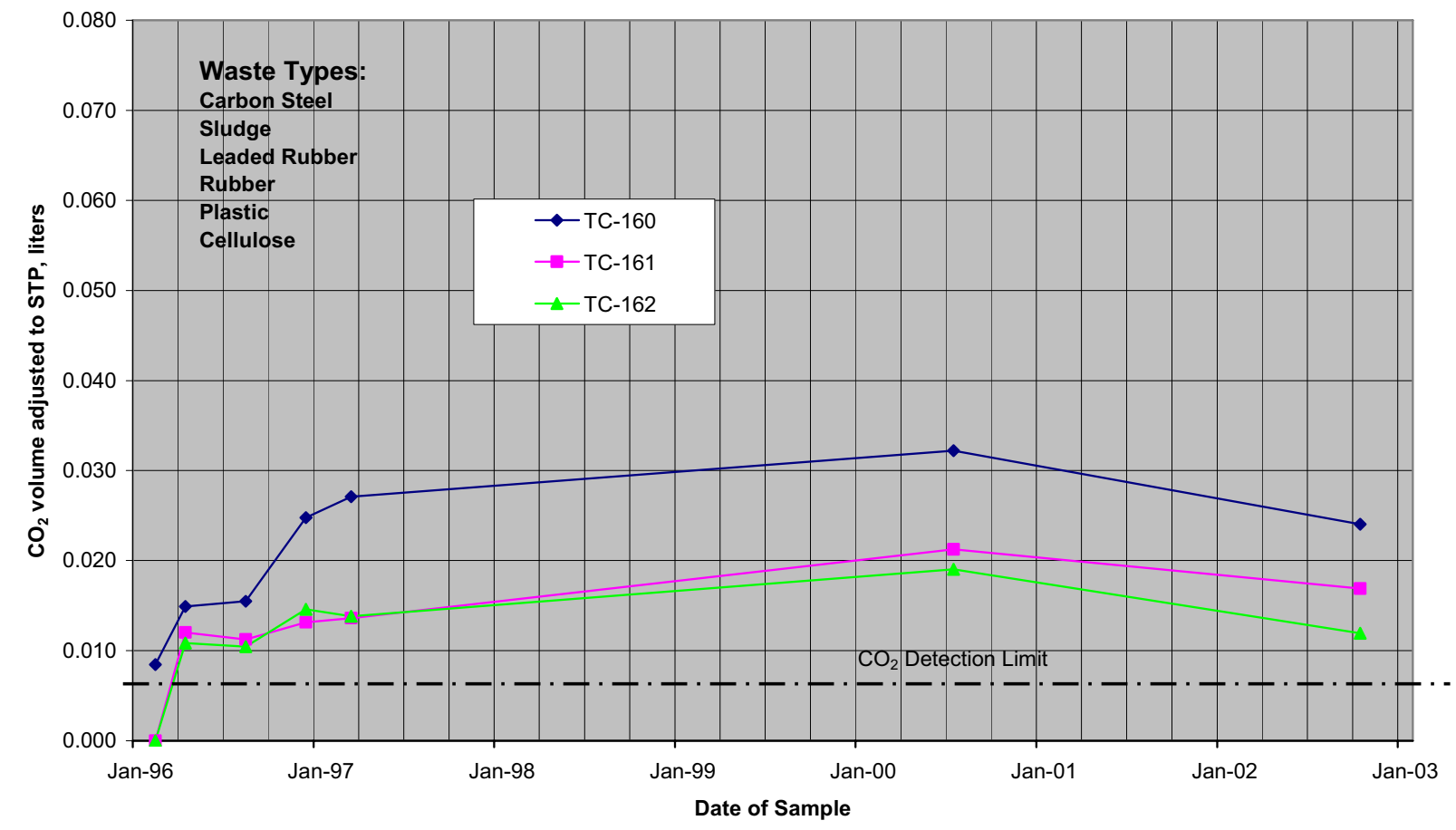

Figure 6. Carbon dioxide generation in replicated vessels TC-160, -161, and -162.

\subsubsection{Vessels TC-163 and -164}

Vessels TC-163 and -164 contained nominally identical quantities of sludge, leaded rubber, and cellulose. Figures 7 and 8 show the STP-adjusted hydrogen and carbon dioxide volumes, respectively, generated over the entire experiment. Unfortunately, vessel TC-164 suffered a partial depressurization while being prepared for drawing the final headspace gas sample, so the most recent directly comparable data available are those from July 2000. The agreement between these two vessels up to that time is reasonable for both hydrogen and carbon dioxide. Since these two vessels did not have any carbon steel in the waste, the hydrogen generation was much less than that found in vessels TC-160, -161, and -162, discussed previously. The carbon-dioxide production, however, was comparable to that in the former replicate group and was comparable to the hydrogen production.

\subsubsection{Vessels TC-168 and -169}

Vessels TC-168 and -169 each contained only cellulose waste. There was no detectable hydrogen produced in either vessel. Comparison of the carbon dioxide generated in each vessel showed good agreement, as seen in Figure 9. The quantity of carbon dioxide generated in these vessels, however, was only about $1 / 3$ of that generated in vessels TC-160 through -164 , despite having the same quantity of cellulose. This suggests that the presence of sludge and, more likely, the carbon content of the leaded rubber in the TC-160 through -164 group contributed substantially to carbon-dioxide generation. 


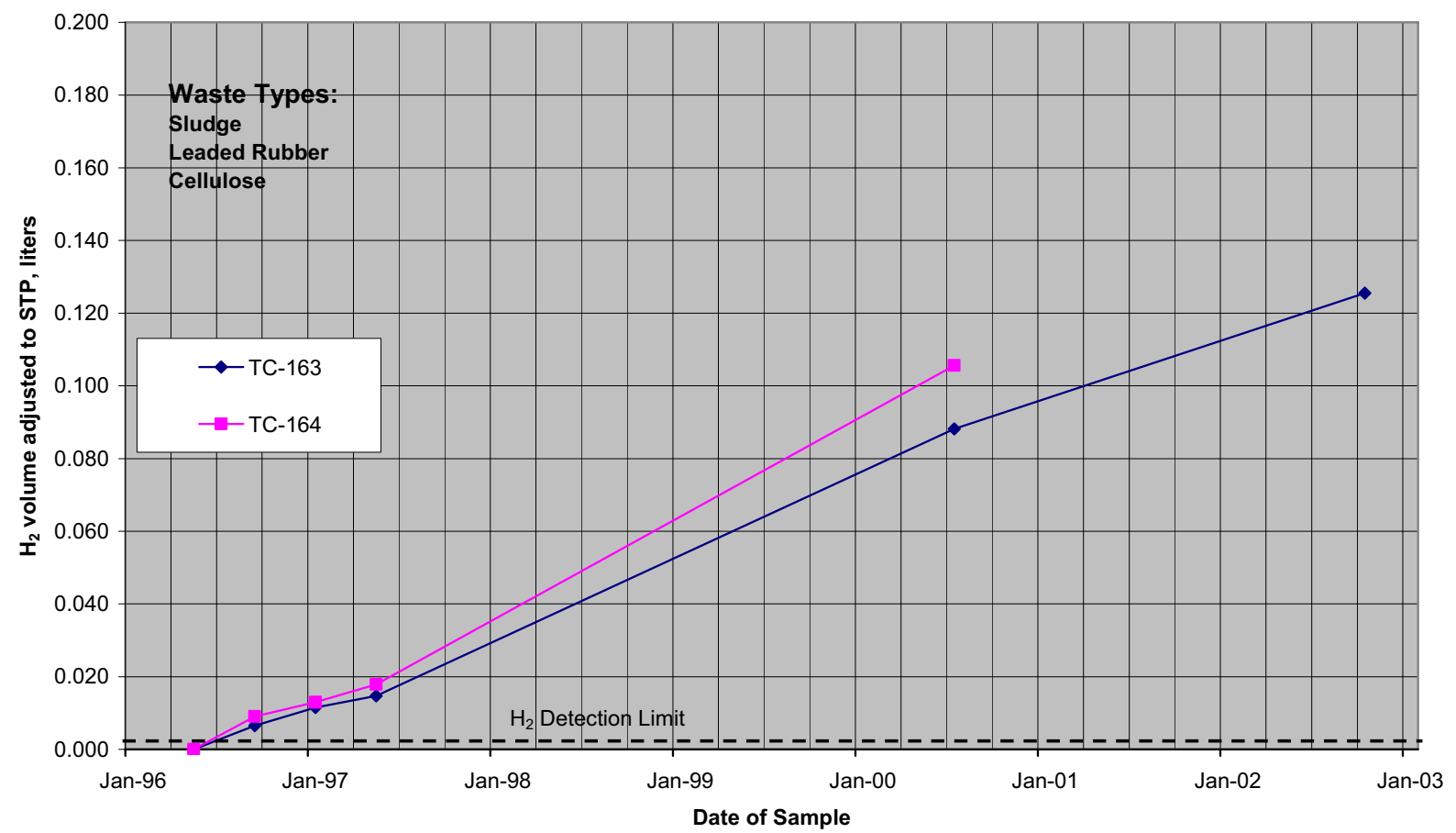

Figure 7. Hydrogen generation in replicated vessels TC-163 and -164.

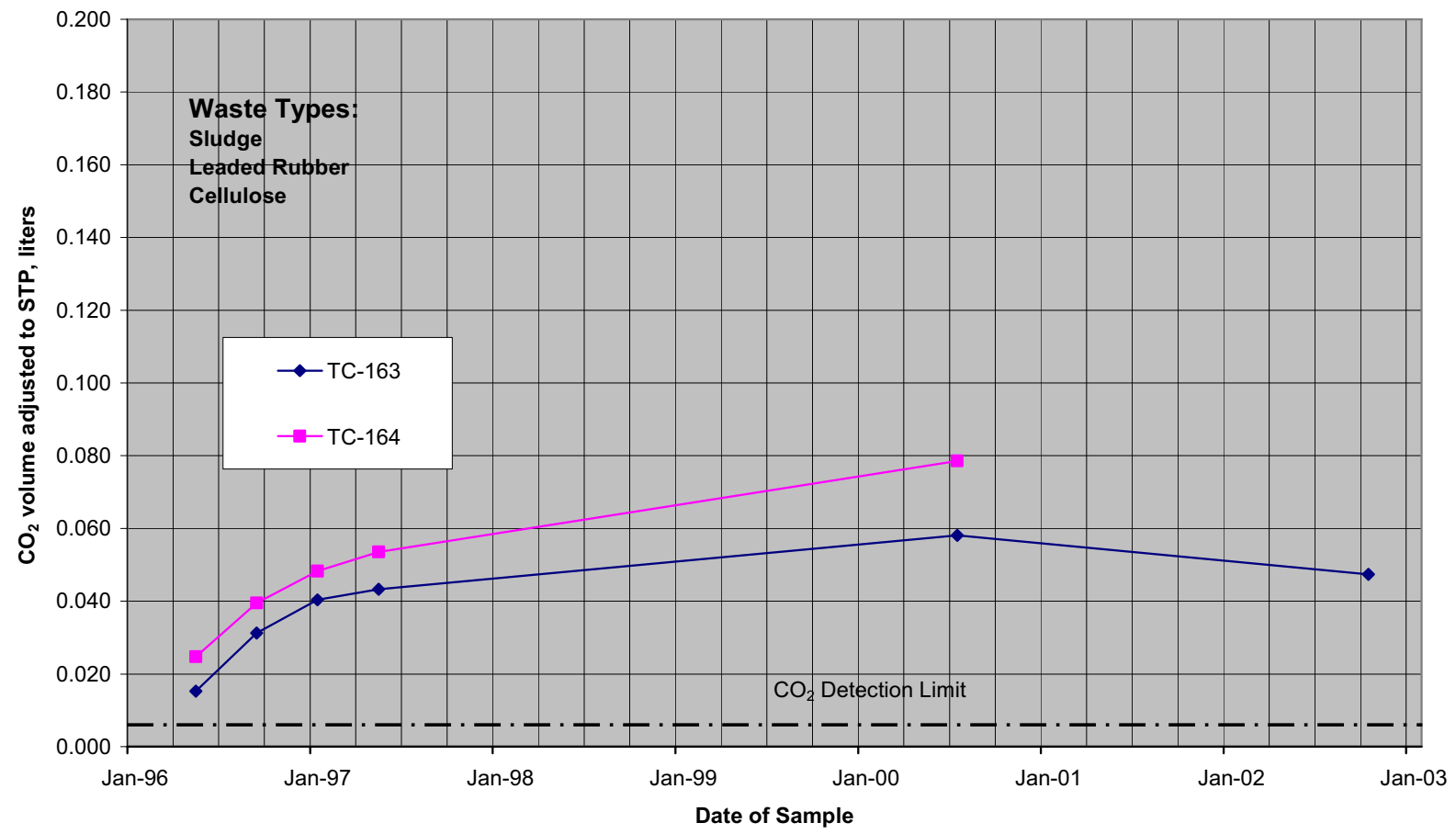

Figure 8. Carbon dioxide generation in replicated vessels TC-163 and -164. 


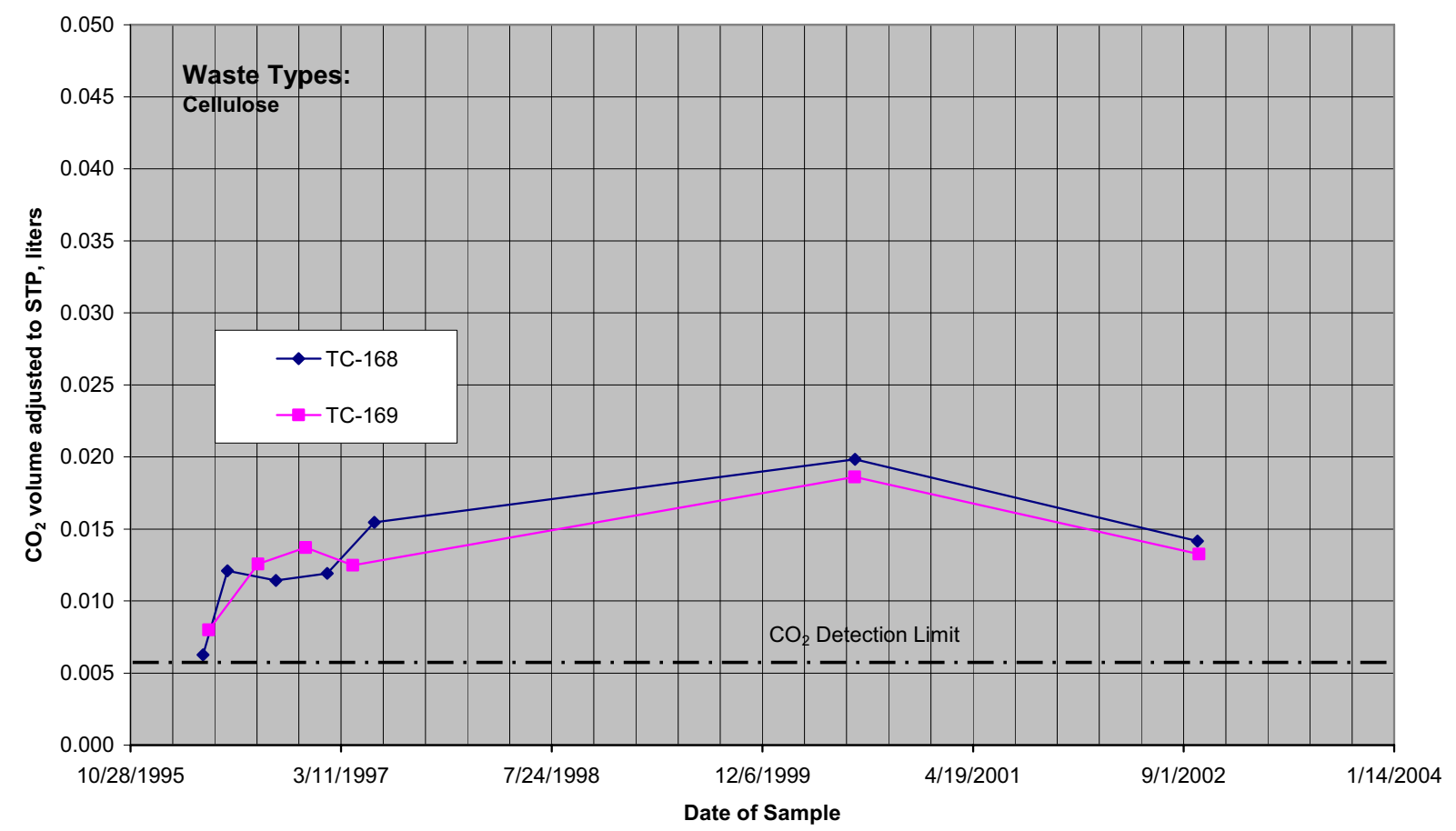

Figure 9. Carbon dioxide generation in replicated vessels TC-168 and -169.

\subsection{Hydrogen Generation}

The final (maximum) volumetric concentrations of hydrogen measured are listed for all of the vessels in Table 3. Figures 10 through 14 show the historical hydrogen (and carbon-dioxide) gas measurements for the remaining, non-replicated vessels. There was never any significant variation for the concentrations of argon or helium in any vessel throughout the duration of the experiment when compared to the initial concentrations. As seen in Table 3, the hydrogen production in vessel TC-166 was prodigious. Measurements over the course of the experiment for vessel TC-166 are shown in Figure 12. This vessel contained only carbon steel and sludge, and only a very small quantity of carbon dioxide was ever measured. The last concentration of hydrogen measured was over $4.2 \%$ by volume (cf. Table 3 ), about 3 times higher than the next most prolific hydrogen generator. The figure shows that the initial hydrogen generation rate was modest, but increased substantially after approximately one year and continued unabated to the very end of the test. The surprisingly high rate of hydrogen production in this vessel compared to the other steel-bearing vessels could not have been the result of its particular waste quantities. Table 2 shows that the surface area of the carbon-steel specimens loaded into TC-166 was actually the lowest compared to the other carbon-steel-bearing-waste vessels. Radiolysis variation does not appear to have been a factor. TC-166 did have the highest level of Am-241, but at $2.21 \mathrm{~g}$ it was only marginally higher than the $2.12 \mathrm{~g}$ in TC-160, where the final hydrogen concentration was less than $1 / 3$ as high. In fact, the very active ${ }^{238} \mathrm{Pu}$ inventory in TC-166 was the lowest of all of the carbon-steel-bearingwaste vessels. 


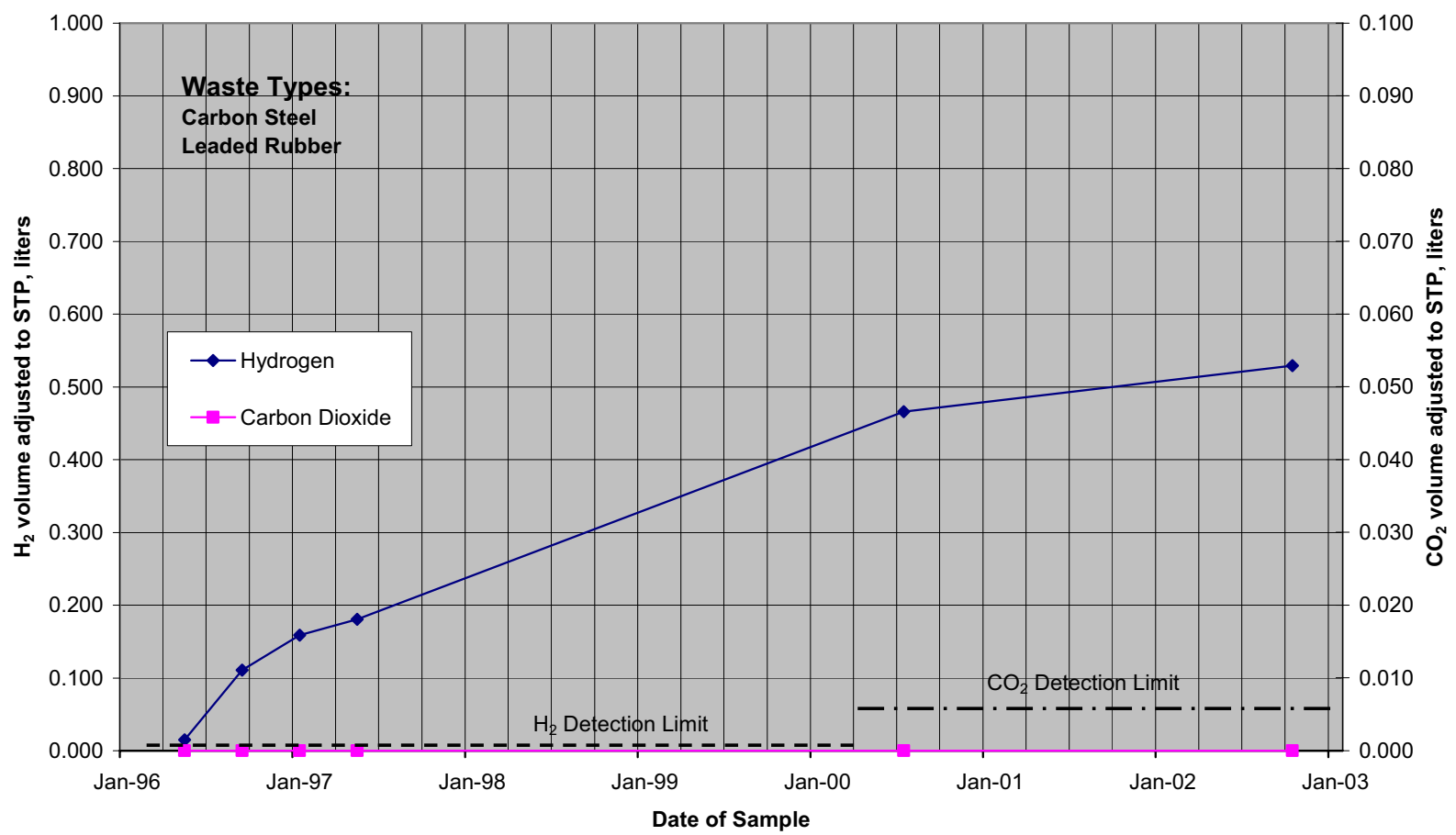

Figure 10. Gas generation in vessel TC-151.

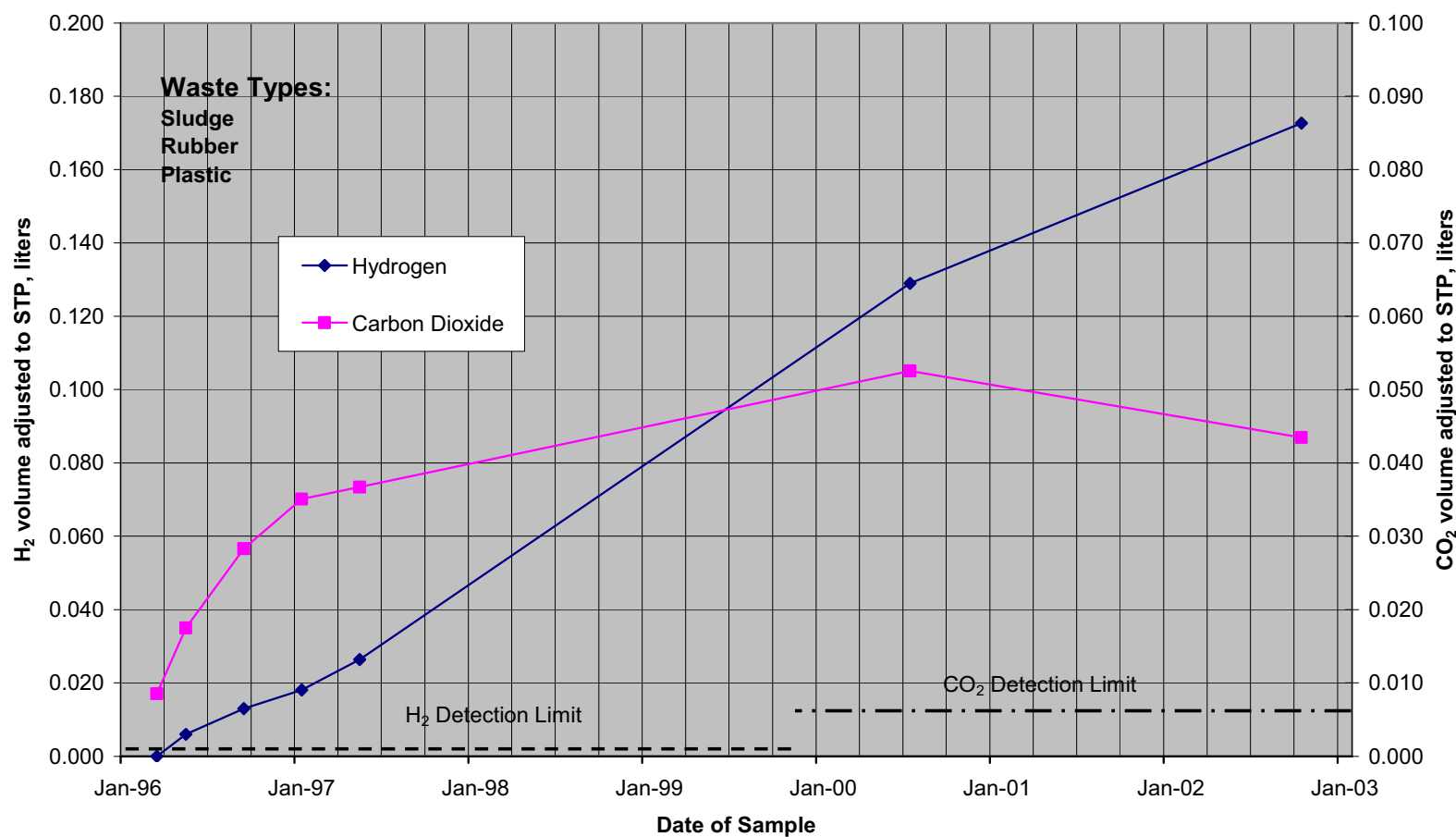

Figure 11. Gas generation in vessel TC-165. 


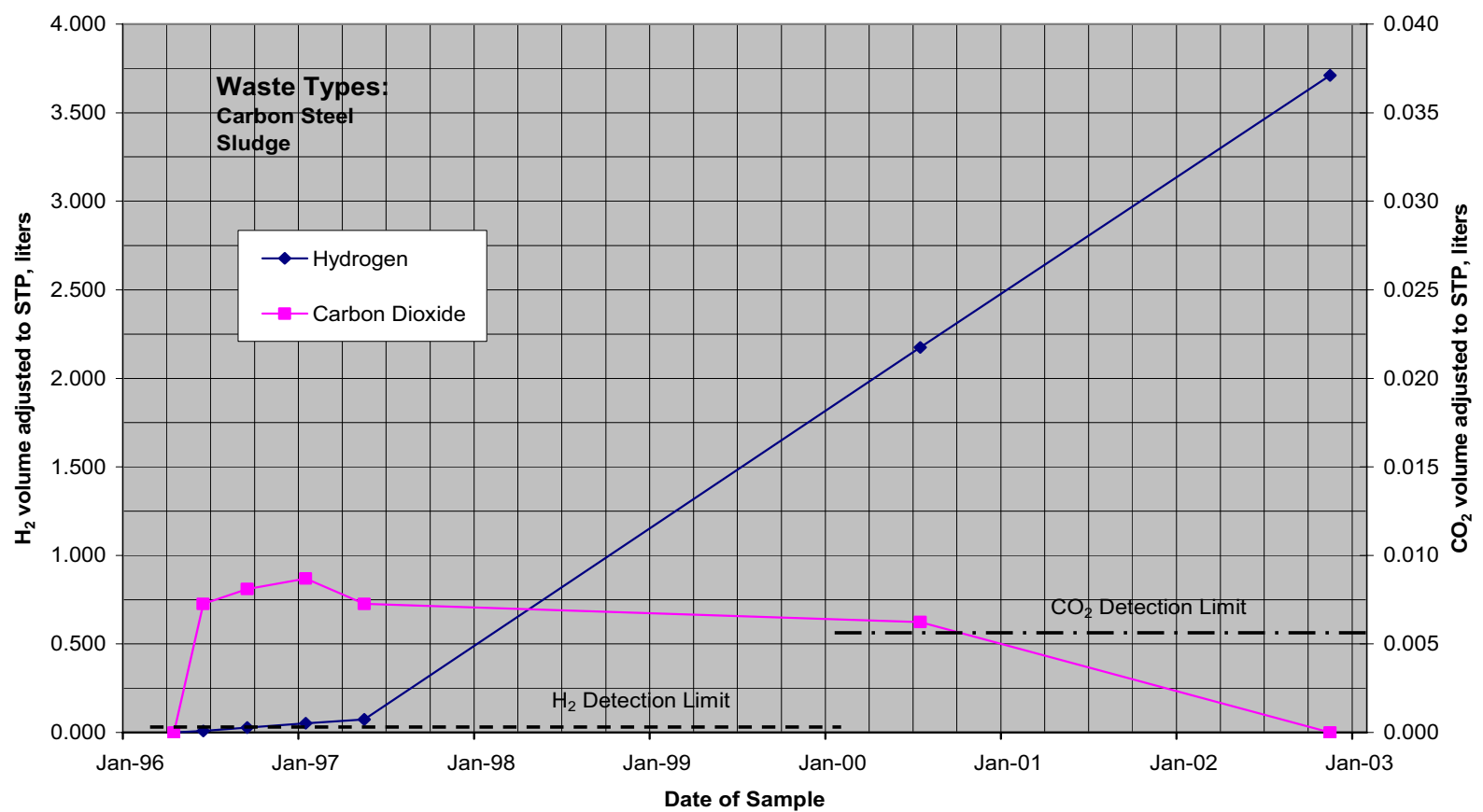

Figure 12. Gas generation in vessel TC-166.

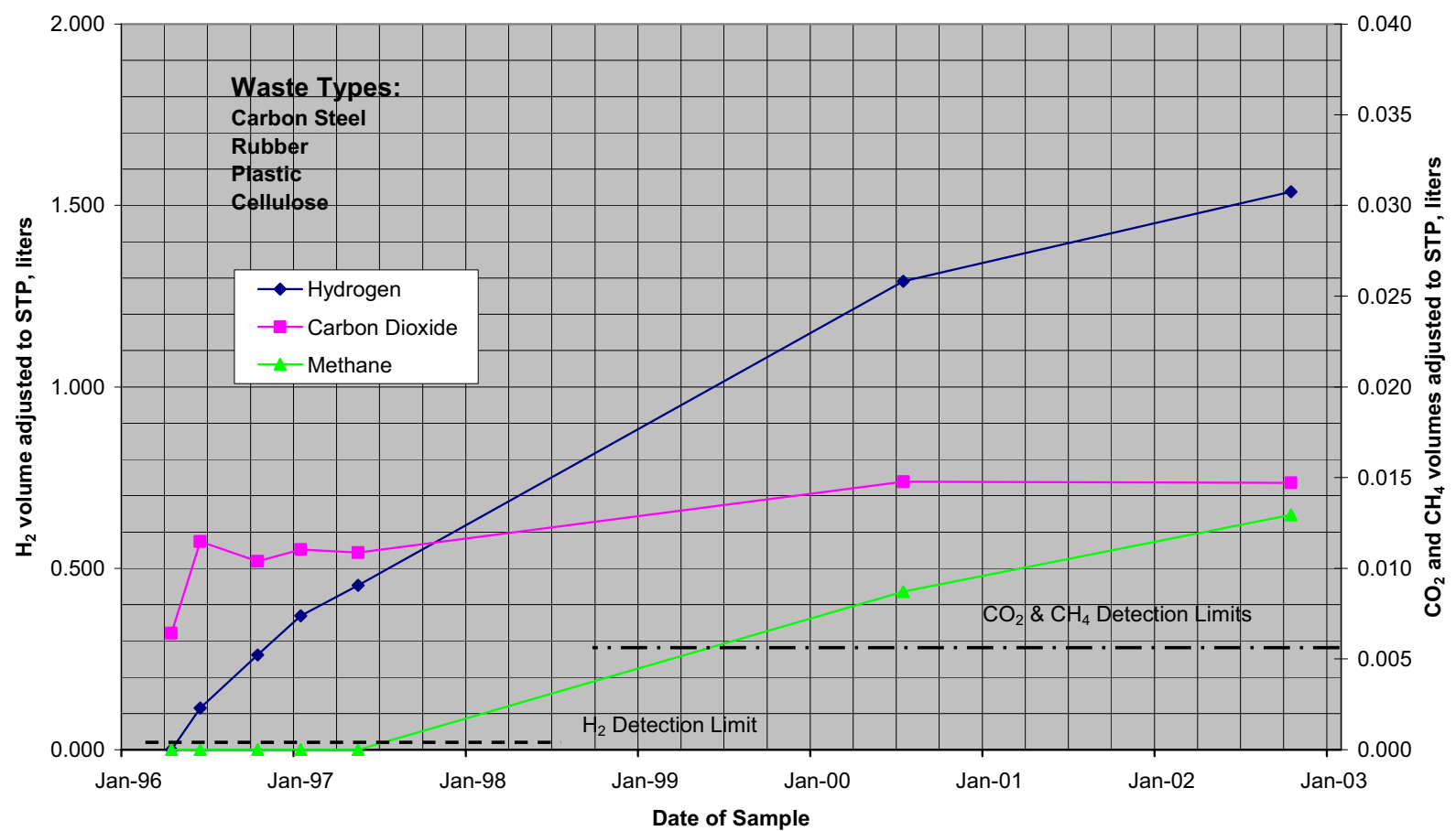

Figure 13. Gas generation in vessel TC-167. 


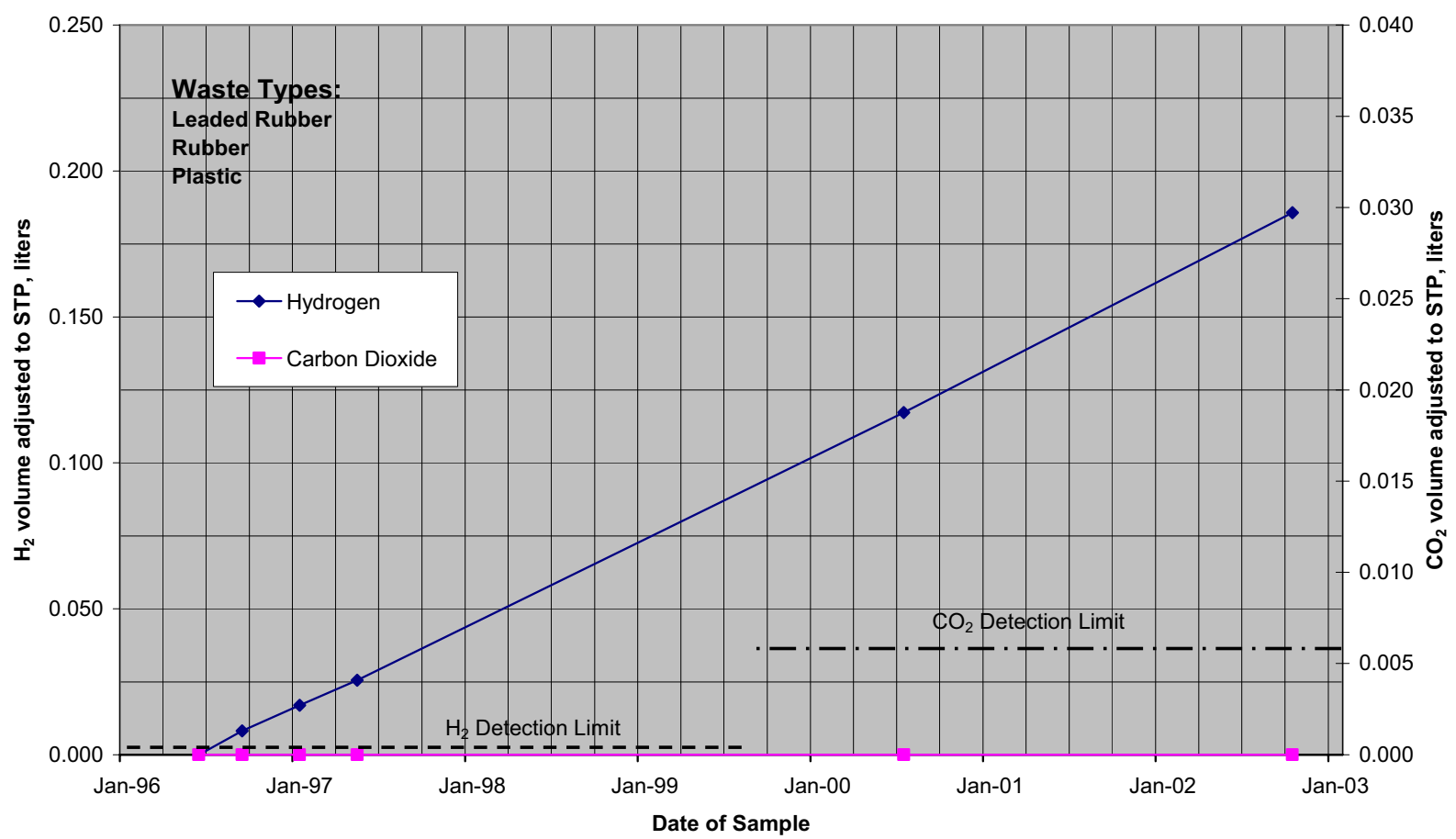

Figure 14. Gas generation in vessel TC-170.

\subsubsection{Specific Gas Generation Rates}

The quantities of gases generated, as discussed previously, are useful to compare gas generation among various waste types, but the gas generation rates per unit of wastes (i.e., mass- or area-specific gas-generation rates) are needed for application of the data to the WIPP performance analyses. Rates of gas generation were computed by taking recent gas analysis data and comparing these data to those generated at a specific time earlier in the program. However, hydrogen measurements from the first year of the experiment were ignored, because in many cases the initial gas generation rates were quite low, perhaps in response to some reaction inhibitors that were initially present but eventually exhausted.

Table 4 shows that the carbon-steel-bearing wastes generated hydrogen gas at rates of $0.024-0.325 \mathrm{~g}-\mathrm{mol} / \mathrm{yr} / \mathrm{m}^{2}$ of steel surface area. The highest rate pertains to measurements from vessel TC-166, as discussed above. Earlier non-nuclear gas-generation experiments, done elsewhere, measured hydrogen production rates of about $0.10 \mathrm{~g}-\mathrm{mol} / \mathrm{yr} / \mathrm{m}^{2}$ from corrosion of steel specimens inundated with the same type of brine (1). With the exception of vessel TC-166, the rate of hydrogen production from steel-bearing-waste vessels in the present experiments would be well represented by the value $0.10 \mathrm{~g}-\mathrm{mole} / \mathrm{yr} / \mathrm{m}^{2}$.

In addition to the rate of gas generation per unit of specimen surface area, another parameter of interest is the corrosion-penetration rate implied. Table 4 includes this parameter based on the assumed equi-molar production of hydrogen gas from reacted iron that has been confirmed in laboratory testing elsewhere, i.e., $0.141 \mathrm{~g}-\mathrm{mol} \mathrm{H} / \mathrm{m}^{2} / \mu \mathrm{m}$ (1). If it is postulated that all of the hydrogen measured in the GGE program resulted from steel corrosion, the corresponding corrosion penetration rates calculated would be $0.17-0.70 \mu \mathrm{m} / \mathrm{yr}$, except for vessel TC-166, for which $2.3 \mu \mathrm{m} / \mathrm{yr}$ was calculated. These corrosion penetration rates should not be used to predict the longevity of steel structures or containers. This penetration rate is an average rate over the entire exposed surface of the carbon steel specimens. Localized pitting corrosion could proceed at a much faster rate. 
Table 4. Gas generation and carbon-steel corrosion rates.

\begin{tabular}{|c|c|c|c|c|c|c|c|c|c|c|c|c|c|}
\hline \multirow[b]{2}{*}{ Hydrogen Generation } & \multirow[b]{2}{*}{ Units } & \multicolumn{12}{|c|}{ Test Container Number } \\
\hline & & VSL-151 & VSL-160 & VSL-161 & VSL-162 & VSL-163 & VSL-164 & VSL-165 & VSL-166 & VSL-167 & VSL-168 & VSL-169 & VSL-170 \\
\hline Time Interval & years & 5.41 & 5.51 & 5.51 & 5.49 & 5.41 & 3.20 & 5.41 & 5.53 & 5.39 & 5.35 & 5.50 & 5.41 \\
\hline Hydrogen Concentration & ppm, vol & 5800 & 9553 & 11480 & 3038 & 1107 & 938 & 1808 & 42040 & 14010 & $<\mathrm{d}$ & $<\mathrm{d}$ & 2017 \\
\hline Net $\mathrm{H}_{2}$ Generated During Interval & g-mol & $1.56 \mathrm{E}-02$ & 4.55E-02 & $4.74 \mathrm{E}-02$ & 1.22E-02 & 4.94E-03 & 3.91E-03 & $6.52 \mathrm{E}-03$ & 1.62E-01 & 4.84E-02 & $<\mathrm{d}$ & $<\mathrm{d}$ & $7.15 \mathrm{E}-03$ \\
\hline Net $\mathrm{H}_{2}$ per Unit Surface Area of Steel & $\mathrm{g}-\mathrm{mol} / \mathrm{m} 2$ & 0.181 & 0.491 & 0.525 & 0.132 & $\mathrm{~N} / \mathrm{A}$ & $\mathrm{N} / \mathrm{A}$ & $\mathrm{N} / \mathrm{A}$ & 1.797 & 0.535 & $<\mathrm{d}$ & $<\mathrm{d}$ & $\mathrm{N} / \mathrm{A}$ \\
\hline Rate of $\mathrm{H}_{2}$ Generation per Area & $\mathrm{g}-\mathrm{mol} / \mathrm{yr} / \mathrm{m} 2$ & 3.35E-02 & $8.92 \mathrm{E}-02$ & 9.53E-02 & $2.40 \mathrm{E}-02$ & $\mathrm{~N} / \mathrm{A}$ & $\mathrm{N} / \mathrm{A}$ & $\mathrm{N} / \mathrm{A}$ & 3.25E-01 & 9.92E-02 & $<\mathrm{d}$ & $<\mathrm{d}$ & $\mathrm{N} / \mathrm{A}$ \\
\hline Corrosion Penetration Rate & micron/yr & 0.237 & 0.632 & 0.676 & 0.170 & $\mathrm{~N} / \mathrm{A}$ & $\mathrm{N} / \mathrm{A}$ & $\mathrm{N} / \mathrm{A}$ & 2.304 & 0.703 & $<\mathrm{d}$ & $<\mathrm{d}$ & $\mathrm{N} / \mathrm{A}$ \\
\hline \multicolumn{14}{|l|}{ Carbon Dioxide Generation } \\
\hline Time Interval & years & 4.14 & 4.49 & 4.45 & 4.41 & 4.18 & 4.35 & 4.34 & 4.30 & 4.28 & 4.26 & 4.22 & 5.41 \\
\hline $\mathrm{CO}_{2}$ Concentration & ppm, vol & $<\mathrm{d}$ & 246 & 193 & 178 & 506 & 698 & 555 & 73 & 134 & 186 & 179 & $<\mathrm{d}$ \\
\hline Net $\mathrm{CO}_{2}$ Generated During Interval & g-mol & $<\mathrm{d}$ & $1.41 \mathrm{E}-03$ & 9.47E-04 & $8.49 \mathrm{E}-04$ & $2.59 \mathrm{E}-03$ & $3.50 \mathrm{E}-03$ & $2.34 \mathrm{E}-03$ & $2.78 \mathrm{E}-04$ & $6.59 \mathrm{E}-04$ & 8.85E-04 & 8.30E-04 & $<\mathrm{d}$ \\
\hline Net $\mathrm{CO}_{2}$ per Mass of Carbon & $\mathrm{g}-\mathrm{mol} / \mathrm{g}$ & $<\mathrm{d}$ & $5.51 \mathrm{E}-06$ & 2.93E-06 & $2.63 \mathrm{E}-06$ & $1.24 \mathrm{E}-05$ & 1.67E-05 & $2.04 \mathrm{E}-05$ & $\mathrm{~N} / \mathrm{A}$ & $2.46 \mathrm{E}-06$ & $5.76 \mathrm{E}-06$ & 5.47E-06 & $<\mathrm{d}$ \\
\hline Rate of $\mathrm{CO}_{2}$ per Mass of Carbon & $\mathrm{g}-\mathrm{mol} / \mathrm{yr} / \mathrm{g}$ & $<\mathrm{d}$ & $1.04 \mathrm{E}-06$ & $6.59 \mathrm{E}-07$ & $5.96 \mathrm{E}-07$ & $2.95 \mathrm{E}-06$ & $3.84 \mathrm{E}-06$ & 4.69E-06 & $\mathrm{N} / \mathrm{A}$ & $5.76 \mathrm{E}-07$ & $1.35 \mathrm{E}-06$ & $1.30 \mathrm{E}-06$ & $<\mathrm{d}$ \\
\hline \multicolumn{14}{|l|}{$\mathrm{CO}_{2}$ in Initial Approx. 200 days } \\
\hline Time Interval & days & 239 & 206 & 192 & 182 & 245 & 180 & 175 & 181 & 179 & 179 & 237 & 232 \\
\hline $\mathrm{CO}_{2}$ Concentration & ppm, vol & $<\mathrm{d}$ & 119 & 103 & 96 & 341 & 352 & 294 & 86 & 94 & 104 & 128 & $<\mathrm{d}$ \\
\hline Net $\mathrm{CO}_{2}$ Generated During Interval & g-mol & $<\mathrm{d}$ & $6.90 \mathrm{E}-04$ & $5.02 \mathrm{E}-04$ & 4.66E-04 & $1.80 \mathrm{E}-03$ & $1.76 \mathrm{E}-03$ & $1.26 \mathrm{E}-03$ & $3.61 \mathrm{E}-04$ & $4.63 \mathrm{E}-04$ & $5.10 \mathrm{E}-04$ & $6.11 \mathrm{E}-04$ & $<\mathrm{d}$ \\
\hline Net $\mathrm{CO}_{2}$ per Mass of Carbon & $\mu \mathrm{g}-\mathrm{mol} / \mathrm{g}$ & $<\mathrm{d}$ & 2.11 & 1.56 & 1.44 & 8.58 & 8.39 & 10.96 & $\mathrm{~N} / \mathrm{A}$ & 1.73 & 3.32 & 4.03 & $<\mathrm{d}$ \\
\hline Rate of $\mathrm{CO}_{2}$ per Mass of Carbon & $\mu \mathrm{g}-\mathrm{mol} / \mathrm{yr} / \mathrm{g}$ & $<\mathrm{d}$ & 3.73 & 2.96 & 2.89 & 12.78 & 17.01 & 22.87 & $\mathrm{~N} / \mathrm{A}$ & 3.53 & 6.76 & 6.20 & $<\mathrm{d}$ \\
\hline
\end{tabular}


Steel-corrosion testing at the PNNL found hydrogen generation rates in tests inundated in Brine-A with nitrogen-pressurized headspace to be approximately four times higher when the headspace pressure was increased from $10 \mathrm{~atm}$ to $73 \mathrm{~atm}$, with a very slight drop for a further increase to $127 \mathrm{~atm}$ (1). All testing in the GGE was performed at approximately 146 atm for over 6 years. The high-pressure testing at PNNL had a duration of only 6 months, however. PNNL observed that the rates of gas generation during the initial 6 months in their lower pressure testing were significantly greater than over longer times. Reference 1 assumed that this would have also been observed had the higher pressure testing continued for longer periods, and interpreted their data accordingly.

\subsubsection{Hydrogen-Generation Temporal Profiles}

Figure 15 shows the hydrogen generation over the course of the experiment for all six vessels that contained carbon steel. The initial generation rates varied considerably. The rates of hydrogen generation in three of the vessels (those that contained sludge) increased markedly after the first year of testing. The rate of hydrogen generation in two other vessels (those without sludge) decreased after the first year. In two of the sludge-containing vessels hydrogen generation proceeded at a constant rate following the first year. These diverse temporal gas-generation rates cast some question on the validity of conclusions on long-term gas generation deduced from short-term testing.

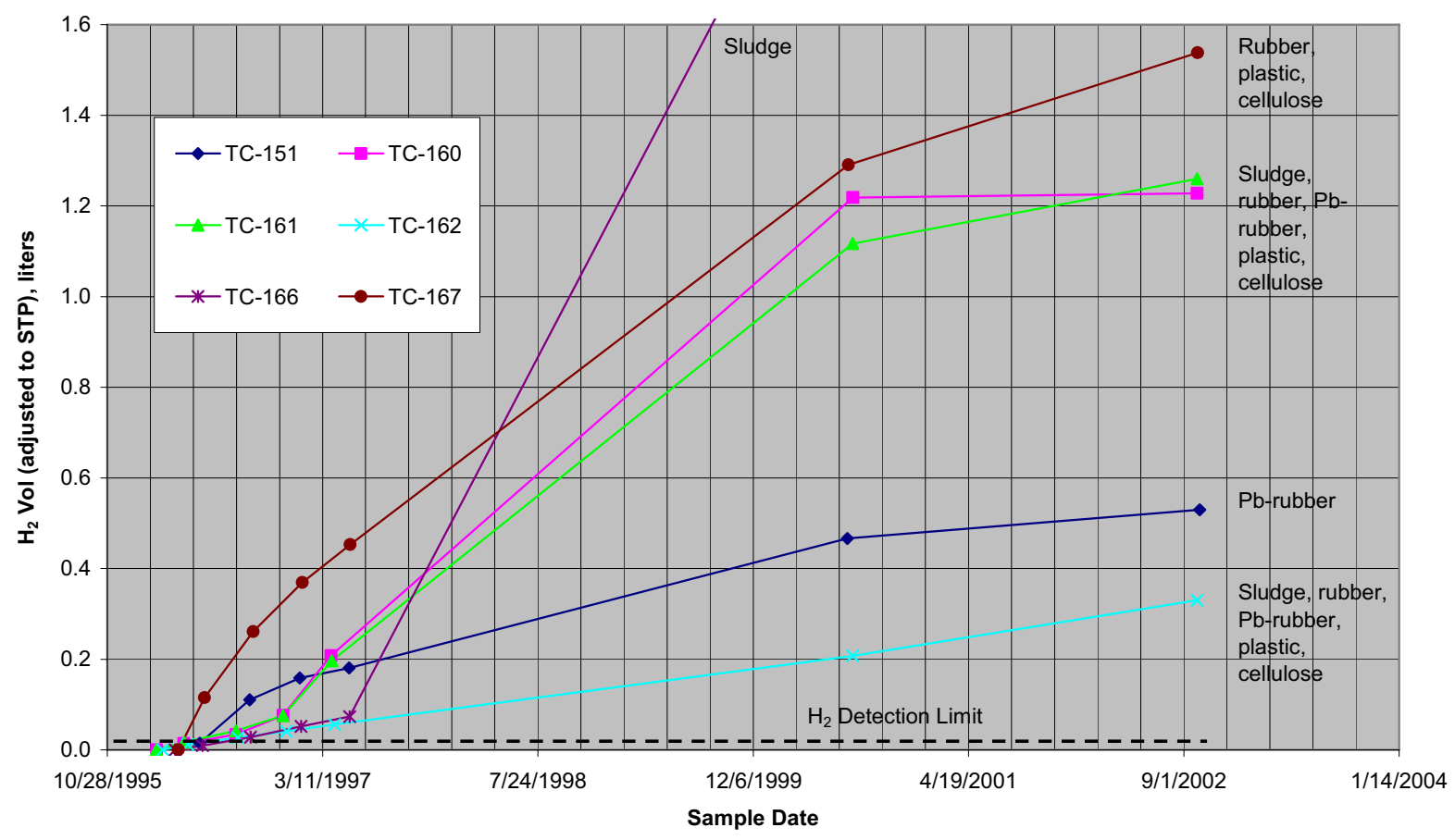

Figure 15. Hydrogen generation in all carbon-steel-bearing vessels.

\subsubsection{Hydrogen Generation in TC-166 vs. Other Carbon-Steel-Bearing Vessels}

Data for TC-166 that lie outside of the range of Figure 15 show the hydrogen generation continuing at a constant rate. Testing at PNNL observed that the presence of carbon dioxide and/or hydrogen sulfide can inhibit the corrosion of carbon steel (1). Vessel TC-166 was the only test vessel in the ANL experiments that contained steel but no carbon-bearing waste. The lack of any significant quantity of carbon dioxide or hydrogen sulfide being detected in this vessel (cf. Figure 12) may have allowed the carbon steel to corrode unabated in the absence of any corrosion inhibitor formation. Microbial activity in the carbon-bearing wastes in the other GGE steel-bearing test vessels may have created enough carbon 
dioxide or hydrogen sulfide to suppress corrosion to the extents observed. This corrosion-inhibition phenomenon would account for the unusually high hydrogen production rate observed in TC-166 as compared to the other steel-bearing-waste vessels.

\subsection{Carbon-Dioxide Generation}

The general characteristics of carbon-dioxide generation over the course of the experiment for all vessels were similar to those for the first replicate group (TC-160 through -162) shown in Figures 5 and 6. Carbon dioxide generation was characterized in terms of the carbon content in the waste. The measured rates of carbon dioxide generated were determined by using the gas analyses made in July 2000 relative to the starting date of the experiment. The most recent (Fall 2002) gas samples were not used for this calculation because they were believed to reflect the higher carbon-dioxide solubility that resulted from the unusually low temperature of the vessels when these samples were taken. These carbon-dioxidefraction differentials were then related to the carbon content shown in Table 2 and used the true waste quantities in each test vessel. The results are shown in Table 4. On this basis, the highest conversion rate of carbon mass to carbon dioxide over this 5-1/2-yr period would be in vessel TC-165, which measured $4.7 \mu \mathrm{g}-\mathrm{mol} / \mathrm{yr} / \mathrm{g}$-carbon. It is worth noting, however, that gases would be generated only from the surfaces of the relatively thick pieces of polyethylene, rubber, and fiber board. Therefore, basing the gas generation on the mass of carbon could produce a misleadingly low rate. Since the surface areas of the rubber, leaded rubber, polyethylene, and fiber board were not measured in the experiment design, this effect could not be further evaluated.

Anaerobic microbial gas-generation investigations performed at the Brookhaven National Laboratory (BNL) reported carbon dioxide production rates of $5.5 \mu \mathrm{g}-\mathrm{mol} / \mathrm{yr} / \mathrm{g}$-cellulose, equivalent to $12.3 \mu \mathrm{g}-\mathrm{mol} / \mathrm{yr} / \mathrm{g}$-carbon, for cellulose immersed in a somewhat different inoculated brine (the so-called G-Seep brine) for 200 days (2). For comparison, carbon dioxide measurements in the GGE program after the first approximately 200 days of testing were computed and are shown in the lower section of Table 4. The BNL value is still about twice as high as the two GGE vessels that contained only cellulose (vessels no. TC-168 and -169). All GGE vessels that produced carbon dioxide exhibited a rapid decline in the rate of carbon dioxide generation after the first year of testing. This might imply that the portion of the microbe population that would generate carbon dioxide simply died off during this period. Biological investigations to confirm this, however, were not funded.

It should also be noted that the cellulose used in the BNL experiments consisted of four different types of relatively thin papers: paper towels (white and brown), filter papers, and lint-less tissue ("Kimwipes") that were reduced to $10-\times-10-\mathrm{mm}$ pieces prior to the experiment. The approximately $60 \times 60 \times 3$-mm-thick $(2.4 \times 2.4 \times 0.125$-in thick $)$ brown fiber-board carton pieces used in the GGE likely restricted microbe access to cellulose within the interior regions of these pieces as compared to the BNL experiments, resulting in a lower mass-specific generation of gas in the GGE vessels.

\subsection{Experiment Design and Statistical Interpretation}

Sandia National Laboratory was cognizant for the experiment specification, data analysis, and reporting. ANL was responsible for the design, construction, and operation of the GGE, but had no involvement in the test specifications. Coupled with the inevitable turnover and retirement of project personnel at SNL since the beginning of the GGE, the full bases and rationale behind the experiment design are not known and can only be surmised. The development and analysis presented in this section is logically correct and technically accurate, however the descriptions and motivations described here for the specific experiment design may not actually correspond to the SNL intent. 
It was noted in Section 2.1 that the GGE investigated six waste types known to be plentiful and susceptible to gas generation. For practicality and economy, only a limited number of waste containers were able to be tested. To make the best possible use of the available assets, the experiments were specified by SNL to test the wastes at two levels only: the specific waste type was either present (in a fixed quantity), or completely absent. Two-level designs are well known approaches for determining the main effects (i.e., in the present application, the propensity of each waste type to generate gases).

For the GGE, the rubber and plastic were always varied in common (see Table 3), so that these two waste types were actually tested as a single waste category, viz., "rubber/plastic." Therefore, there were, effectively, five different waste types tested, each of which, in the context of the GGE, is a main variable:

- $\quad$ Carbon Steel

- $\quad$ Sludge

- $\quad$ Leaded Rubber

- Rubber/Plastic

- Cellulose.

All vessels were nominally identical and shared a common environment. Thus, each test vessel in the GGE can be considered to constitute a single test run. Factorial experiment designs require fewer test runs compared to changing one variable at time, and, in addition to revealing the main variable effects, also provide information on all possible interaction effects among the variables. A full factorial design for five variables at even just two treatment levels each, however, would have required $2^{5}=32$ test runs. Therefore, 32 vessels would have been needed to complete a full factorial experiment design. To reduce the number of test runs (vessels), the experiment was structured as a fractional factorial design. This was a $2^{5-2}$ design, requiring only $2^{3}=8$ test vessels. Four additional vessels were used to provide some replication to allow the variance of the data to be quickly assessed, as shown in Table 3 (viz., vessels TC-160, -161, and -162; vessels TC-163 and -164; and vessels TC-168 and -169). Two additional vessels, TC-152 and -153, containing inoculated brine but no wastes, provided the experiment controls. Altogether, 14 vessels were tested. The great reduction in the number of test runs makes fractional factorial designs very economical to conduct, but they must be applied judiciously. This is because in fractional designs the main treatment effects will be confounded with some of the interaction effects, i.e., the results of the experiment analysis will not yield a value for the effect of a main waste constituent, e.g., sludge, but, rather, for the sum of, say, sludge plus some interaction among the waste types. The ambiguity increases as the departure from a full factorial design widens, causing the main effects to become confounded with multiple interaction effects. For this reason, fractional factorial designs are generally used as initial screening devices to home in on the important variables to guide subsequent, more specific testing. The GGE did not, itself, pursue further testing, so the results of the statistical analysis can be expected to have rather low certainty, from a purely statistics perspective.

The confounding among variables that occurred in the GGE severely impacted the ability to decipher the statistical results. In fact, the $2^{5-2}$ design caused the main effects to be confounded with twofactor interactions (interactions between two waste types), which are often significant, whereas higher level interactions, e.g., interactions among three, four, or all five variables in the case of GGE, are usually insignificant. Had a $2^{5-1}$ design been conducted, it would have been possible to limit main-factor confounding to three-factor and higher interaction effects, although this would have required $2^{4}=16$ test runs. In retrospect, it would have been worthwhile to have added a few more test vessels and used a $2^{5-1}$ design, even if doing so would have required omitting some of the replication vessels. 


\subsubsection{Statistical Development}

Five main variables, call them $A, B, C, D$, and $E$, are tested at two levels each: high (+) and low (-). A $2^{5-2}$ fractional factorial experiment design is constructed by varying the settings (high or low) for three of the variables $(A, B$, and $C)$ independently within each test run and letting the settings of the remaining two variables $(D$ and $E$ ) be derived by fixed combinations of the settings of the three primary variables. For a $2^{5-2}$ design, the run settings (high or low) for variables $D$ and $E$ are deduced by the algebraic sign that results from two of the possible product combinations among the three primary variables, viz., $A B$, $A C, B C$, or $A B C$. A plus or minus sign ( \pm ) may be applied to each of these products, if done consistently. Several different associations may be made with these variable designators and match the vessel waste specification used in the GGE. The latter option (viz., $\pm A B C$ ), however, cannot be made to fit the waste loading schedule shown in Table 3 that SNL specified. So long as the variable settings correspond to the waste loading actually used in the GGE, which waste types are assigned to which variable is unimportant, and the same results are obtained.

The variable correspondence applied in the statistical development described here was as follows:

- $\quad A$ Leaded Rubber

- $\quad B$ Carbon Steel

- $\quad C$ Cellulose

- $\quad D$ Sludge $(D$ setting $=+A C)$

- $\quad E \quad$ Rubber/Plastic $(E$ setting $=+B C)$.

The accumulated hydrogen gas quantity (in g-mol) measured in the Fall, 2002 was the experiment response selected for analysis. Gas-generation rates could also have been used in the analysis, with very little effect on the results. Arithmetic-averaged responses were used for those test vessels that had replicates. The mechanics of the statistical calculation were organized using Yate's Algorithm (References 9 and 10) to deduce the effects of the waste types.

The formal analysis is provided in the spreadsheets in Appendix A. It was assumed that all 3-factor, 4-factor, and the 5-factor interactions among the variables $A, B, C, D$, and $E$ are all negligible, i.e., any non-zero result calculated for these higher-order interactions are only the result of uncontrollable, random, experimental errors that are normally distributed with a mean value of zero and variance $\sigma^{2}$. The two-factor interactions, however, are often real and therefore were retained.

A specific combination of wastes, i.e., the loading of various wastes in a test vessel, constitutes a unique test "treatment." The quantity of hydrogen generated by each full treatment was measured directly via the gas-samples analyses. In contrast to the quantity of gas generated by the combined waste loading within a test vessel, the statistical analysis reveals the tendency of each waste type, and/or interactions among waste types, to generate hydrogen. These are deemed the effects of the variables. The estimated variables and their effects are shown in the last two columns of the Yate's Algorithm table (see Appendix A). Large effects, in an absolute-value sense, are presumed real, whereas the lesser-value effects are assumed to be only the result of uncontrollable, random experimental errors. With these criteria, three effects stand out as probably real:

- $\quad B+C E=0.0698$

- $A B+D E=-0.0437$

- $A+C D=-0.0409$ 
The other effects deduced by the analysis (i.e., $A C+D, B D+A E, C+A D+B E$, and $B C+E$ ) were assumed to be negligible, but, with the largest of these having a value of 0.0301 , where the cutoff line for significance should be taken could certainly be questioned. It is noted that the effect for each of the main variables is confounded with at least one 2-factor interaction effect.

The three treatment effects listed above as likely to be real are analyzed as follows. In the first effect the main variable $B$ (carbon steel) is confounded by the effect of the $C E$ (cellulose-rubber/plastic) interaction. This interaction effect may have been positive or negative, since only the sum $B+C E$ is revealed by the Resolution III fractional factorial design used here (again, assuming that higher order interactions are negligible). Considering that cellulose and rubber/plastic are both large carbon sources, an interaction between these two components, i.e., the $C E$ interaction, would not be expected to be very significant if at all. So it is concluded that the $B$ effect is the predominant term in this sum, i.e., that carbon steel is very likely a strong gas producer. This certainly appears consistent with the observations from the headspace measurements made on vessel TC-166.

The third effect that appeared significant shows that the sum of the $A$ and $C D$ effects is negative. The $A$ effect (leaded rubber), by itself, would surely have been positive or, at least, zero, since leaded rubber can produce hydrogen via radiolysis. Therefore, the $C D$ interaction (cellulose-sludge) must have produced a rather strong negative interaction to cause the sum of these terms to be negative. This means that the presence of cellulose and sludge together would tend to suppress the hydrogen gas generated by leaded rubber, if any.

The interpretation of the second effect is not immediately clear. One or both of the two-factor interactions, $A B$ or $D E$ (leaded rubber-carbon steel or sludge-rubber/plastic) is negative. If only one is negative, it must be very strong to produce a negative sum of this magnitude. From knowledge of the experiment, it is surmised that both of the interactions are probably negative, since positive interactions would occur only if the waste types in the interaction were to combine to cause the $\mathrm{pH}$ of the brine solution to depart markedly from neutral, i.e., to become more acidic or much more basic. The interaction between sludge and cellulose was deduced previously to be negative, and the combination of sludge with rubber/plastic, another sludge-carbon twosome, is likely to be similar. The leaded rubber-carbon steel interaction may well have also been negative, owing to the known passivation of carbon steel by small quantities of carbon dioxide or hydrogen sulfide, as observed by Telander and Westerman at PNNL (Ref. 1). With this supposition, the values of each interaction in the second term are both assumed to be negative, so that each term, alone, would be smaller than the other effects. This, however, is very speculative, since the data are too sparse to support very strong conclusions.

\subsubsection{Analysis of the Variance}

Analyzing the variance among the data yields some interesting results. Variance analysis is a method that discriminates random errors from true effects. An Analysis of Variance (ANOVA) table was used. The ANOVA table is simply a concise way to organize the variance calculations. ANOVA techniques are discussed in most textbooks that deal with experiment design. It must be remembered that this experiment design is attempting to evaluate a relatively large number of variables with only a few number of test runs. Statistically, it will be unlikely that any strong, i.e., high probability, conclusions can be drawn, but rather only estimates and information that would be useful if further experiments were conducted.

The second spreadsheet in Appendix A summarizes the ANOVA analysis. Statistically, the data from this experiment are sparse. The limited data prevents the variance from being estimated directly from the overall experiment design because all of the "degrees of freedom" are consumed. Had there been more data, for example, had the entire experiment been replicated, the residuals in the ANOVA table 
would provide $s^{2}$, an estimate of the true variance, $\sigma^{2}$. In the absence of more data, the effects presumed to be the result only of random errors, can, however, be used to estimate the variance (it is the variance that caused these to not be identically zero). These four effects have a total sum of squares of $4.96 \mathrm{E}-03$ with 4 degrees of freedom. Dividing yields an estimate for the experiment variance, $s^{2}$, of 1.24E-03.

A confidence interval for the effects can be determined from the estimated variance. The limits are

$$
\text { Limits }= \pm t_{v, \text { critical }} \sqrt{4 s^{2} / N}
$$

$N$ is the number of test runs in the experiment design, and $s^{2}$ is the estimated variance. The term $t$ is the well known Student's $t$-distribution, a standard probability distribution applicable when the variance must be estimated. The degrees of freedom are designated by $v$, and the critical value is indicative of the confidence level chosen. For a two-tailed test at the $95 \%$ confidence level, the critical position is 0.025 (half of the $5 \%$ balance is left in each tail of the symmetrical $t$-distribution). With $v$ equal to 4 , a table of the $t$-distribution gives a 2.776 value for $t_{4,0.025}$. In the present case $N$ equals 8 , so substituting these together with the variance estimate into Equation 1 gives $95 \%$ confidence interval limits of $\pm 6.912 \mathrm{E}-2$.

These limits are shown overlaid on the distribution of the effects in Figure 16. Applying these confidence limits to the effects judged significant, the large statistical uncertainty at the $95 \%$ confidence level that exists from analyzing the variance this way becomes evident. In the figure the limits bar has arbitrarily been shown centered at the zero position, however it is actually movable, as indicated by the double-headed arrow, and can be slid back and forth to determine if it is possible to envelope all of the effects. Examination of the confidence limits indicates that, with $95 \%$ confidence, none of the derived effects data are necessarily distinct from the other data, because the limits of this confidence interval can easily envelope all seven data points together. This even includes the rightmost data point, $B+C E$, which pertains to the effect of carbon steel (plus the cellulose-rubber/plastic interaction). This, most likely, results from the scarcity of the data. When the confidence limits are relaxed to $80 \%$, the $t$ distribution has a 1.533 value for $t_{4,0.10}$, giving limits of $\pm 3.817 \mathrm{E}-2$. These limits are also shown in Figure 16. Accepting this reduced level of confidence, the $B+C E$ data point is now clearly outside of the limits, and the $C D$ interaction is close to being so. The same could be said for the $A B+D E$ effect, but each interaction in this sum was argued earlier to be negative, so that each interaction by itself should comfortably fall within the $80 \%$ confidence limits.

Another estimate of the variance can be calculated from the valid treatment effects data under the "null" hypothesis that these effects have no significant influence at all on the response. This variance estimate can then be divided by the overall variance estimate to derive another standard statistic called the $F$ statistic. The magnitude of the $F$ statistic determines whether the treatment effect falls well into the "tail" of the $F$ distribution. If so, the observed effect would be a very rare event if the null hypothesis were valid. Rare events have such a low probability of occurrence that, statistically, these are judged as evidence that the underlying hypothesis is not supported by the data. The critical $F$-distribution for $95 \%$ confidence is a tabulated function of the degrees of freedom, $v_{1}$ and $v_{2}$, which pertain to the treatment and overall estimates of the variance, respectively. The ANOVA spreadsheet shows the results of this test. The $F$ statistic for the $B+C E$ effects (carbon steel plus the cellulose-rubber/plastic interaction) at 7.85 just exceeds the critical $F_{1,4}$ value of 7.71 for $95 \%$ confidence. This indicates that the hypothesis of "no treatment effect' from the $B+C E$ effects is not supported by the data. Similar $F_{1,4}$ statistics for the $A+C D$ and for the $A B+D E$ treatments effects, however, do not contradict the hypothesis of 'no treatment effect'.

The $F$-test can be made for the totality of all effects taken together, as well as for a single effect. If all of the three effects deemed significant are taken as a whole, it is found that the $F_{3,4}$ statistic does not exceed the critical value for $95 \%$ confidence of 6.59 for the case of $v_{1}, v_{2}=3,4$ applicable to this 


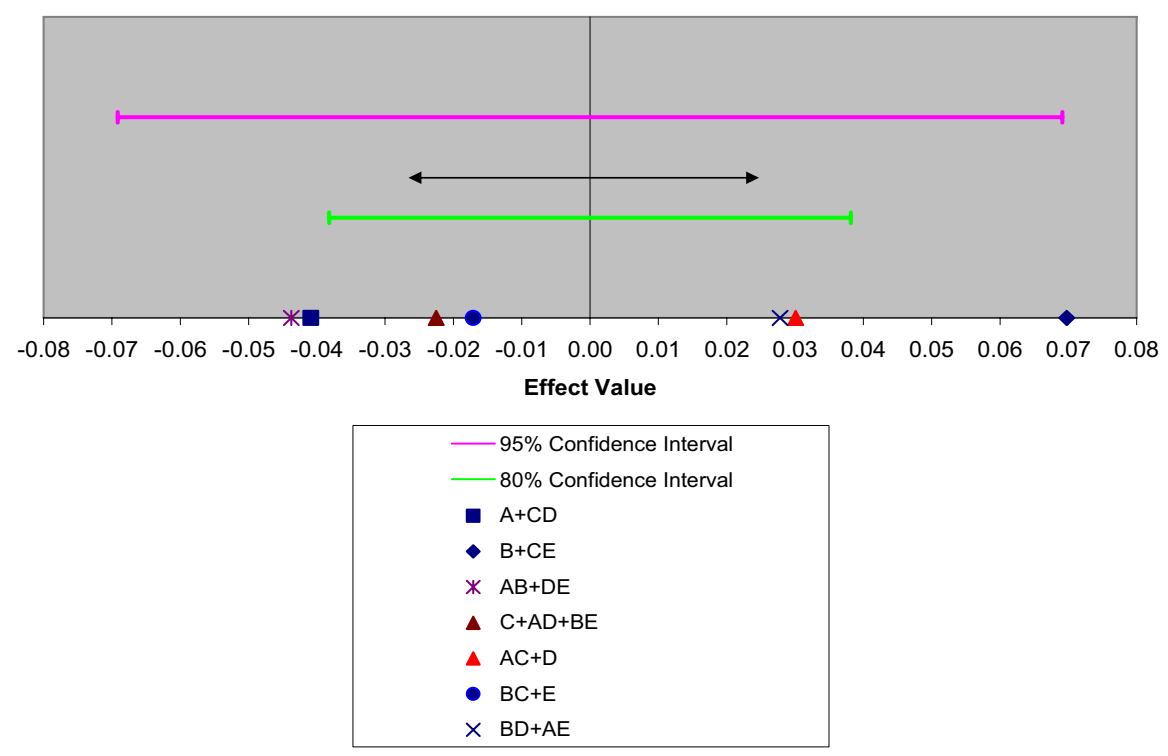

Figure 16. Statistical confidence limits for final hydrogen measurements.

calculation. This is an example of how, when a single-degree-of-freedom effect is on the borderline of being significant or not, an individual effect can be indicated as significant while the totality of effects do not contradict the hypothesis of no significance. This occasional masking of a significant single-degreeof-freedom effect is a well-known shortcoming of the $F$ statistic.

\subsubsection{Replicated Vessel Analyses}

The additional data afforded by the three groups of test vessels that were replicated can provide a greatly improved estimate of the experiment variance. These are computed from the simple definition of the variance,

$$
s^{2}=\frac{\sum\left(y_{i}-\bar{y}\right)^{2}}{N-1}=\frac{1}{N-1}\left[\sum y_{i}^{2}-\frac{1}{N}\left(\sum y_{i}\right)^{2}\right]
$$

The responses are $y_{\mathrm{i}}$, and the bar denotes the arithmetic average. It is clear how the variance can be reduced by increasing the number of test runs, $N$. Table 5 shows the final headspace-gas concentrations measured in Fall 2002 and the quantities of hydrogen and carbon dioxide in g-moles, together with some of the intermediate calculations. The final sample for TC-164 was lost when the vessel inadvertently depressurized. Therefore, the earlier sample for the replicate, TC-163, is shown in Table 5 as well to allow an equivalent-test-duration comparison to TC-164.

Using the final gas quantities as the measured response, the variances computed for the three replicate groups are shown in Tables 6 and 7. Using these variances, confidence limits can be established for each group of replicated test vessels. The $95 \%$ confidence limits are shown in the right-most column of Tables 6 and 7. Data for the replicated vessels together with the $95 \%$ confidence limits are plotted in Figure 17. The plot clearly shows the large effect that resulted from the variation in the hydrogen generation in TC-162 vs. that in TC-160 and -161. A second interval has been plotted in this figure to show how the confidence interval for this replicate group would be greatly tightened if the data for TC-162 were considered either atypical (see hypothesized explanation in Section 6.2.1) or simply an unexplained outlier and omitted. 
Table 5. Gas generation and carbon-steel corrosion rates.

\begin{tabular}{|c|c|c|c|c|c|c|c|c|c|c|c|c|c|c|}
\hline HS Sample Volume & $\mathrm{ml}$ & 3.05 & & & & & & & & & & & & \\
\hline Volume/g-mol at STP & I/g-mol & 22.42 & & & & & & & & & & & & \\
\hline Vessel \& Sample No. & & $151-7$ & $160-8$ & $161-8$ & $162-10$ & $163-11$ & $163-12$ & $164-7$ & $165-8$ & $166-8$ & $167-8$ & $168-8$ & 169-7 & $170-9$ \\
\hline & & & & & & & & & & & & & & \\
\hline Steel Surface Area Exposed & $i^{2}$ & 133.19 & 143.61 & 140.18 & 144.11 & 0 & 0 & 0 & 0.00 & 139.90 & 140.33 & 0 & 0 & 0.00 \\
\hline Sludge Mass & g & & 269.10 & 273.68 & 267.56 & 271.62 & 271.62 & 269.87 & 285.10 & 275.63 & & & & \\
\hline Leaded Rubber Mass & $\mathrm{g}$ & 129.28 & 124.72 & 125.96 & 123.36 & 125.52 & 125.52 & 127.41 & & & & & & 123.03 \\
\hline Rubber (Neoprene) Mass & $\mathrm{g}$ & & 44.83 & 43.64 & 45 & & & & 43.77 & & 42.52 & & & 43.48 \\
\hline Plastic Mass & $g$ & & 91.84 & 86.38 & 86.9 & & & & 88.47 & & 88.43 & & & 88.80 \\
\hline Cellulose Mass & $\mathrm{g}$ & & 344.24 & 344.35 & 343.85 & 345.22 & 345.22 & 343.72 & & & 345.56 & 345.9 & 341.83 & \\
\hline & & & & & & & & & & & & & & \\
\hline Date of Measurement & & $10 / 8 / 2002$ & $10 / 2 / 2002$ & $10 / 2 / 2002$ & $10 / 2 / 2002$ & $7 / 20 / 2000$ & $10 / 3 / 2002$ & $7 / 19 / 2000$ & $10 / 3 / 2002$ & $11 / 22 / 2002$ & $10 / 3 / 2002$ & $10 / 4 / 2002$ & $10 / 8 / 2002$ & $10 / 8 / 2002$ \\
\hline $\mathrm{H}_{2}$ Concentration Measured & ppm (vol) & 5800 & 9553 & 11480 & 3038 & 768 & 1107 & 938 & 1808 & 42040 & 14010 & \begin{tabular}{l|l}
$<50$ &
\end{tabular} & \begin{tabular}{|l|}
$<50$ \\
\end{tabular} & 2017 \\
\hline $\mathrm{CO}_{2}$ Concentration Measured & ppm (vol) & $<50$ & 187 & 154 & 110 & 506 & 418 & 698 & 455 & $<50$ & 134 & 134 & 127 & $<50$ \\
\hline Pressure (initial) & psia & 1980.9 & 1980.8 & 1951.6 & 1925.7 & 2147.9 & 1998.1 & 2158.3 & 1913.8 & 1850.8 & 2008.8 & 1943.2 & 1999.6 & 1965.6 \\
\hline Pressure (final) & psia & 1972.6 & 1974.9 & 1944.9 & 1919.1 & 2140.4 & 1991.3 & 2150.6 & 1906.4 & 1843.3 & 2001.7 & 1936.3 & 1992.2 & 1957.5 \\
\hline & std-atm & 134.23 & 134.38 & 132.34 & 130.59 & 145.65 & 135.50 & 146.34 & 129.72 & 125.43 & 136.21 & 131.76 & 135.56 & 133.20 \\
\hline TC RTD Reading when Sampled & C & 18.1 & 18.3 & 18.4 & 18.2 & 29.0 & 18.3 & 30.0 & 18.3 & 17.8 & 18.3 & 18.2 & 18.1 & 18.0 \\
\hline Glovebox RTD Reading when Sampled & C & 18.1 & 18.3 & 18.4 & 18.2 & 27.0 & 18.3 & 27.0 & 18.3 & 17.8 & 18.3 & 18.2 & 18.1 & 18.0 \\
\hline HS Temperature Estimate for Sample & C & 18.10 & 18.30 & 18.40 & 18.20 & 28.50 & 18.30 & 29.25 & 18.30 & 17.80 & 18.30 & 18.20 & 18.10 & 18.00 \\
\hline Vapor Pressure of Brine $\left(\mathrm{H}_{2} \mathrm{O}\right)$ & psia & 0.3011 & 0.3050 & 0.3069 & 0.3031 & 0.0000 & 0.3050 & 0.5894 & 0.3050 & 0.2954 & 0.3050 & 0.3031 & 0.3011 & 0.2992 \\
\hline $\mathrm{HS}\left(\mathrm{N}_{2}\right)$ Compressibility Factor (initial) & -- & 1.0200 & 1.0200 & 1.0200 & 1.0200 & 1.0200 & 1.0200 & 1.0200 & 1.0200 & 1.0200 & 1.0200 & 1.0200 & 1.0200 & 1.0200 \\
\hline $\mathrm{HS}\left(\mathrm{N}_{2}\right)$ Compressibility Factor (final) & -- & 1.0200 & 1.0200 & 1.0200 & 1.0200 & 1.0200 & 1.0200 & 1.0200 & 1.0200 & 1.0200 & 1.0200 & 1.0200 & 1.0200 & 1.0200 \\
\hline HS Volume at Measurement Conditions & $\mathrm{ml}$ & 724.8 & 1020.8 & 885.2 & 886.7 & 870.4 & 893.0 & 851.6 & 785.6 & 749.5 & 859.8 & 855.8 & 821.0 & 737.0 \\
\hline HS Volume adjusted to STP & 1 & 91.2 & 128.6 & 109.8 & 108.6 & 114.8 & 113.4 & 112.6 & 95.5 & 88.3 & 109.8 & 105.7 & 104.4 & 92.1 \\
\hline $\mathrm{H}_{2}$ vol at Prevailing Press \& Temp & $\mathrm{ml}$ & 4.204 & 9.751 & 10.162 & 2.694 & 0.668 & 0.989 & 0.799 & 1.420 & 31.508 & 12.045 & $<\mathrm{d}$ & $<\mathrm{d}$ & 1.486 \\
\hline $\mathrm{H}_{2}$ vol adjusted to STP & 1 & 0.529 & 1.228 & 1.260 & 0.330 & 0.088 & 0.126 & 0.106 & 0.173 & 3.710 & 1.538 & $<\mathrm{d}$ & $<\mathrm{d}$ & 0.186 \\
\hline $\mathrm{CO}_{2}$ vol at Prevailing Press \& Temp & $\mathrm{ml}$ & $<\mathrm{d}$ & 0.191 & 0.136 & 0.098 & 0.440 & 0.373 & 0.594 & 0.357 & $<\mathrm{d}$ & 0.115 & 0.115 & 0.104 & $<\mathrm{d}$ \\
\hline $\mathrm{CO}_{2}$ vol adjusted to STP & I & $<\mathrm{d}$ & 0.024 & 0.017 & 0.012 & 0.058 & 0.047 & 0.079 & 0.043 & $<\mathrm{d}$ & 0.015 & 0.014 & 0.013 & $<d$ \\
\hline $\mathrm{H}_{2}$ quantity & g-mol & $2.36 \mathrm{E}-02$ & $5.48 \mathrm{E}-02$ & $5.62 \mathrm{E}-02$ & $1.47 \mathrm{E}-02$ & $3.93 \mathrm{E}-03$ & $5.60 \mathrm{E}-03$ & $4.71 \mathrm{E}-03$ & $7.70 \mathrm{E}-03$ & $165 \mathrm{E}-01$ & $6.86 \mathrm{E}-02$ & $<\mathrm{d}$ & $<\mathrm{d}$ & $8.29 \mathrm{E}-03$ \\
\hline $\mathrm{CO}_{2}$ quantity & g-mol & $<\mathrm{d}$ & $1.07 \mathrm{E}-03$ & $7.54 \mathrm{E}-04$ & $5.33 \mathrm{E}-04$ & $2.59 \mathrm{E}-03$ & $2.11 \mathrm{E}-03$ & $3.50 \mathrm{E}-03$ & $1.94 \mathrm{E}-03$ & $<\mathrm{d}$ & $6.56 \mathrm{E}-04$ & $6.32 \mathrm{E}-04$ & $5.91 \mathrm{E}-04$ & $<d$ \\
\hline
\end{tabular}


Table 6. Statistical analyses of hydrogen generation in replicated vessels.

\begin{tabular}{|c|c|c|c|c|c|c|c|}
\hline \multicolumn{7}{|c|}{ Note: Responses are quantities of headspace gas (g-mole) as sampled in Fall, 2002.} \\
\hline
\end{tabular}


Table 7. Statistical analyses of carbon dioxide generation in replicated vessels.

\begin{tabular}{|c|c|c|c|c|c|c|c|c|c|c|}
\hline \multicolumn{11}{|c|}{ Note: Responses are quantities of headspace gas (g-mole) as sampled in Fall, 2002.} \\
\hline \multicolumn{11}{|c|}{ Response values shown for TC-163 and -164 are from July, 2000.} \\
\hline & & & & & & & & & & \\
\hline \multicolumn{11}{|c|}{ Estimated Variance: $\mathrm{s}^{2}=1 /(\mathrm{N}-1){ }^{*}\left[\sum \mathrm{y}_{\mathrm{i}}^{2}-1 / \mathrm{N} *\left(\sum \mathrm{y}_{\mathrm{i}}\right)^{2}\right]$} \\
\hline \multicolumn{11}{|c|}{$95 \%$ Confidence Limits $= \pm t_{v, 0.025} \sqrt{ }\left(\mathrm{s}^{2} / \mathrm{N}\right)$} \\
\hline & & & & & & & & & & \\
\hline & & & & & & & & & & \\
\hline \multicolumn{2}{|c|}{ Carbon Dioxide Generation } & & \multicolumn{4}{|c|}{ Response, g-mol } & & & & \\
\hline & & & $\mathrm{N}$ & $\mathrm{y}_{\mathrm{i}}$ & $y_{i}^{2}$ & & $s^{2}$ & $v=N-1$ & $t_{v, 0.025}$ & $95 \%$ Conf. \\
\hline & Group 1: TC-160, $-161,-162$ & & & & & & & & & Limits \\
\hline & & & 3 & & & 0.0007857 & $7.28 \mathrm{E}-08$ & 2 & 4.303 & $6.71 \mathrm{E}-04$ \\
\hline & & TC-160 & & 1.07E-03 & $1.14 \mathrm{E}-06$ & & & & & \\
\hline & & TC-161 & & 7.54E-04 & 5.69E-07 & & & & & \\
\hline & & TC-162 & & 5.33E-04 & $2.84 \mathrm{E}-07$ & & & & & \\
\hline & & & & & & & & & & \\
\hline & Group 2: TC-163, -164 & & & & & & & & & \\
\hline & & & 2 & & & 0.003045 & 4.14E-07 & 1 & 12.706 & $5.78 \mathrm{E}-03$ \\
\hline & & TC-163 & & $2.59 \mathrm{E}-03$ & $6.71 \mathrm{E}-06$ & & & & & \\
\hline & & TC-164 & & $3.50 \mathrm{E}-03$ & $1.23 \mathrm{E}-05$ & & & & & \\
\hline & & & & & & & & & & \\
\hline & Group 3: TC-168, -169 & & & & & & & & & \\
\hline & & & 2 & & & 0.0006115 & $8.40 \mathrm{E}-10$ & 1 & 12.706 & $2.60 \mathrm{E}-04$ \\
\hline & & TC-168 & & $6.32 \mathrm{E}-04$ & 3.99E-07 & & & & & \\
\hline & & TC-169 & & $5.91 \mathrm{E}-04$ & $3.49 \mathrm{E}-07$ & & & & & \\
\hline
\end{tabular}




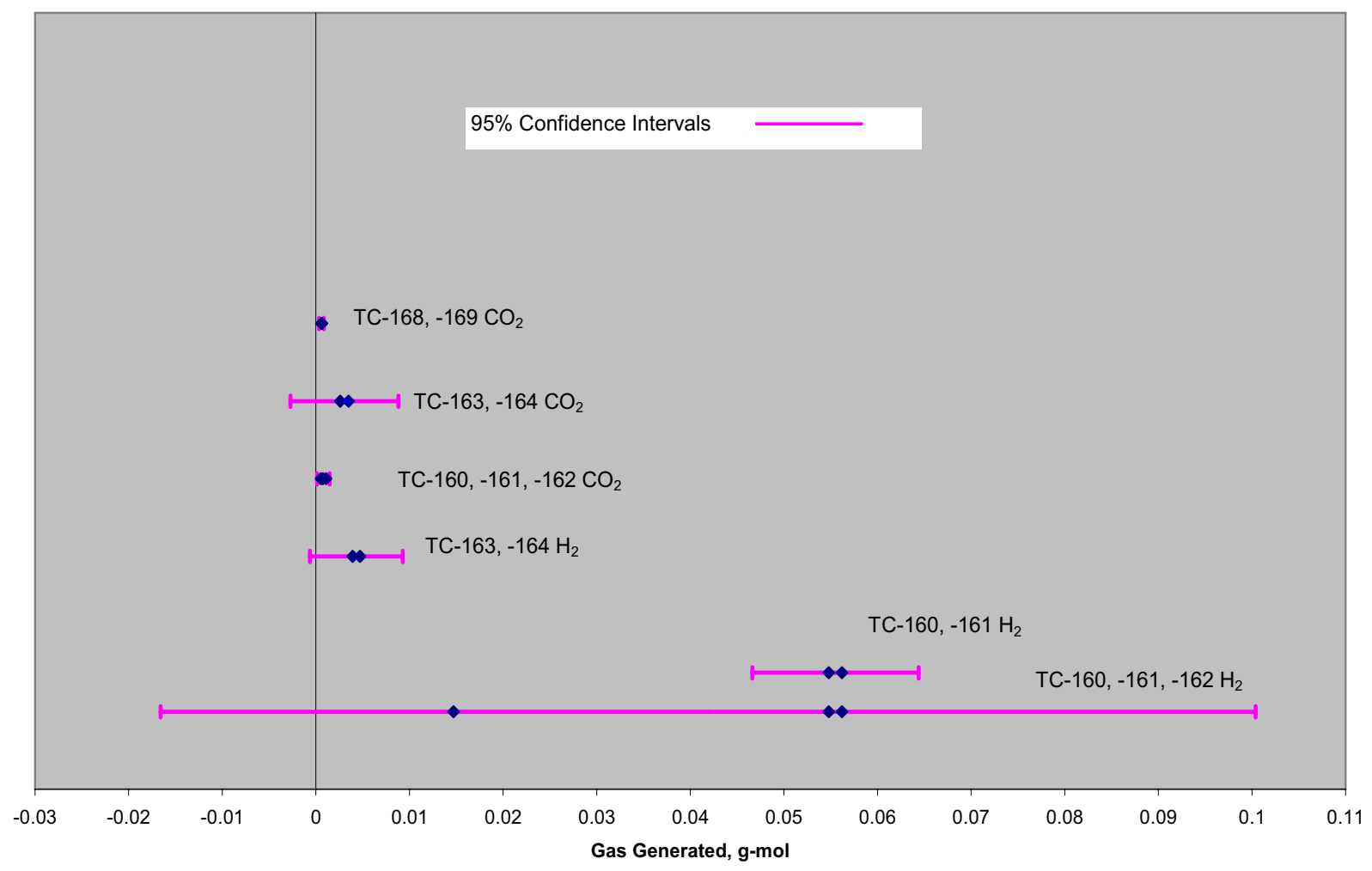

Figure 17. Statistical confidence limits for replicated vessels.

The variances computed from the replicated vessels can be combined, or "pooled," to yield a bestestimate variance applicable to all of the replicated test vessels:

$s_{\text {pooled }}^{2}=\frac{\sum v_{i} s_{i}^{2}}{\sum v_{i}}$

Even when the hydrogen data from TC-162 are included, Equation 3 gives a pooled variance of 1.59E-04 with 7 degrees of freedom. The experimental techniques were common to all test vessels. Therefore, it is not unreasonable to assume that this variance applies equally to all of the vessels tested, and would have been statistically substantiated for the non-replicated vessels had more data been available. Making this assumption, the variances computed in the ANOVA table for the effects can be reexamined for significance by use of the $F$-statistic. In fact, now there would be no need to arbitrarily separate out the effects assigned random status earlier, and all of the effects can be tested for significance.

Results of the test for significance are shown in Table 8 using the estimated variances shown in the ANOVA table (Appendix A) for the different effects under the null hypothesis of no significance. The estimated variances of the effects are all single degree of freedom, so the comparison for significance is

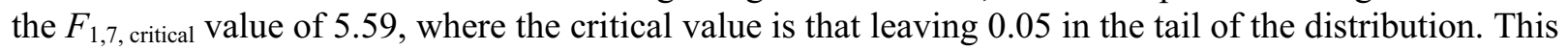
says that the probability of an effect having an $F$ statistic that exceeds the critical value under the presumption of no effect at all is less than $5 \%$. Such a case would be rare, and statistically would require that the hypothesis be discarded. Examination of Table 8 shows that the $F_{1,7}$ statistic for all of the effects with the exception of the $B C+E$ effect (carbon steel-cellulose interaction plus the rubber/plastic main effect), exceed the critical value and are therefore statistically significant. 
Table 8. Significance test for effects.

\begin{tabular}{|c|c|c|c|c|c|}
\hline & \multirow{2}{*}{$\begin{array}{l}\mathrm{s}_{\text {pooled* }}^{2} \\
F_{1,7, \text { critical }}\end{array}$} & \multirow{2}{*}{$\begin{array}{c}1.59 \mathrm{E}-04 \\
5.59\end{array}$} & \multicolumn{2}{|c|}{ with 7 degrees of freedom } & \\
\hline & & & & & \\
\hline Effect * & Variance * & Degrees of & $F_{1,7}$ & $\mathrm{~F}_{1,7} / \mathrm{F}_{1,7, \text { critical }}$ & Significant? \\
\hline & $\mathrm{s}^{2}$ & Freedom * & $\mathrm{s}^{2} / \mathrm{s}_{\text {pooled }}^{2}$ & & \\
\hline$A+C D$ & 3.34E-03 & 1 & 21.03 & 3.76 & Yes \\
\hline$B+C E$ & 9.73E-03 & 1 & 61.27 & 10.96 & Yes \\
\hline$A B+D E$ & $3.83 \mathrm{E}-03$ & 1 & 24.12 & 4.31 & Yes \\
\hline$C+A D+B E$ & 1.02E-03 & 1 & 6.42 & 1.15 & Yes \\
\hline & & & & & \\
\hline$A C+D$ & 1.81E-03 & 1 & 11.40 & 2.04 & Yes \\
\hline $\mathrm{BC}+\mathrm{E}$ & $5.85 \mathrm{E}-04$ & 1 & 3.68 & 0.66 & No \\
\hline$B D+A E$ & $1.55 \mathrm{E}-03$ & 1 & 9.76 & 1.75 & Yes \\
\hline${ }^{*}$ See sprea & ets in Appendi & & & & \\
\hline
\end{tabular}

The $A C$ (leaded rubber-cellulose) interaction, as was argued for the $C E$ (cellulose-rubber/plastic) interaction in Section 6.5.1, is an interaction between two materials rich in carbon. A significant interaction, positive or negative, between these two materials is unlikely. This would then indicate that the $D$ component of this effect (i.e., sludge) is a significant gas generator.

In summary, the statistical analyses of the experiment support the test observations that carbon steel has a strong effect on the hydrogen generation and that cellulose and sludge may interact significantly to suppress the generation of hydrogen. Indications are that nearly all of the constituent interactions are negative. It is best, however, to not infer too much from a statistical analysis of such limited data. The headspace-gas sample results presented earlier certainly suggest that there are negative interactions occurring. All of the waste types are known to produce gases, and the quantity of each waste constituent was constant when present. Therefore, gas generation would have increased as the number of waste types in the vessel increased had there been no negative interactions occurring. This was not observed to be the case (compare in Figure 15 the hydrogen generated in TC-167 or TC-166 to that in TC-160, -161, and -162, which had additional wastes present). Conclusions derived from the earlier direct analyses of the gas samples are not invalidated by the statistical analyses. The lack of definitive statistical corroboration is best interpreted as simply that the quantity of data are insufficient to support highconfidence conclusions.

\subsection{Visual Examinations}

All of the vessel internal areas that were not in direct contact with the liquid brine were observed to be very clean. There was only a thin coloration on the interior of the vessel in areas where the vessel was in direct contact with the brine. Brine extracted from near the surface appeared very clear, while the brine near the bottom of the vessels was typically very dark and opaque, indicating that there was a settling of particulate matter. The brine was a medium brown to dark grey color, depending on the waste contents: brine in vessels that contained sludge tended to be dark grey, whereas the brine was brown in vessels having only cellulose materials. All waste materials were easily identifiable after the 6-1/2 years of testing. The rubber and leaded rubber showed no noticeable changes, and the fiber board and cloth appeared simply as soggy variants of their appearance at the beginning of the experiment, with only slight 
discoloration. The metal coupons all had a very dark, bluish/greenish-black color. Upon exposure to the ambient, the metal coupons tended to develop streaks of familiar yellow and orange rust coloration.

The brine in vessel TC-152, a non-waste-bearing, experiment-control vessel, was very clear except in the very lower portion of the vessel where there was a black sediment. This must have been the results of microbe activity on the brine, or possibly microbe competition within the inoculum. The brine contained both iron and sulfur (see Table 1), so this may have been an iron-sulfite material. Leftover brine stored at room temperature during the entire period of the experiment showed no perceptible change from its initial, clear appearance. Figure 18 shows the brine extracted from near the brine surface, while Figure 19 shows the homogenized brine. A view into the bottom of the vessel, Figure 20, shows the residue. Since analyses of the non-steel-bearing vessels were not funded, the composition of the dregs from this vessel remains only speculative.

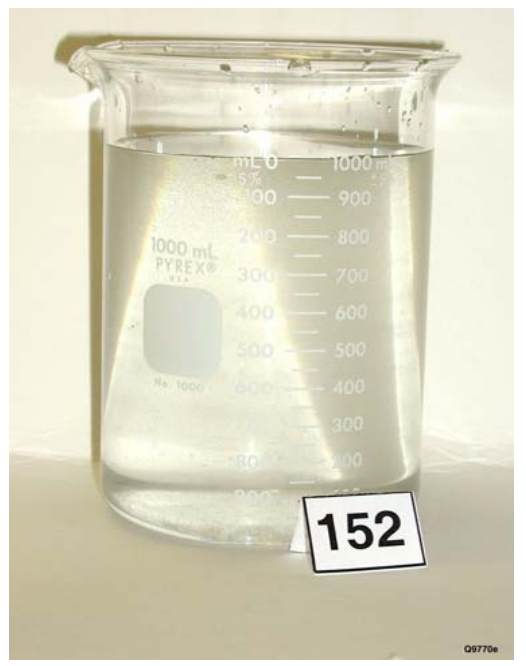

Figure 18. Brine from the upper region of vessel TC-152.

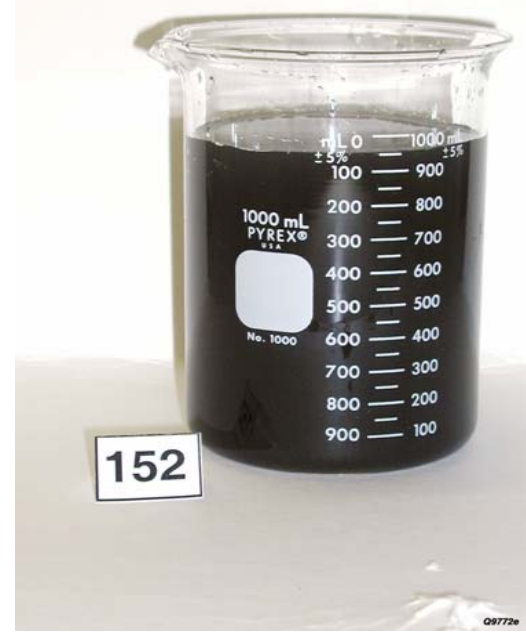

Figure 19. Homogenized Brine from vessel TC-152.

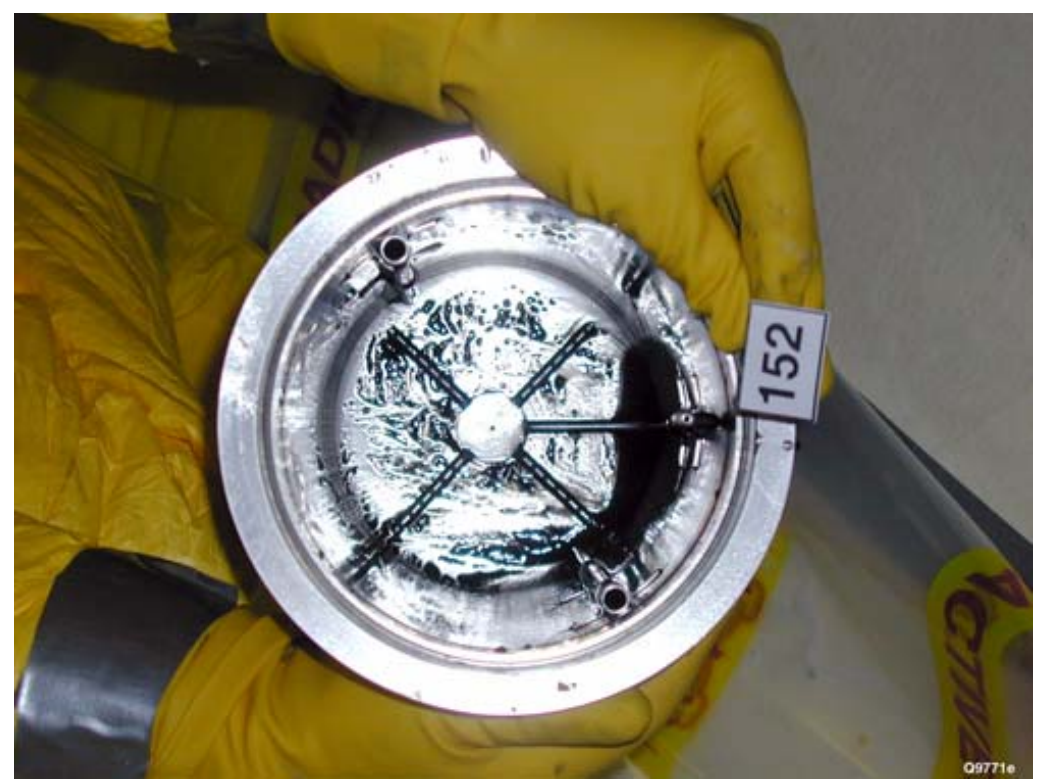

Figure 20. Residue in experiment control test Vessel TC-152. 
Photographic records were made that generally show the inside of the vessel head, a 1000-ml beaker of the brine extracted from near the surface, a 1000-ml beaker of the homogenized brine, the waste materials, a view into the vessel, and a dip-stick depth measurement of the brine after the solid waste items had been removed. For example, Figures 21 through 28 show the photo record of the visual examination of a typical vessel, TC-167. Waste types in this vessel were carbon steel, rubber, polyethylene, and cellulose (fiber board and cloth). The increasing opacity of the brine nearer to the bottom of the vessel is apparent. Figure 21 shows the homogenized brine. Figure 22 shows the underside of the vessel top closure, with waste-hold-down screen. Figure 23 is a view into the vessel upon opening, and the wastes (polyethylene and cloth) near the brine surface appear very clean. Figures 24 and 25 show the inside of the vessel as waste and brine are being progressively removed. Cotton cloth, fiberboard, and steel wastes are shown in Figures 26 and 27. The brine volume (depth) measurement via a dip-stick is shown in Figure 28.

Photographic images of each of the other steel-bearing vessels are presented in Appendix B. Waste contents for each vessel are listed in Table 2.

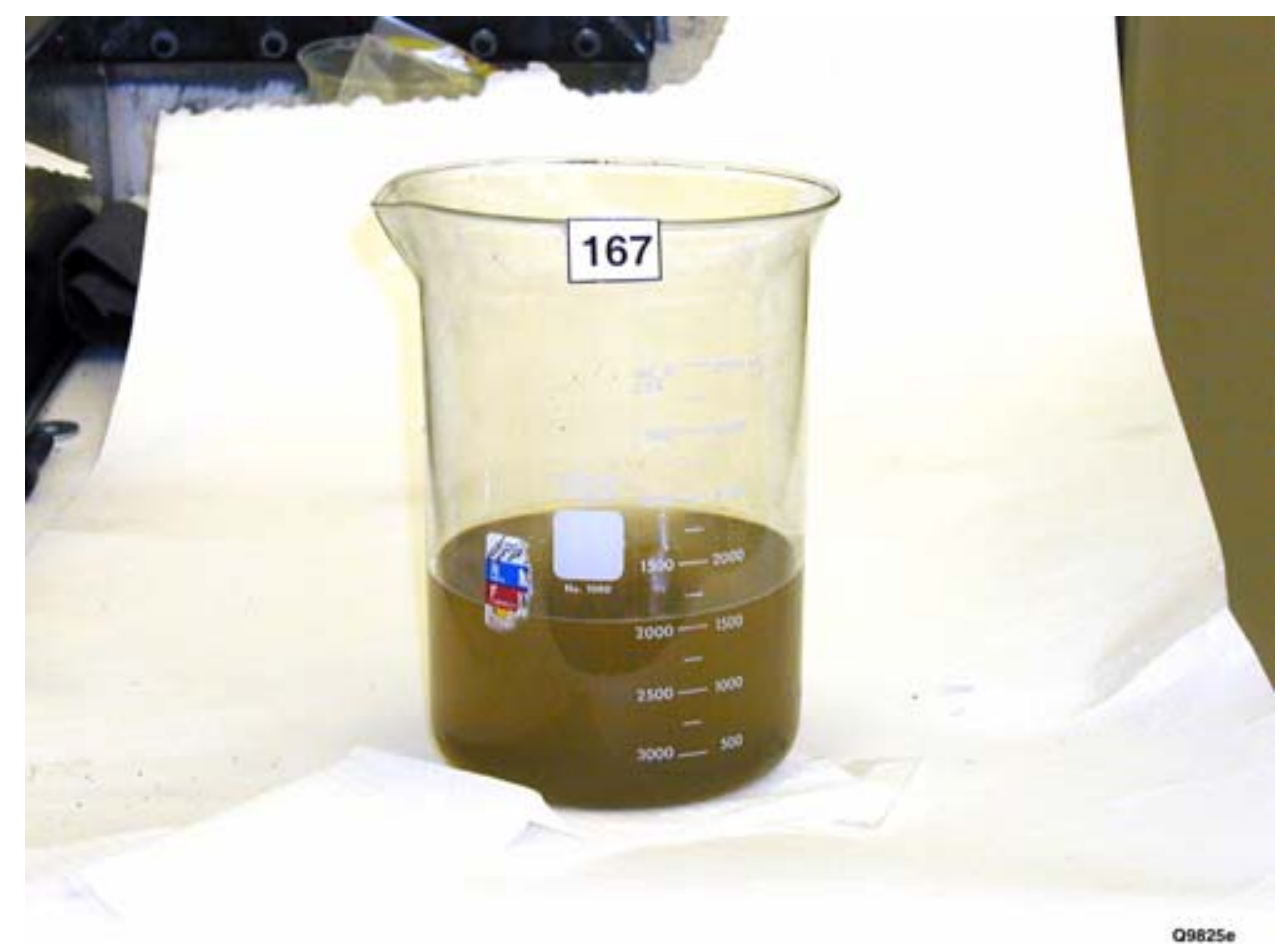

Figure 21. Homogenized Brine sample, TC-167. 


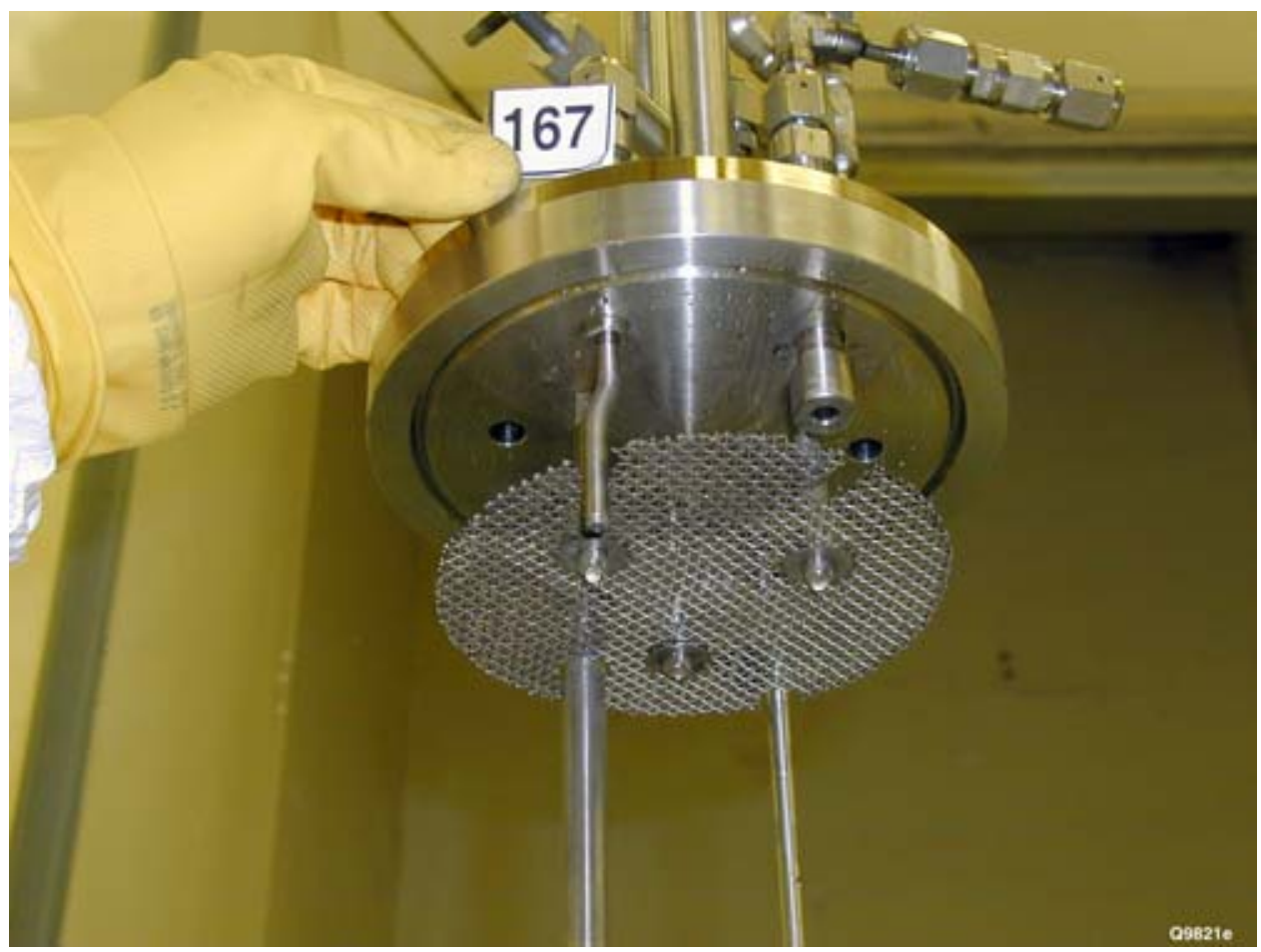

Figure 22. Underside of vessel head, TC-167.

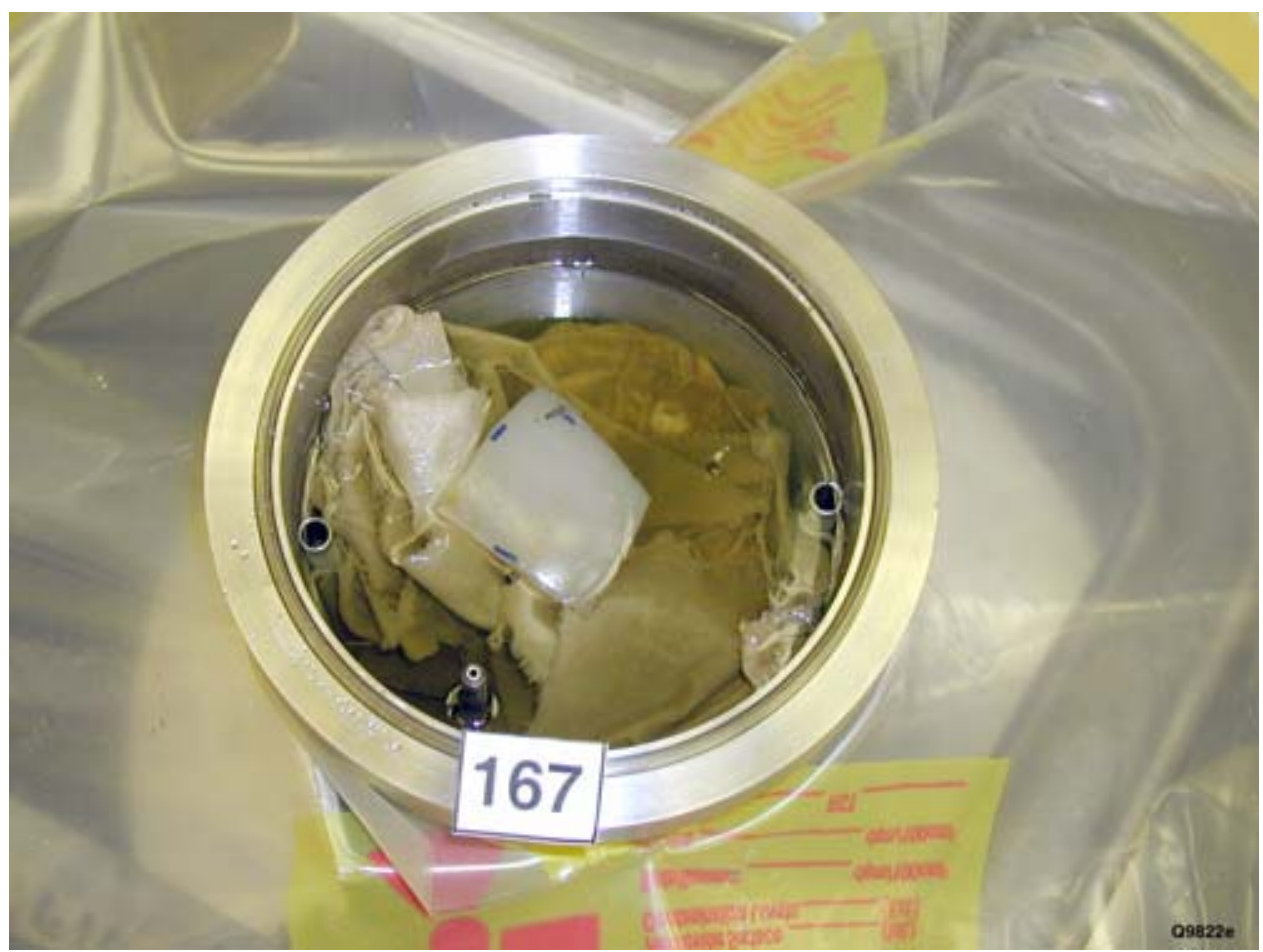

Figure 23. All wastes within vessel TC-167. 


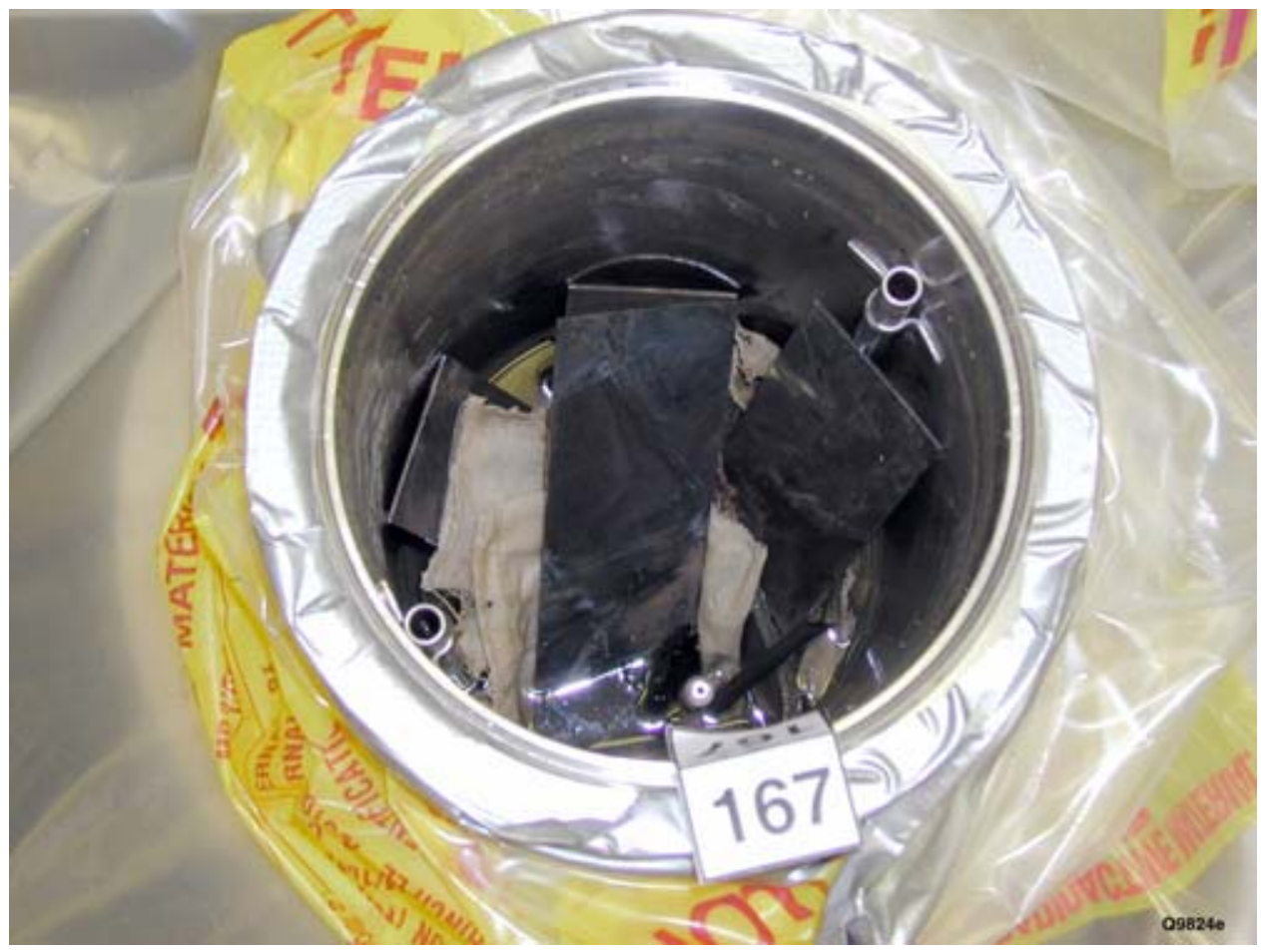

Figure 24. Partial wastes within vessel TC-167 during unloading.

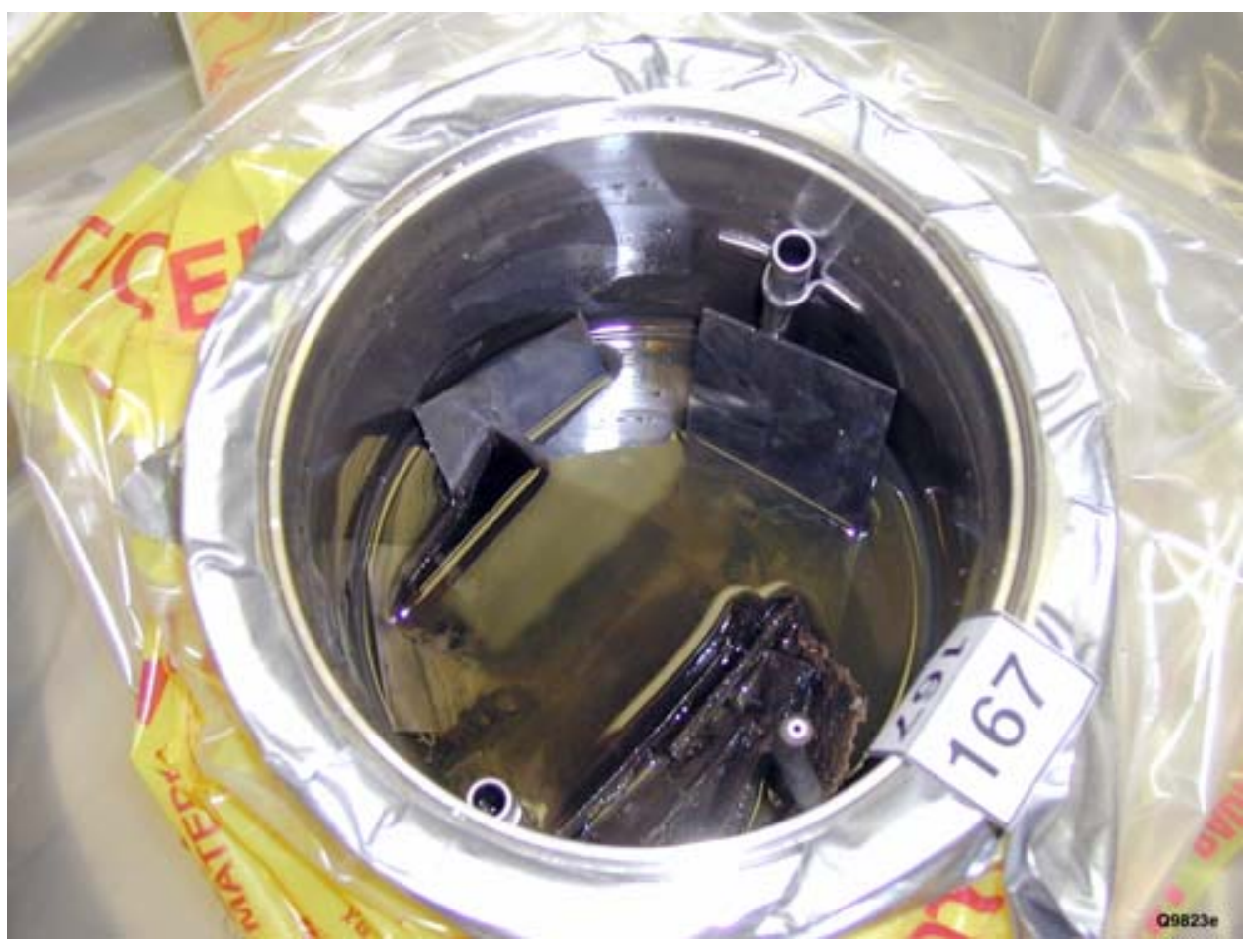

Figure 25. Partial wastes within vessel TC-167 during unloading. 


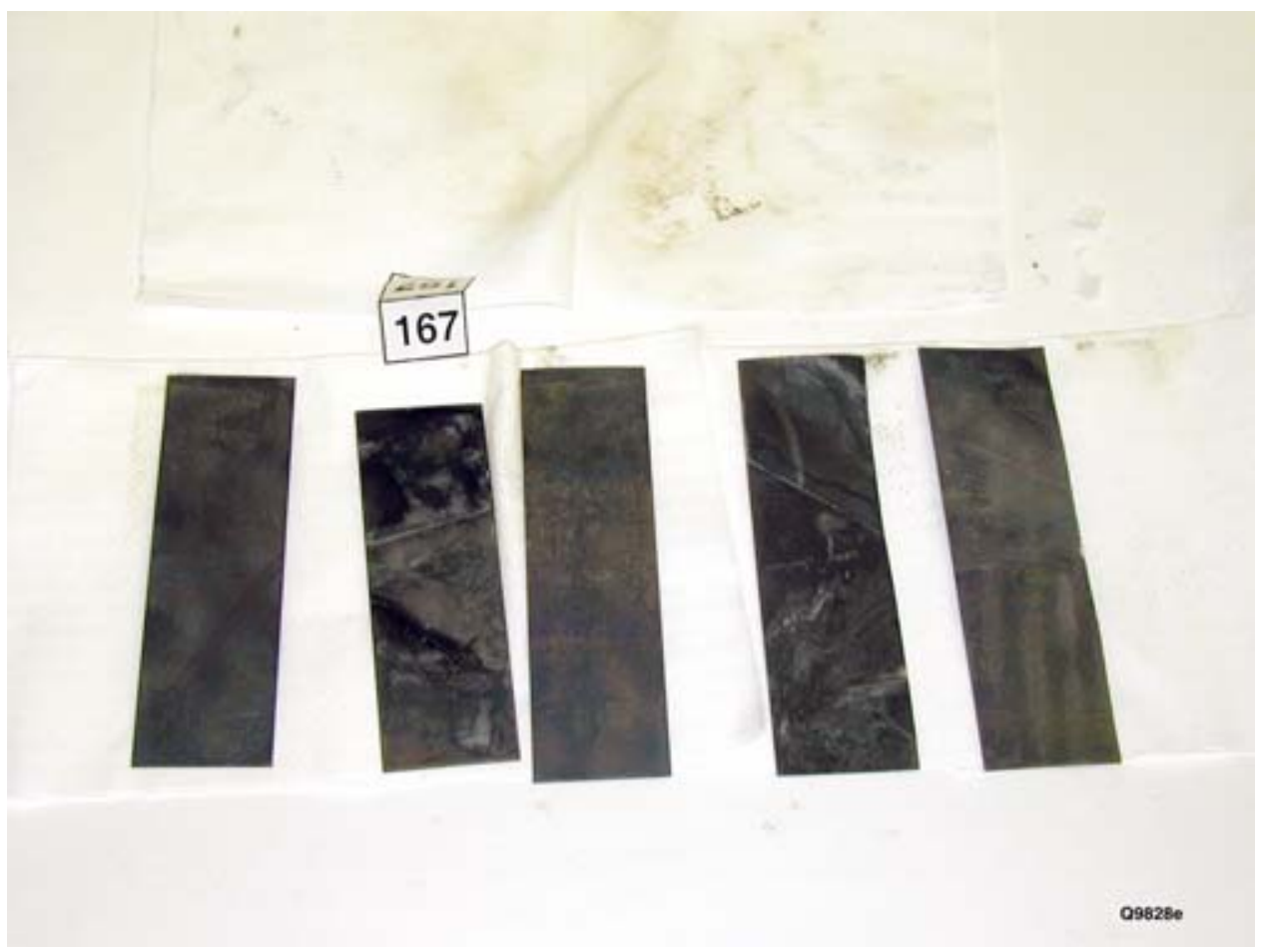

Figure 26. Carbon-steel specimens, vessel TC-167.

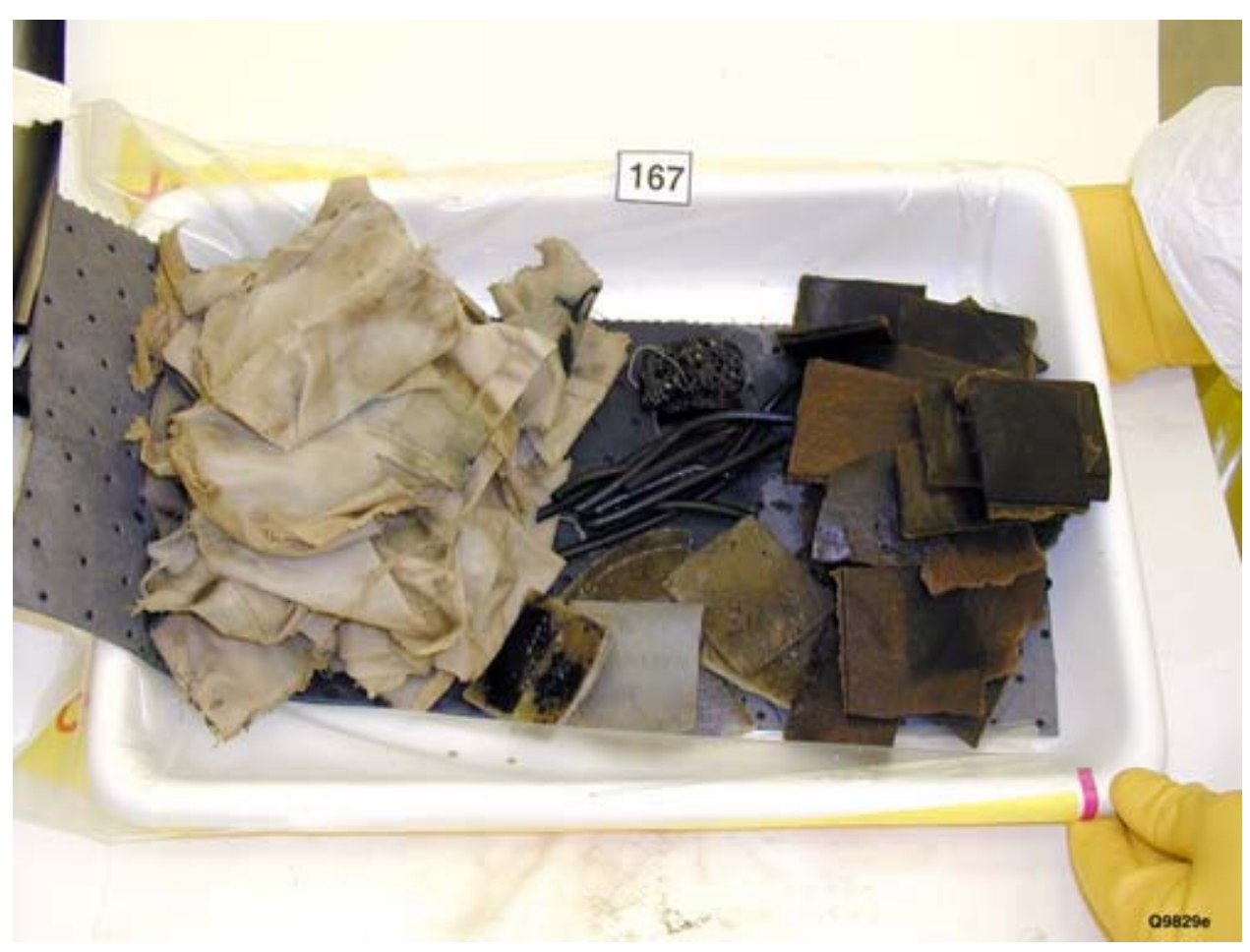

Figure 27. Rubber, plastic, and cellulose, vessel TC-167. 


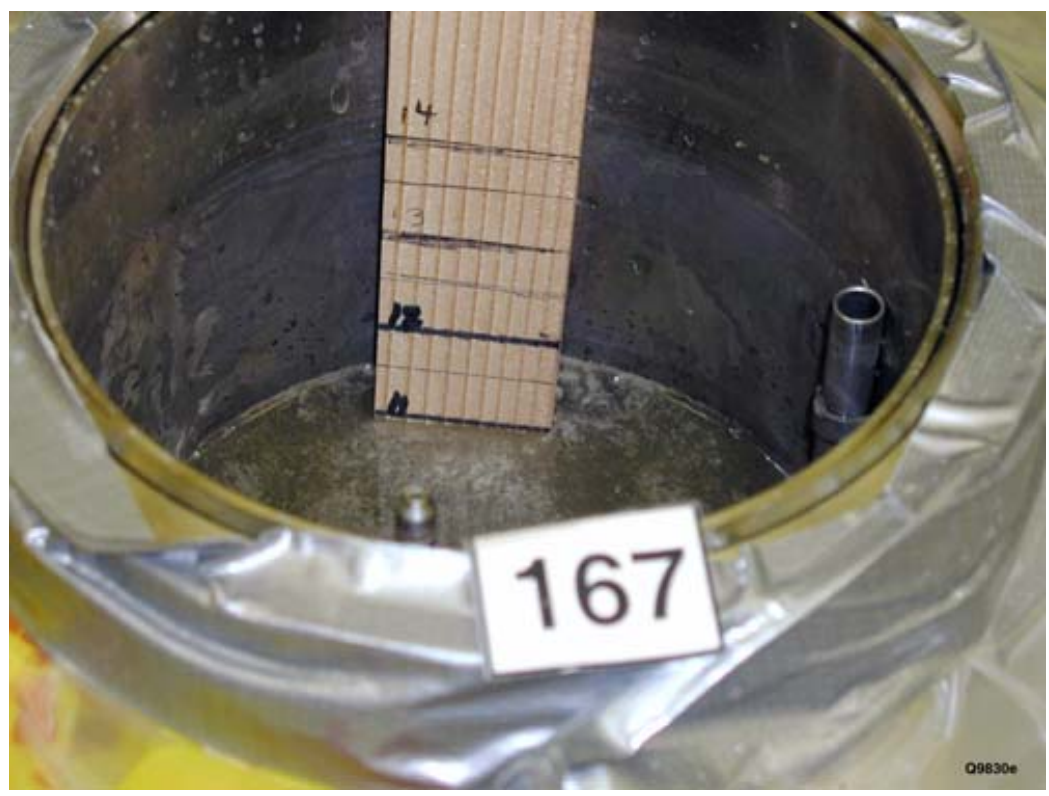

Figure 28. Dip-stick measurement of Brine level, TC-167.

\subsection{Carbon-Steel Coupon Analyses}

Conditions inside the containers during the GGE test period were extremely anoxic, mimicking the WIPP repository environment after closure. Once the test containers were opened, however, it was not possible to maintain the anoxic conditions. This probably had the greatest affect on the steel corrosion coupons. Figure 29 shows the corrosion coupons from TC-166 immediately after removal from the brine and sludge solution. The coupons shown in Figure 29 were coated with the dark colored sludge, but the surface of the corrosion coupons from all test containers generally were dark or black in appearance with areas of dark yellow/green discoloration that were assumed to be various corrosion products on the surface of the coupons.
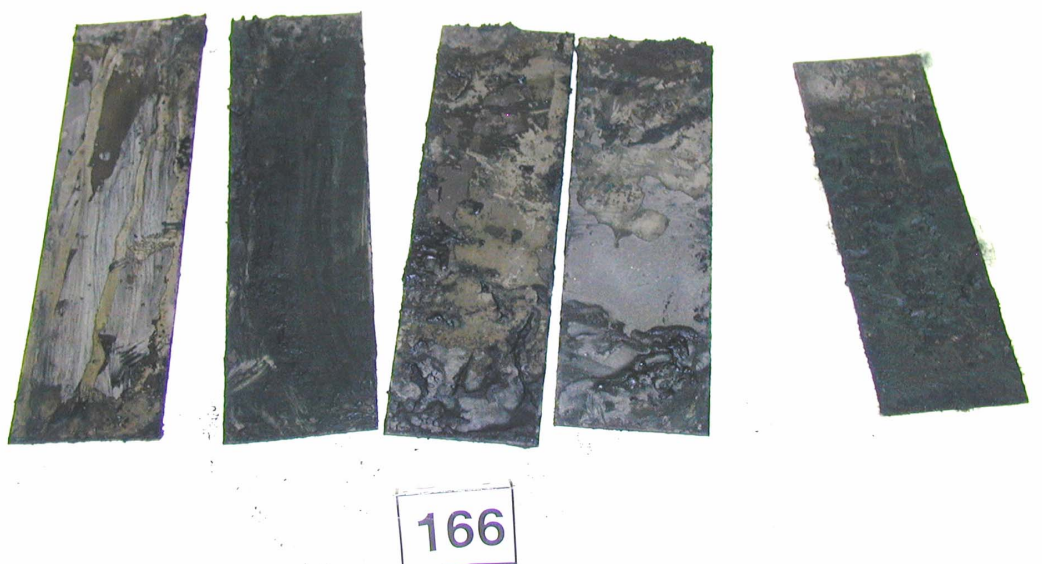

Figure 29. Sludge-covered carbon-steel coupons immediately after removal and separation, TC-166. 
The bags containing the corrosion coupons were opened in the analytic laboratory and one representative coupon was selected for analysis from the coupons that had been in TC-160 and -166. These coupons were chosen because TC-166 produced, by far, the most hydrogen gas during the experiment, presumably due to the greatest amount of metal corrosion; and TC-160 because that vessel was one of the three vessels having the most varied waste materials. The selected coupons were then rinsed with de-ionized water and wiped with cloth towels to remove the sludge material. This step was required to decrease the high alpha activity from the actinides present in the sludge (see Table 2 ). The coupons were then dried in air. The two cleaned-and-dried corrosion coupons from TC-160 and -166 were then cut into smaller pieces for XRD and SEM analyses using metal snips. One approximately $30 \times 50$-mm sample was cut from each coupon for XRD analysis, and two smaller samples were cut from each coupon for SEM analysis.

After cleaning, the black and dark yellow/green colored corrosion areas were still observed on the coupons in addition to rust colored areas that were not observed when the coupons were initially removed from the test containers. The rust colored corrosion apparently occurred after the coupons had been removed from the test containers. The appearances of the steel coupons varied from vessel to vessel, from within a vessel, and in some cases from front to back of a single coupon. The corrosion coupon chosen from TC-160 had relatively light areas of corrosion that were rust, black, and yellow/green in color. Both the front and back sides of this coupon were similar in appearance. The single coupon chosen from TC-166 appeared much more corroded than the TC-160 coupons. The TC-166 coupon was extensively covered with orange- or rust-colored corrosion product, and had small regions of black and yellow/green corrosion. The other side of the coupon was much less corroded with larger areas that were black or yellow/green in color. Overall, the steel coupons from TC-166 appeared to have undergone more corrosion.

\subsubsection{X-Ray Diffraction Analyses}

For analysis by XRD, the cut samples were wrapped in Mylar film to prevent the spread of contamination. Each sample was then analyzed using the single sample holder of the diffractometer. Analysis scans were performed using the theta-theta goniometer configuration and $\mathrm{Cu} \mathrm{K}$-alpha radiation. The x-ray tube voltage was $45 \mathrm{kV}$ with a current of $40 \mathrm{~mA}$; tube power was $1.8 \mathrm{~kW}$. The scan range was from $10^{\circ}$ to $90^{\circ}$ two-theta with a scan rate of 0.5 degrees/minute. Phase identification was performed using the Scintag DMSNT search match routine.

The XRD scan from TC-166 is shown in Figure 30. The pattern shows both the Fe-alloy diffraction pattern and possible surface corrosion product patterns. The large reflection at approximately 26 deg-two theta is from the Mylar film that covered the sample. The pattern shows the Fe-alloy phase of the coupon and minor phases indicating the presence of corrosion products. Possible corrosion products identified in the XRD pattern of TC-166 consisted of iron chlorides such as $\mathrm{FeCl}_{2}$ or $\mathrm{FeCl}_{3}$ (lawrencite and molysite, respectively) and iron oxides including $\mathrm{FeO}, \mathrm{Fe}_{2} \mathrm{O}_{3}$, and $\mathrm{Fe}_{3} \mathrm{O}_{4}$. Other unidentified phases may also be present. The XRD pattern from TC-160 showed the Fe-alloy phase only, the quantity of corrosion product being below the detection limit of the instrument. 


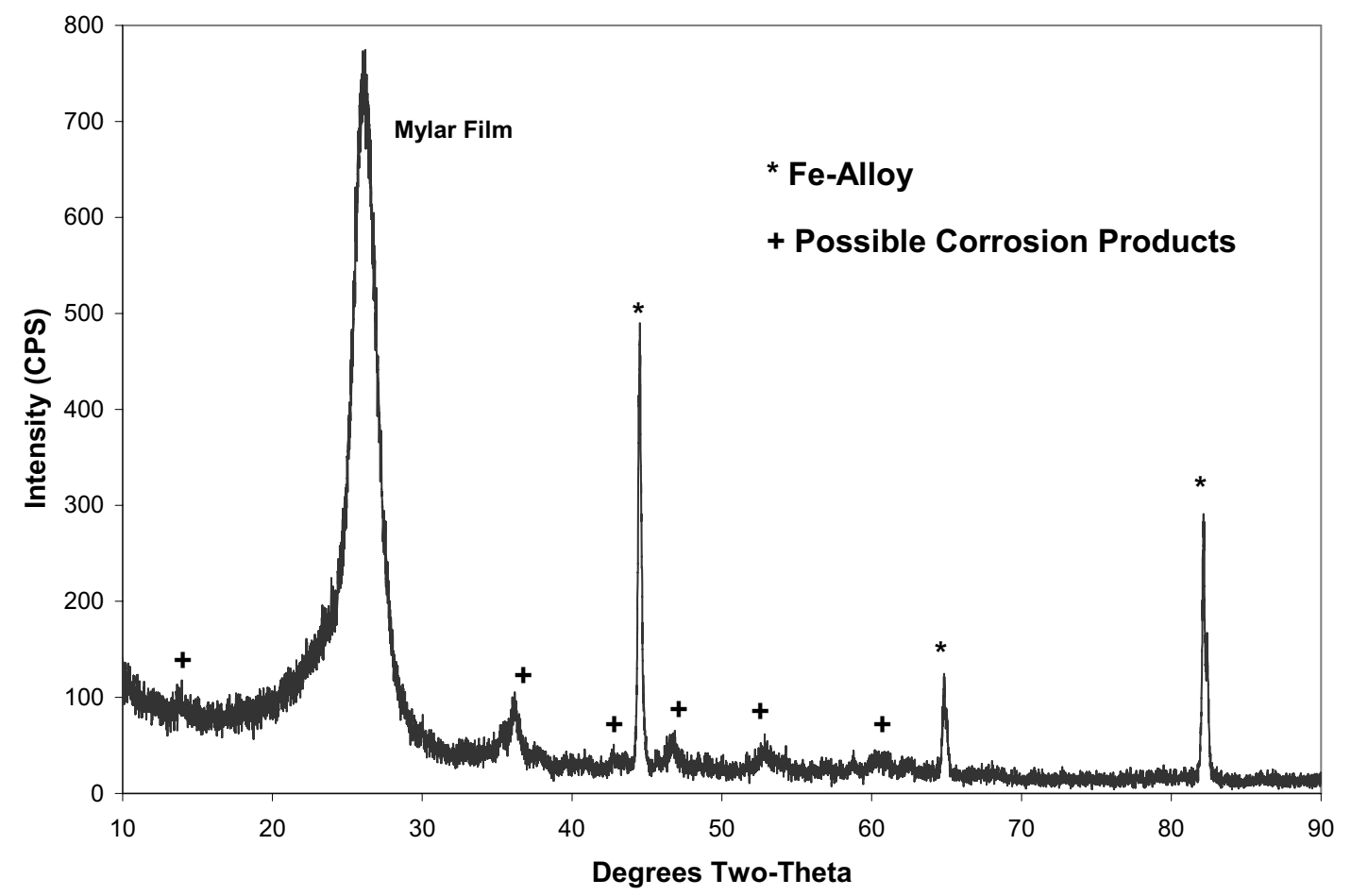

Figure 30. X-ray diffraction pattern of the carbon-steel corrosion coupon, TC-166.

\subsubsection{Scanning Electron Microscopy Analyses}

Two samples, each about $25 \mathrm{~mm}$ (1.0 in) long by $12 \mathrm{~mm}$ ( $0.5 \mathrm{in})$ wide, were cut using shears from larger corrosion coupons. These sliced samples were visually inspected and then sent to the ANL Electron Microscopy Laboratory for analysis. One of the samples from each drum was mounted in epoxy longitudinally on edge so that after polishing a cross-section would be exposed. The mounted samples were polished with grinding papers through 1200 -grit. The remaining samples were examined in an as-received condition, so that the corrosion product adhering to the outer surfaces could be analyzed. All the samples were coated with palladium $(\mathrm{Pd})$ to eliminate charging effects. The samples were analyzed using a scanning electron microscope equipped with energydispersive and wavelength-dispersive spectrometers (see Figure 31).

Based on the morphology of the corrosion products, three different types of products were observed. One product is

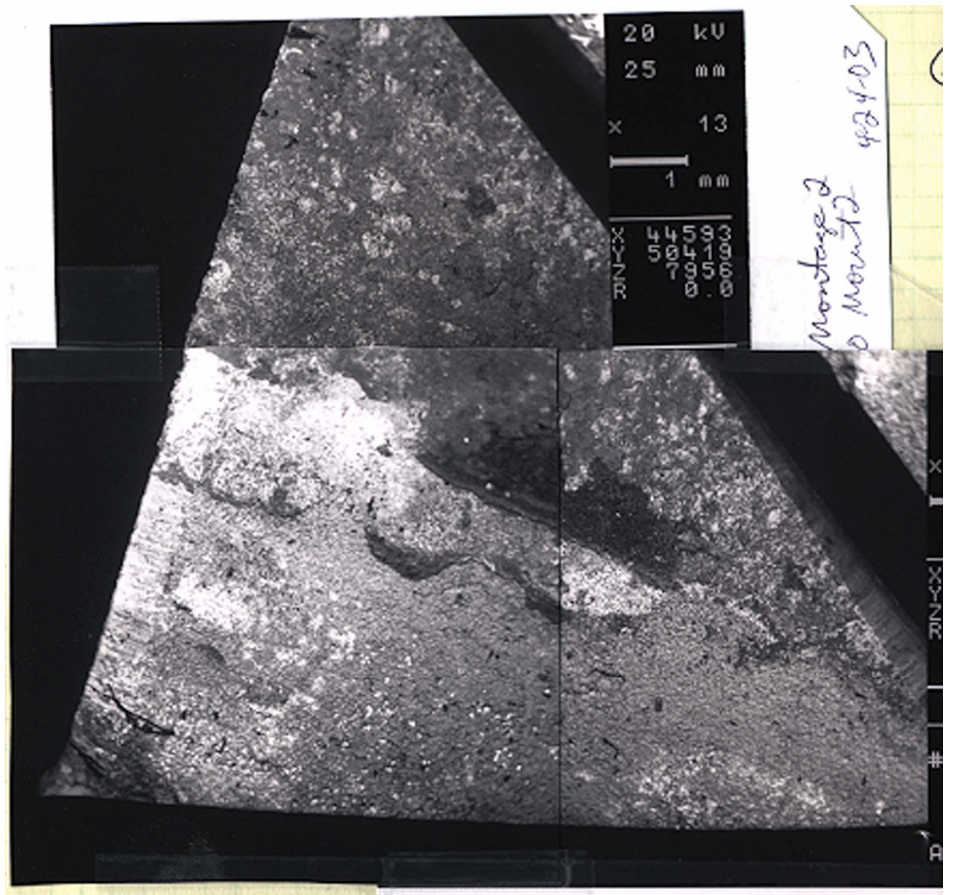

Figure 31. Montage of backscattered electron micrographs for the carbon-steel specimen, TC-160. 
bright in contrast. Another is medium in contrast. The final product is dark in contrast. Figure 32 shows higher magnification images of the various corrosion products observed on the surface of the TC-160 sample. Figure 33 shows the EDS spectra generated from a box-scan analysis taken on the surface of the sample. It shows that corrosion products containing iron $(\mathrm{Fe})$, uranium $(\mathrm{U})$, chlorine $(\mathrm{Cl})$, and oxygen $(\mathrm{O})$ are present in the backscattered electron image. X-ray maps that were taken of a specific area of the sample are presented in Figure 34. This figure shows in more detail the phases enriched in $\mathrm{Fe}, \mathrm{U}$, or oxygen. Using point-scan analysis, it was determined that the brightest phase in Figure 34a contained U, $\mathrm{Fe}$, and oxygen. The darker phase in Figure 34a primarily contained $\mathrm{Fe}$ and oxygen. The medium-contrast phase contained different amounts of Fe and oxygen compared to the dark-contrast phase.

(a)

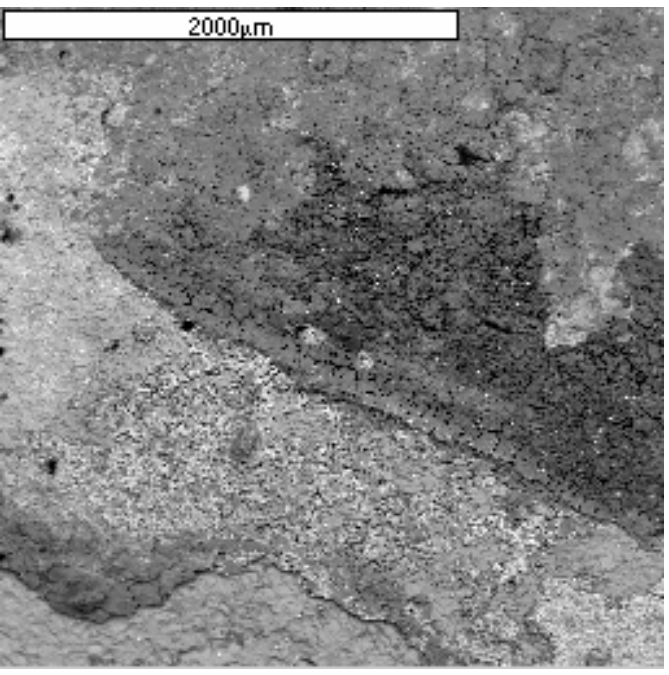

(b)
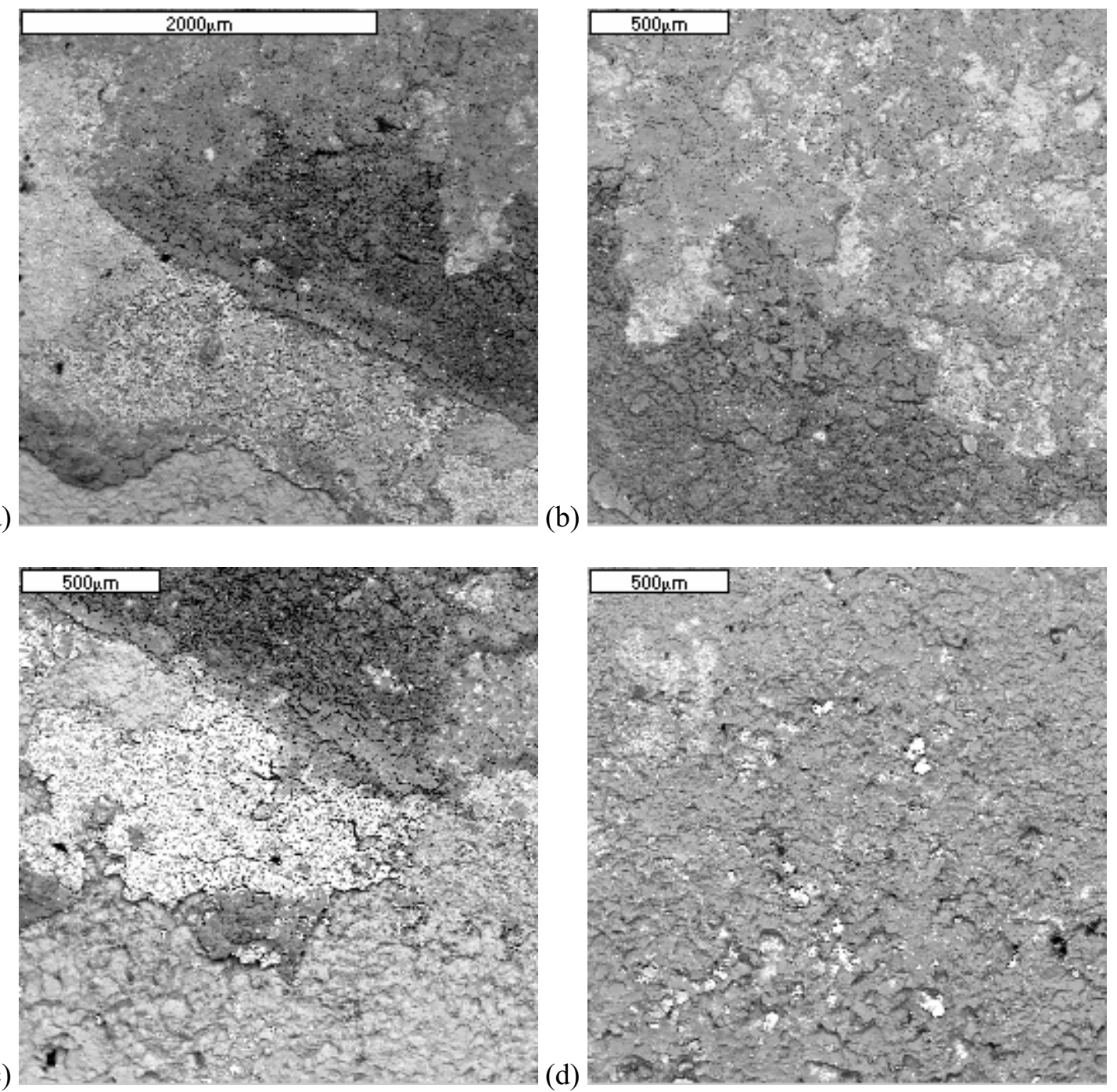

(d)

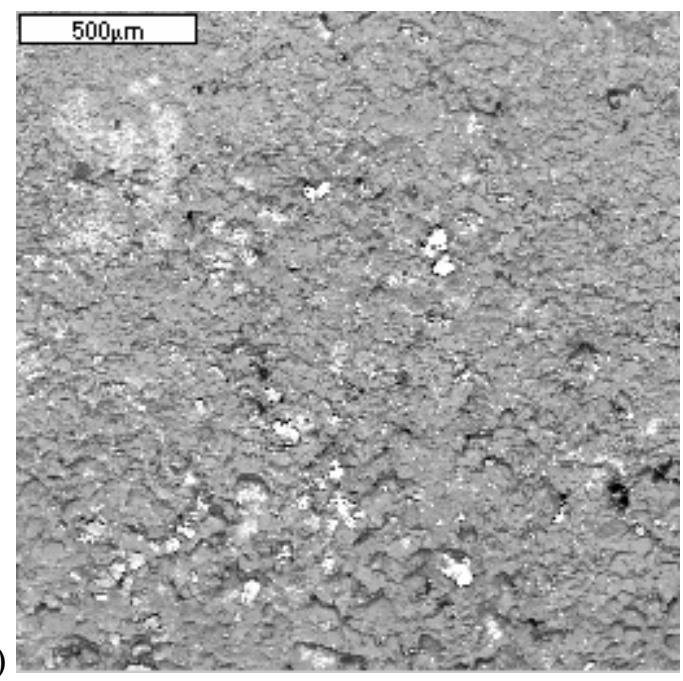

Figure 32. Backscattered electron images of the surface of the carbon-steel coupon, TC-160. 
(a)
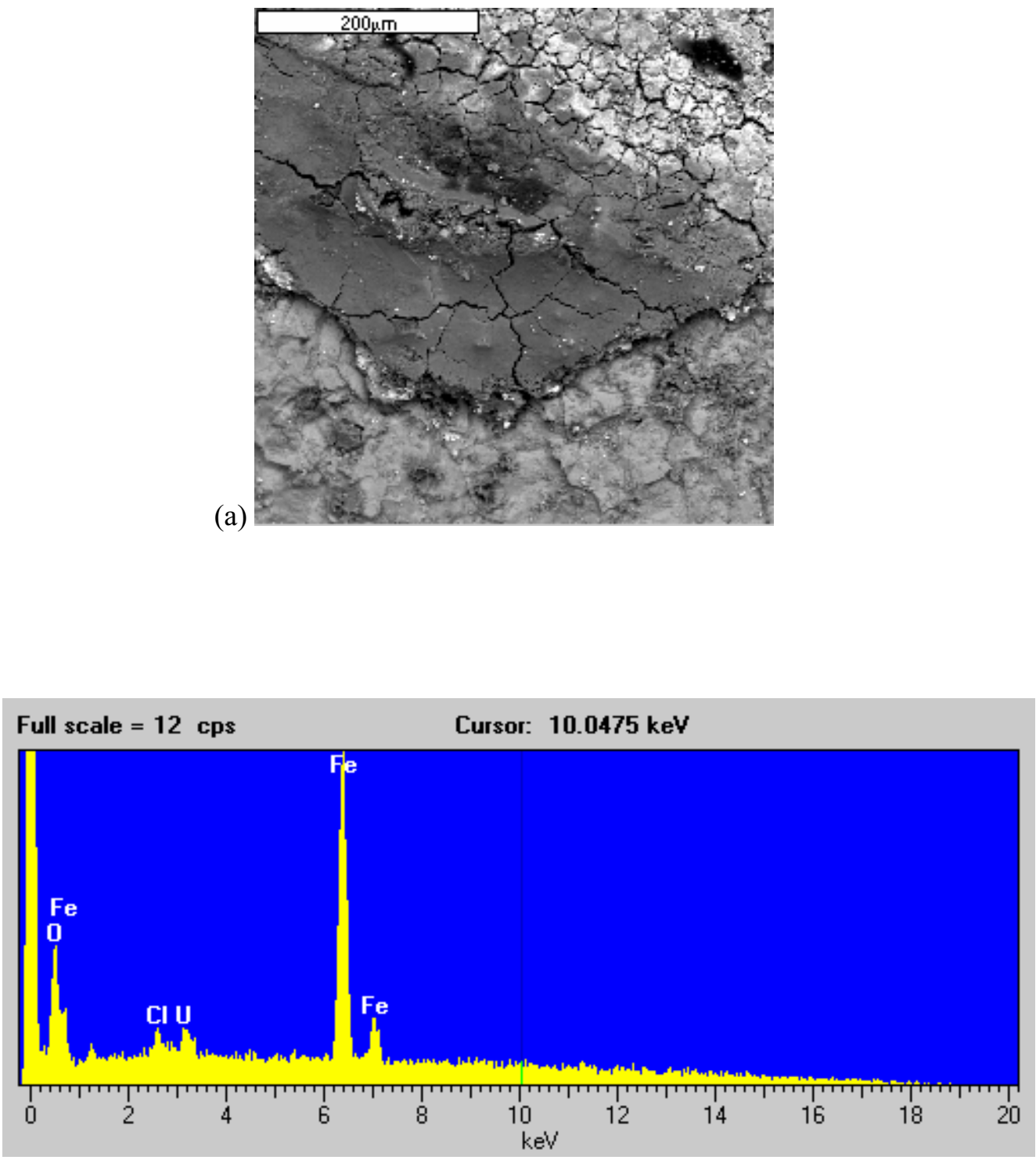

Figure 33. (a) Backscattered electron micrograph of bright-contrast phase; and (b) EDS spectrum of a box scan of the area depicted in view $a$. 
(a)

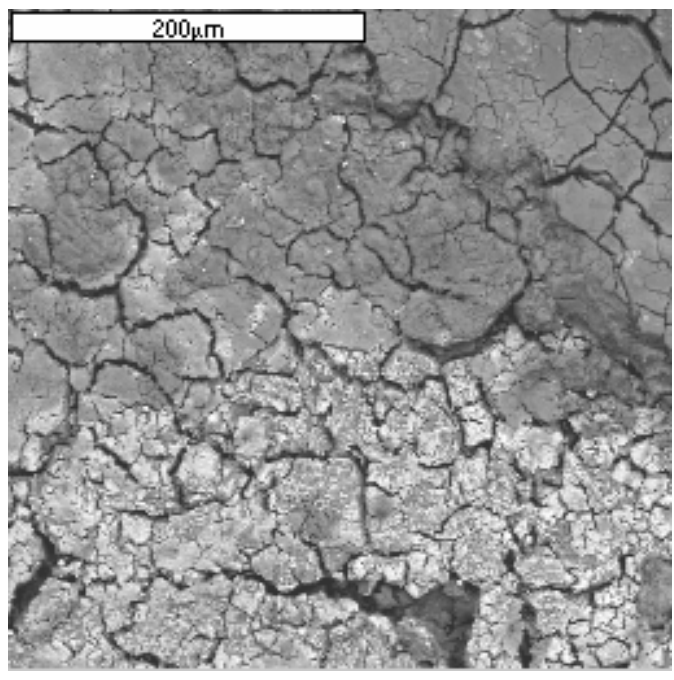

(b)
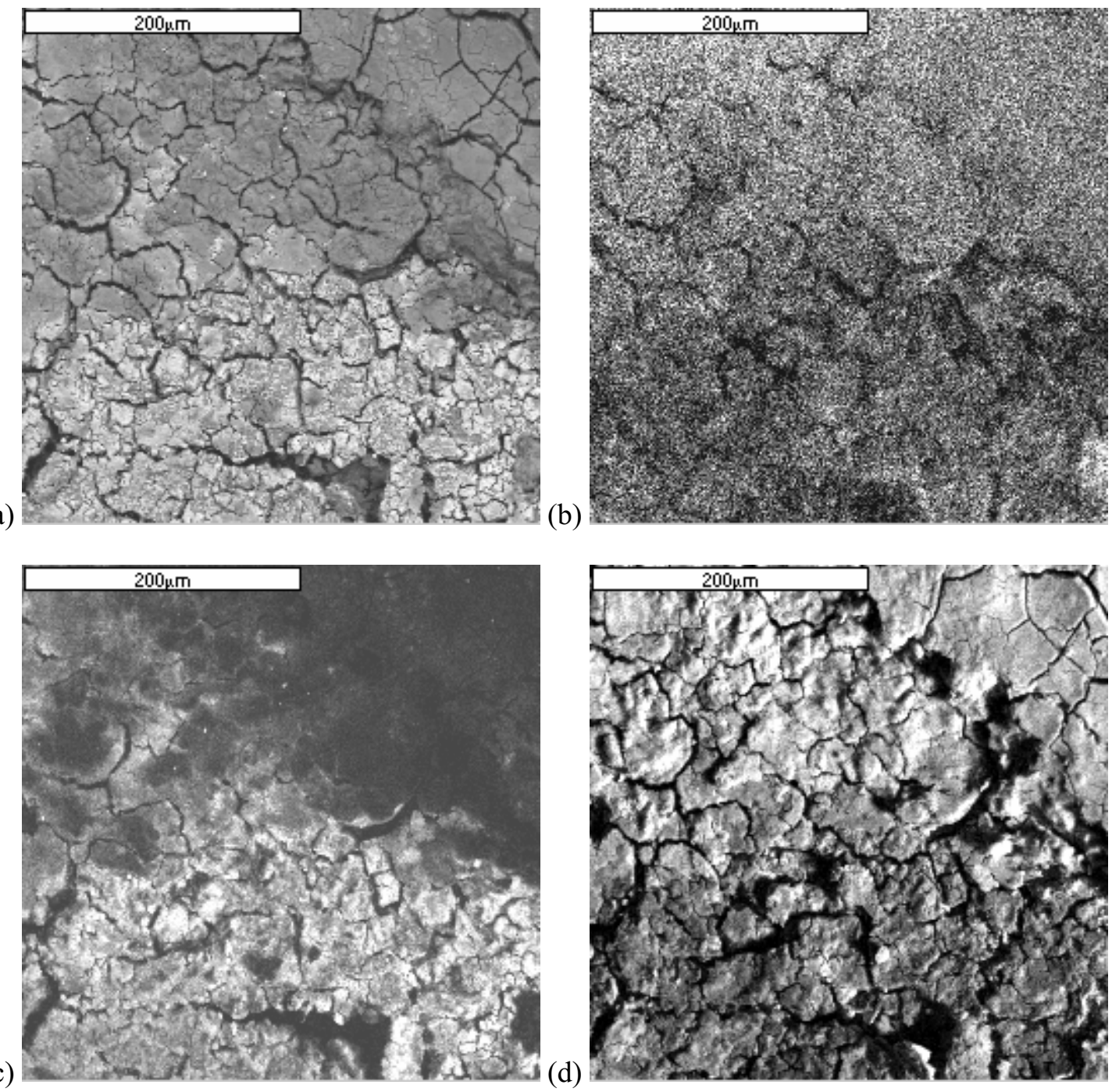

(d)

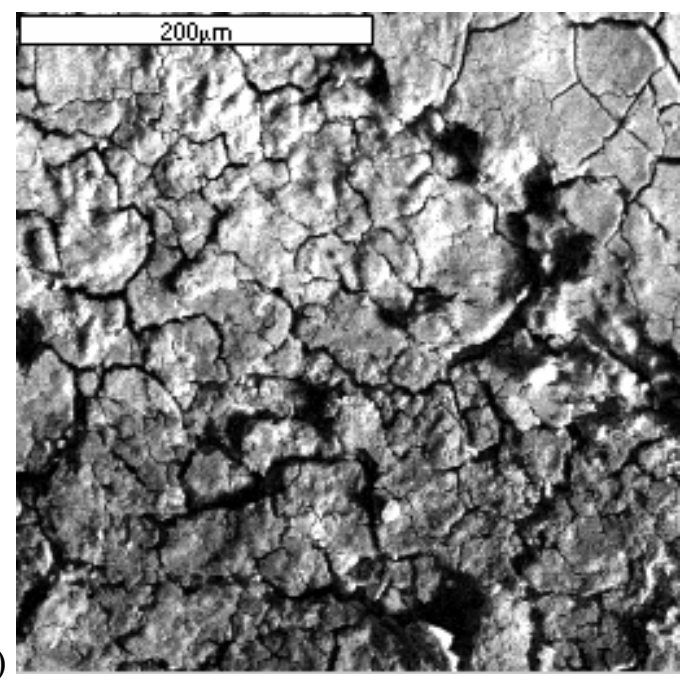

Figure 34. (a) Backscattered electron image of corrosion products observed on carbon-steel coupon, TC-160 (X-ray maps for Iron (View $b$ ), Uranium (View $c$ ), and Oxygen (View $d$ )).

\section{Carbon-Steel Specimen from TC-166}

Figure 35 shows the corroded surface of the carbon-steel sample from TC-166. The sample surface is very similar to that observed for the sample from TC-160. Higher magnification images of the corrosion products are shown in Figure 36. Figure 37 shows some of the specific corrosion products that were observed. EDS spectra for the brightest phase in Figure 37a, the darkest phase in Figure 37b, the primary, medium-contrast phase in Figure 37c, and the darkest phase in Figure 37d are shown in Figure 38. These spectra show that the major constituents observed in the corrosion products are $\mathrm{U}, \mathrm{Fe}$, and $\mathrm{O}$. Magnesium $(\mathrm{Mg}), \mathrm{Cl}$, calcium $(\mathrm{Ca})$, and silicon $(\mathrm{Si})$ have been observed in some phases. Neither americium (Am) nor neptunium (Np), both present in the test vessels, was observed in any of the corrosion products. These same observations were made for the corrosion products for the carbon-steel sample from TC-160. Figure 39 shows how the Fe-rich corrosion products exhibit great variations in their oxygen content. 


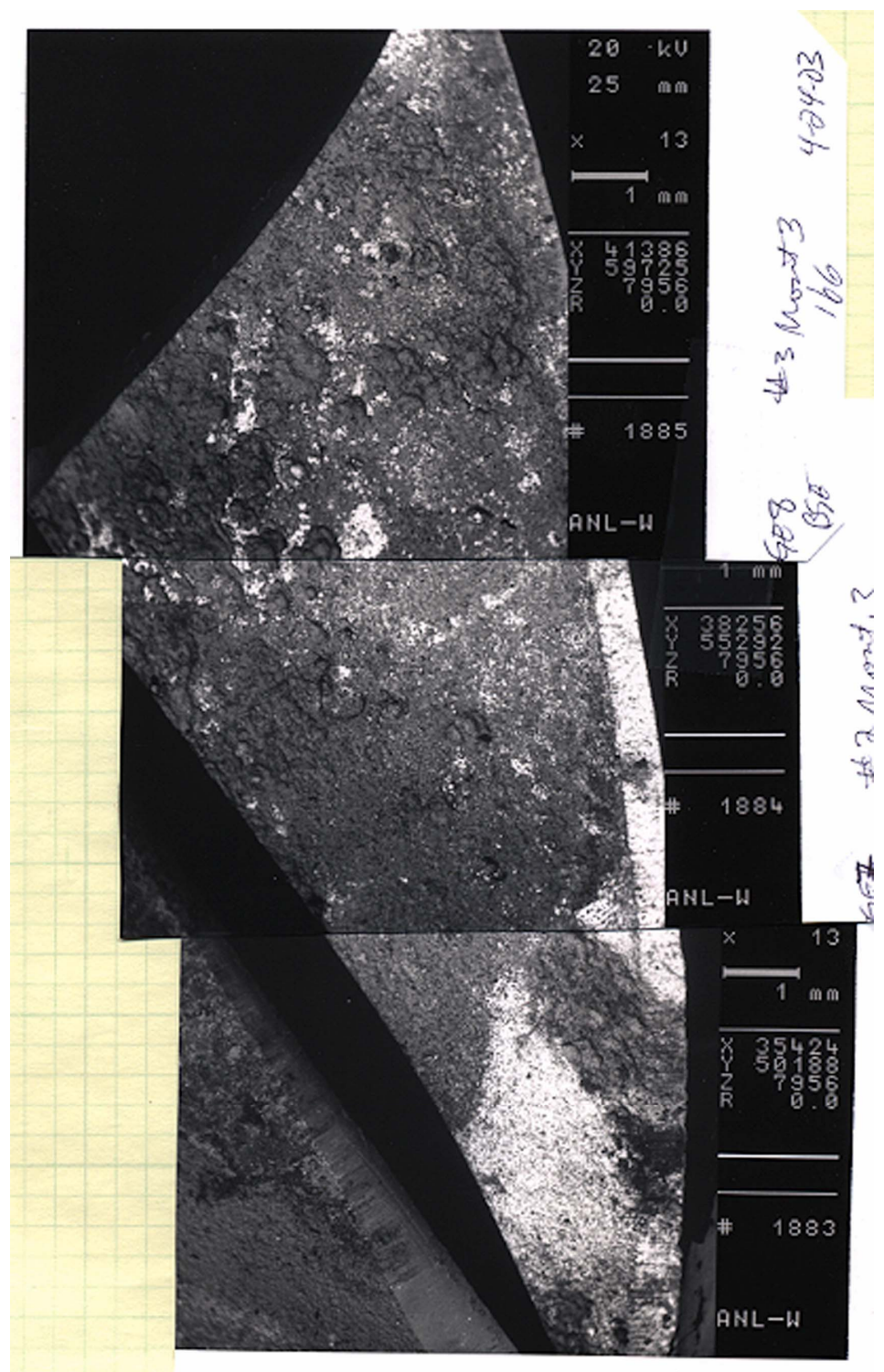

Figure 35. Montage of carbon-steel-coupon surface backscattered electron micrographs, TC-166. 
(a)

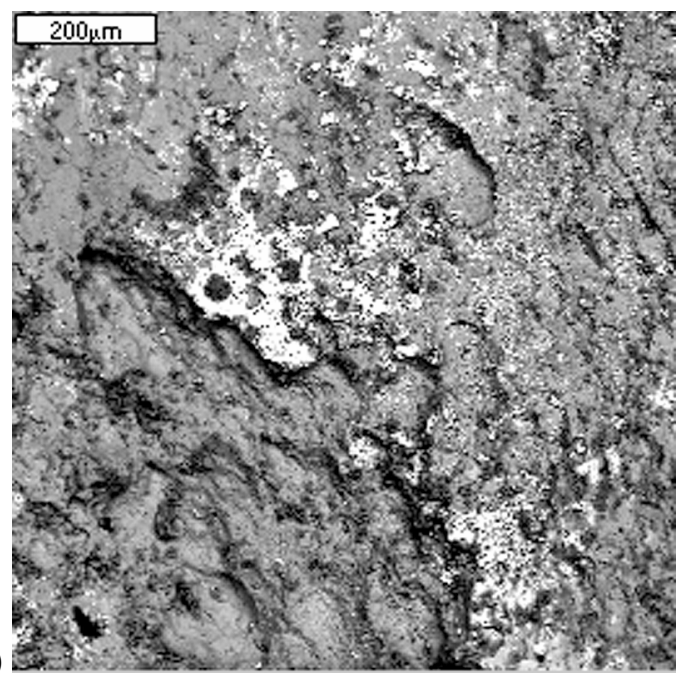

(b)
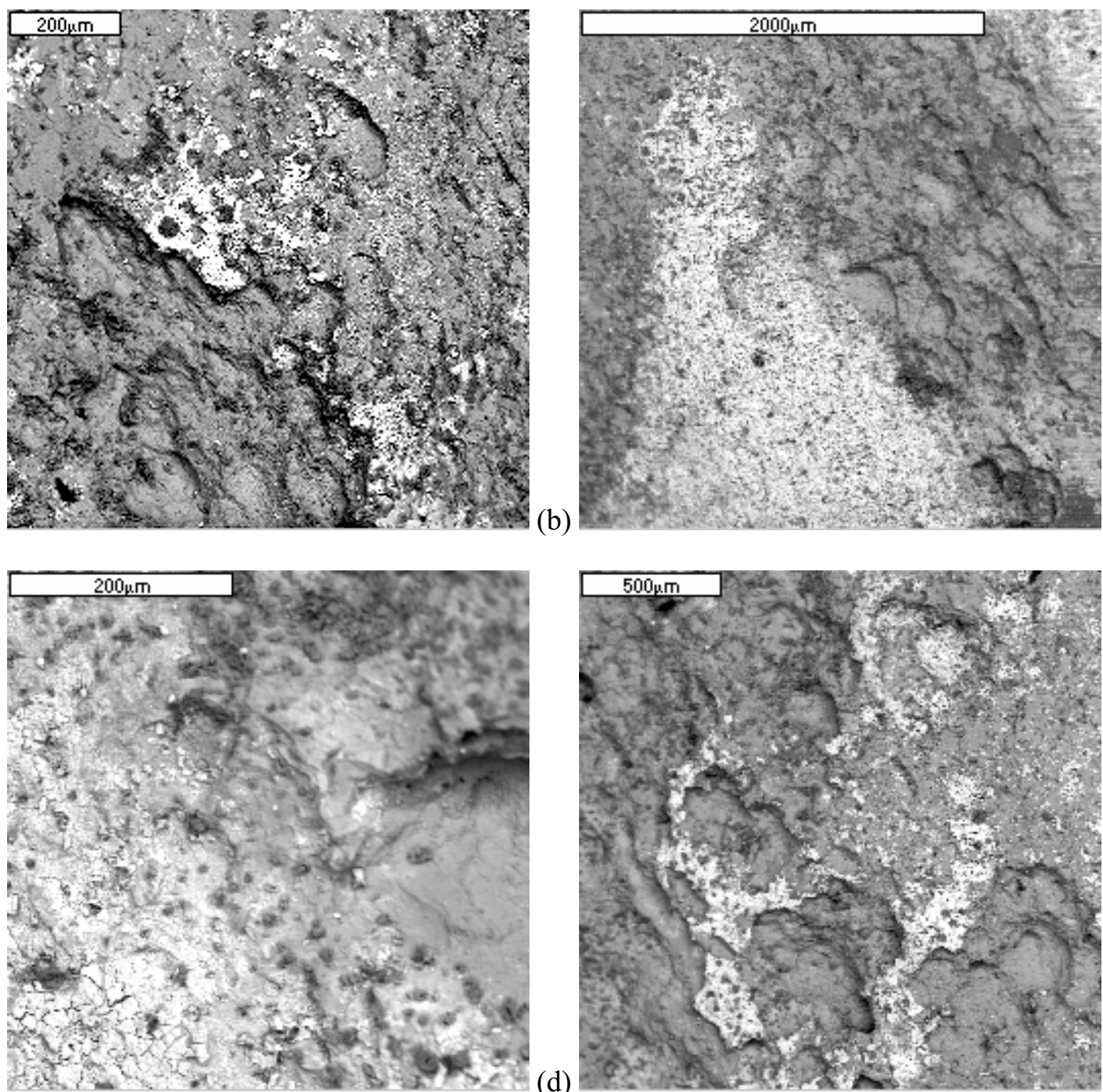

(d)

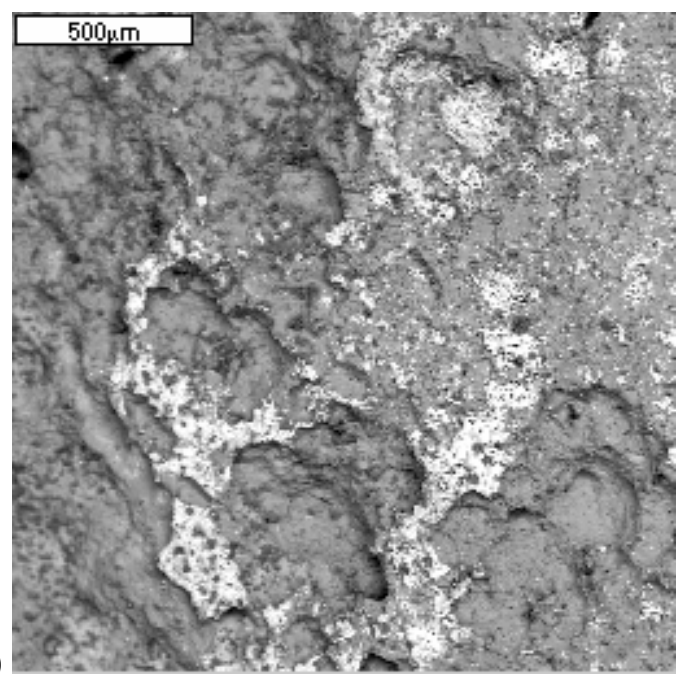

Figure 36. Carbon-steel-coupon surface backscattered electron images, TC-166. 
(a)

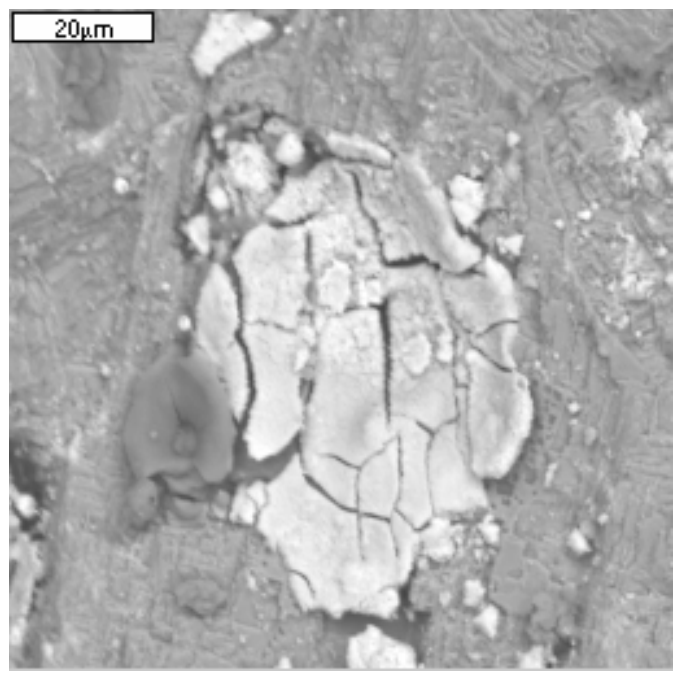

(b)
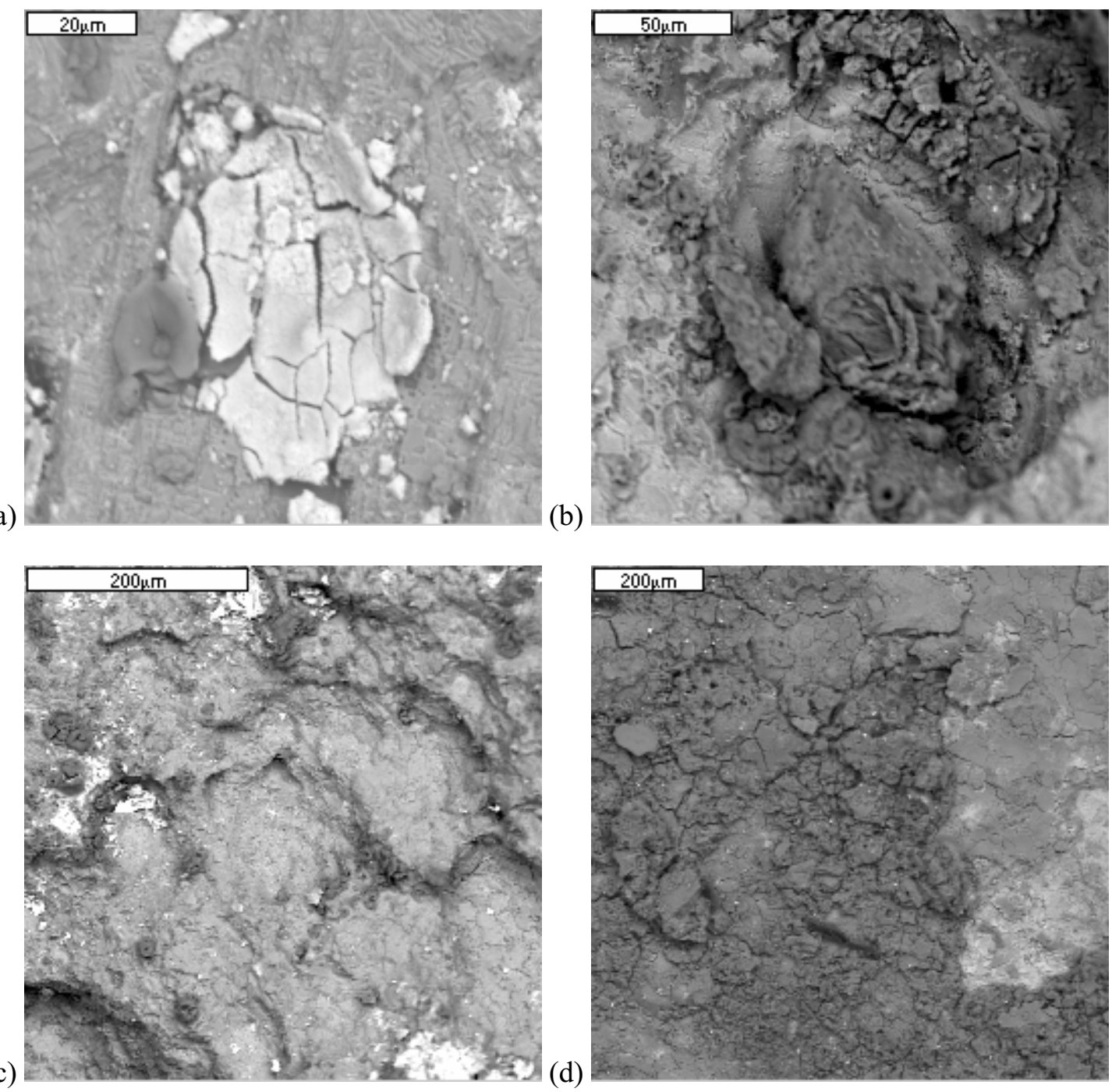

(d)

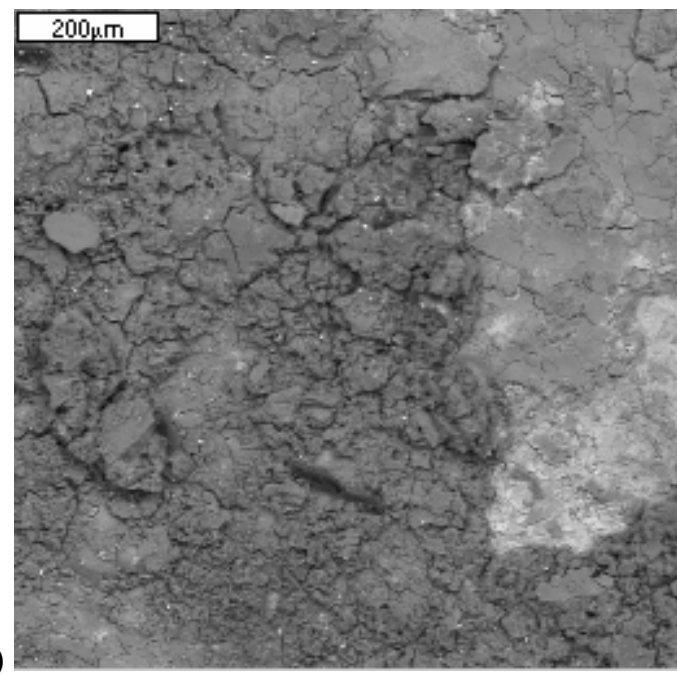

Figure 37. Backscattered electron images of specific corrosion products, carbon-steel-coupon surface, TC-166. 
(a)
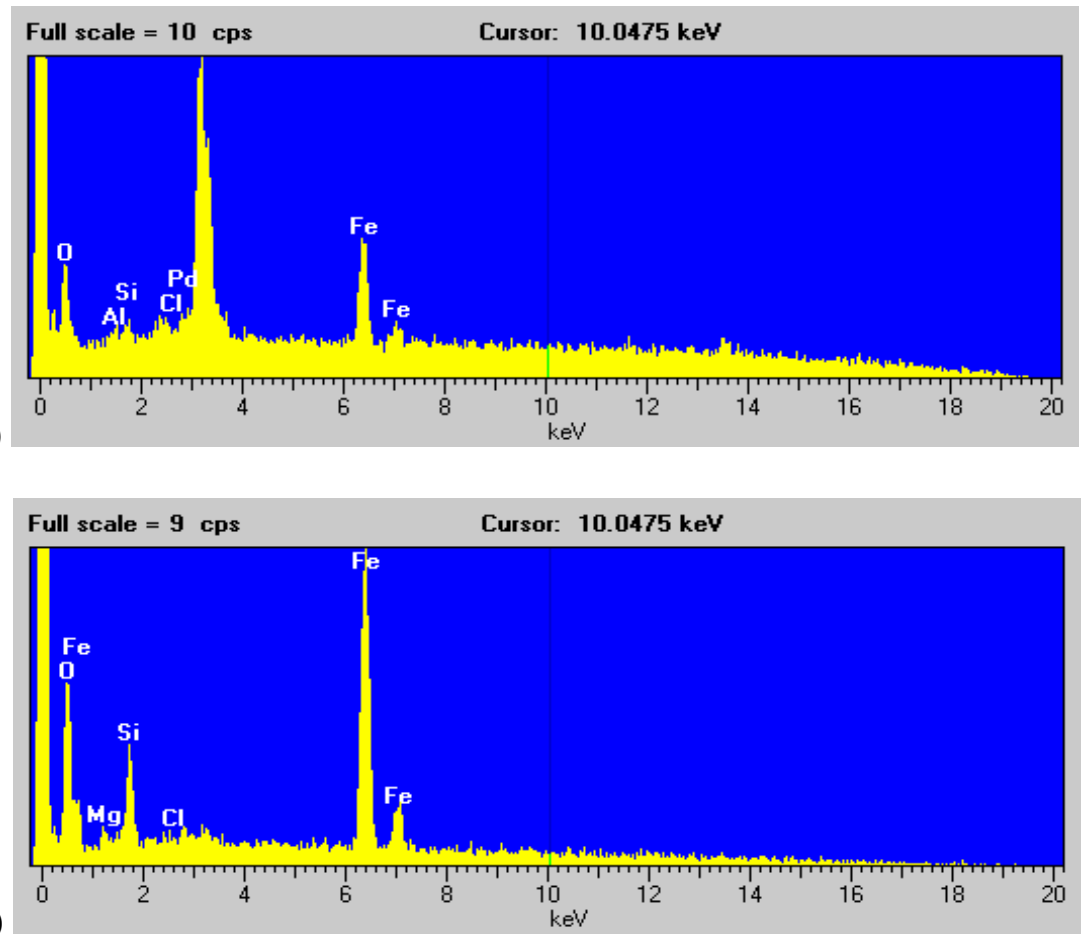

(b)

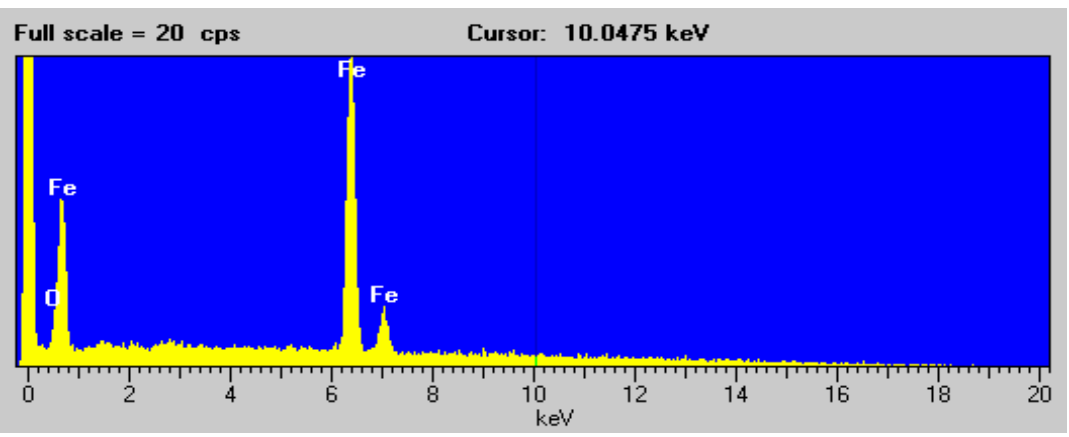

(c)
Full scale $=9$ cps
Cursor: $10.0475 \mathrm{keV}$

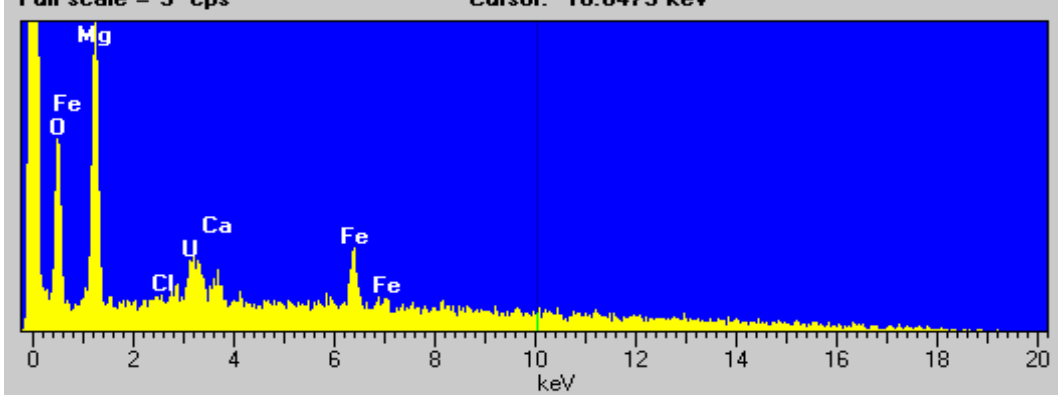

(d)

Figure 38. EDS spectra for the phases shown in Figure 37a (the largest peak in $(a)$ is U, and the palladium $(\mathrm{Pd})$ is from the coating process). 
(a)

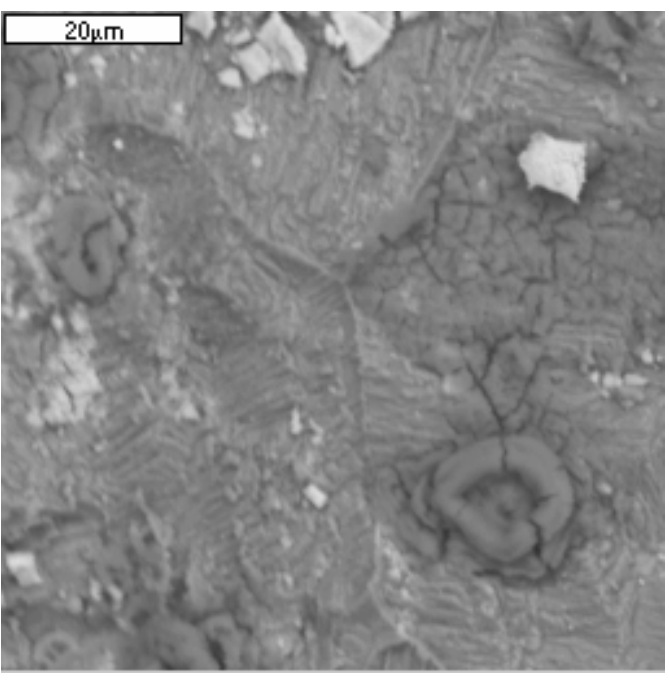

(b)
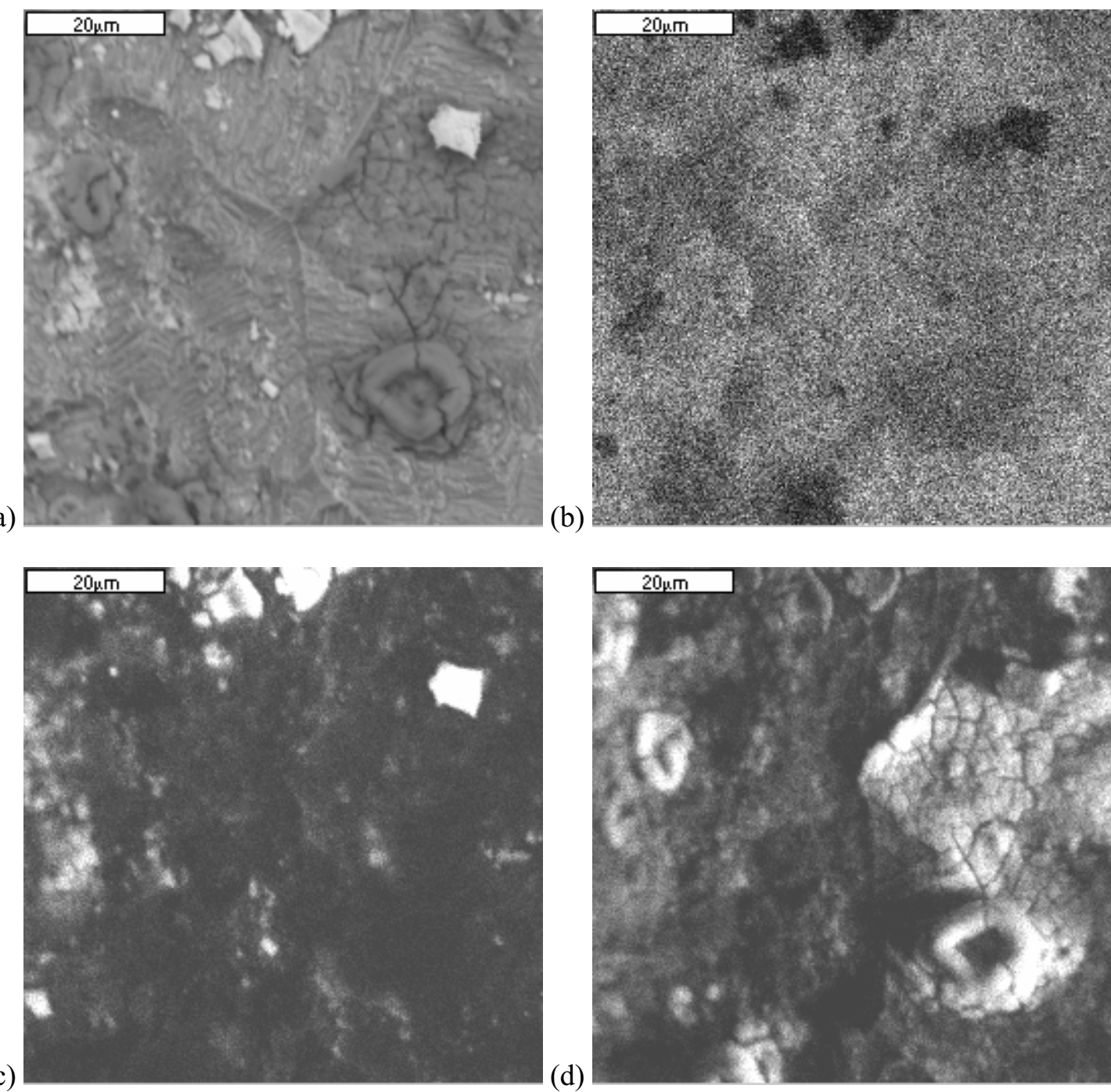

(d)

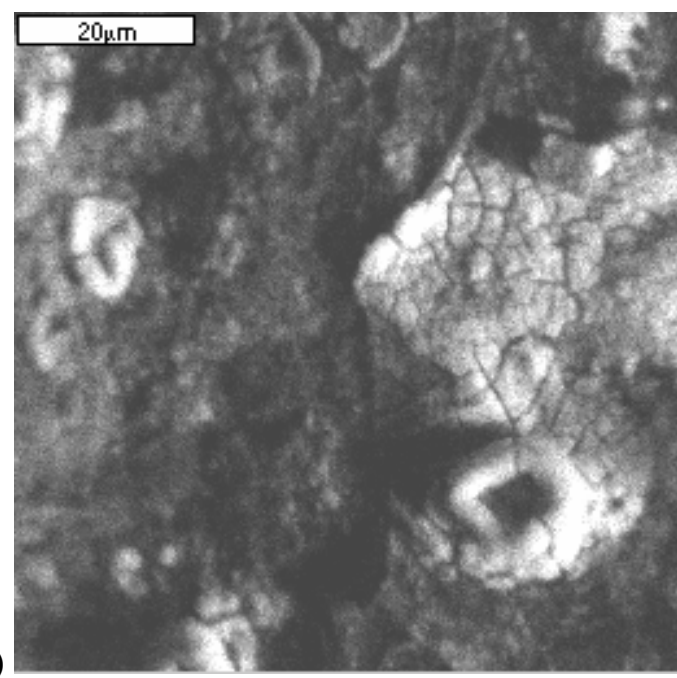

Figure 39. (a) Carbon-steel coupon backscattered electron image of corrosion products, TC-160. Xray maps for Iron (view $b$ ), Uranium (view $c$ ), and Oxygen (view $d$ ).

\section{Comparison of the Cross-Sections for Carbon-Steel Samples from TC-160 and-166}

The cross-sections of steel samples from TC-160 and -166 are presented in Figure 40. No corrosion products were identified on the surfaces of the samples. Any corrosion products that were present may have been lost due to the polishing process. Not much attack of the outer surfaces of the sample from TC-160 is apparent, leaving parallel surfaces. The TC-166 sample, on the other hand, exhibits deep localized corrosion. As a result, the surfaces of sample TC-166 are much more uneven and jagged than are those of the sample from TC-160. 

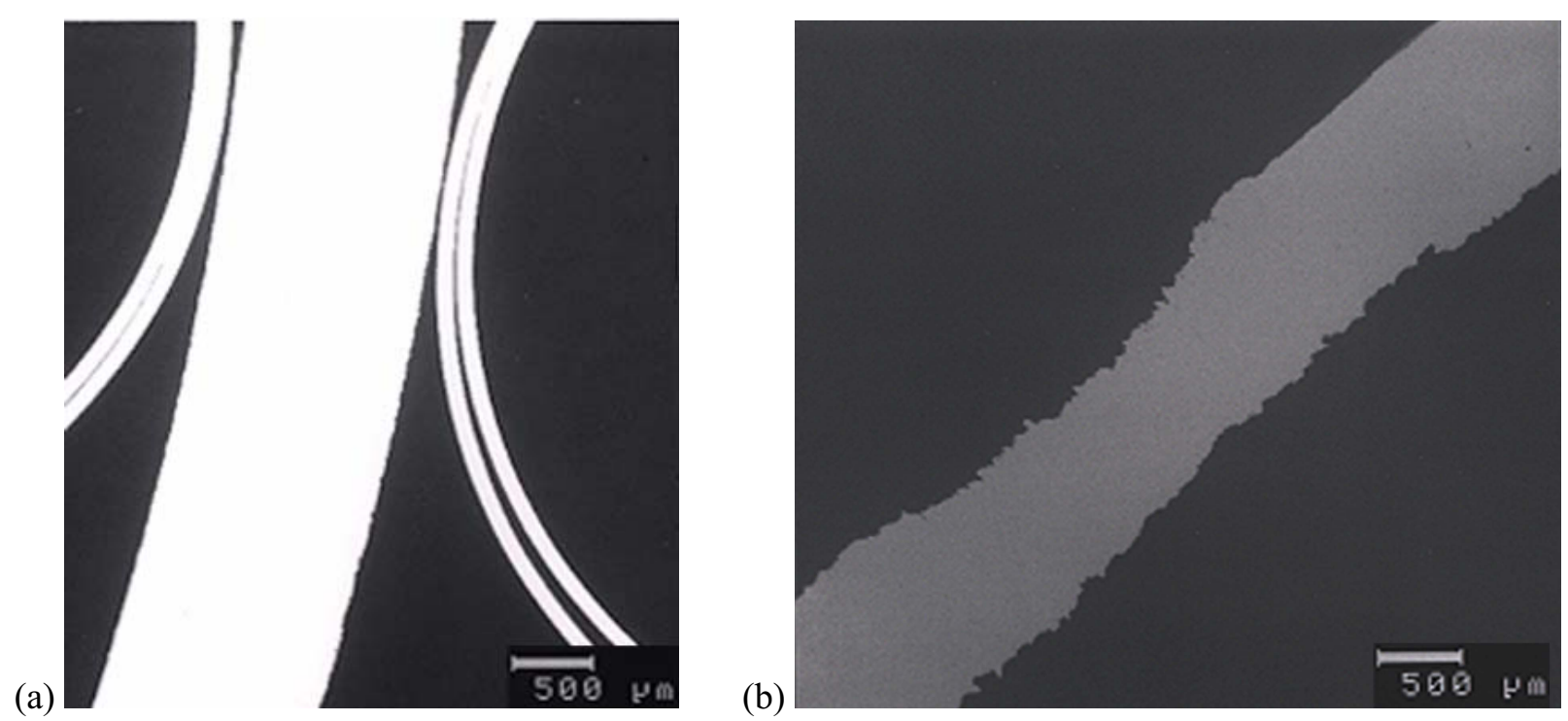

Figure 40. Sample cross-section backscattered electron images, (a) TC-160 and (b) TC-166.

Based on the SEM analysis of the GGE corrosion coupons described above, it appears that the TC-166 samples corroded at a higher rate than did the TC-160 samples. This agrees with the observations from the visual inspection that was performed before the SEM analysis, where more corrosion products were observed on the surface of the sample from TC-166. This is also consistent with the measurements of hydrogen gas, see Table 4 and Figure 12. The sample cross-sections displayed different amounts of corrosive attack. TC-166 appeared to exhibit more corrosive attack than occurred in TC-160, and the increased attack seemed to be localized.

Specimens from both vessels had corrosion products adhering to their surfaces, and the amounts of these products varied around the surfaces of the samples. Most of the corrosion products formed as uniform layers, yet some discrete phases were also observed. Based on the morphology of the corrosion products and the different compositions that were measured, different types of corrosion products formed on the surfaces of the samples. All the corrosion products appeared to contain $\mathrm{Fe}$ and $\mathrm{O}$ in varying concentrations. Some of the corrosion products also contained $\mathrm{U}, \mathrm{Mg}$, aluminum (Al), Ca, Cl, and/or Si. None of the corrosion products contained either Am or Np, both of which were present in the test vessels in small quantities.

\subsection{Brine and Sludge Analyses}

\subsection{1 pH Measurement in the Brine}

Separation of the sludge from the brine solution was required before chemical analysis. However, before separation the $\mathrm{pH}$ of the mixed solutions was determined. It is difficult to make accurate $\mathrm{pH}$ measurements using $\mathrm{pH}$ meters in very high ionic-strength solutions such as the GGE brine. Limitations on resources did not permit the measurement of $\mathrm{pcH}$, a measurement of hydrogen ion concentration. A decision was therefore made to measure the $\mathrm{pH}$ using $\mathrm{pH}$ paper. The $\mathrm{pH}$ results from the six solution mixtures are shown in Table 9 and ranged from near neutral $\mathrm{pH}$ to slightly acidic. 
Table 9. $\mathrm{pH}$ values of Sludge/Brine mixtures (measurement uncertainty $\pm 1 \mathrm{pH}$ unit).

\begin{tabular}{|l|c|c|c|c|c|c|}
\hline Test Container & 151 & 160 & 161 & 162 & 166 & 167 \\
\hline $\mathrm{pH}$ & 6.0 & 5.5 & 5.5 & 5.5 & 5.5 & 5.0 \\
\hline
\end{tabular}

\subsubsection{Radionuclide Leaching into the Brine}

Separation of the mixed solution involved filtering through a $0.7-\mu \mathrm{m}$ pore-size glass filter that effectively removed the solid sludge from the liquid brine. A portion of the $0.7-\mu \mathrm{m}$ filtered brine solution was then filtered a second time through a $0.005-\mu \mathrm{m}$ pore-size centrifuge filter. The purpose of the second filtration was to separate any colloidal or particulate material that may have passed though the $0.7-\mu \mathrm{m}$ filter. Actinides measured in the second filtrate are assumed to be completely solubilized. The filtrate solutions were then acidified to $1 \%$ by volume with concentrated nitric acid to prevent absorption, precipitation or polymerization of actinides in the solution containers.

Preparation of the remnant sludge for analysis involved first drying the sludge on the $0.7-\mu \mathrm{m}$ glass filter. "Remnant sludge" refers to that material collected on the filters. This is not necessarily the specific inorganic sludge that was a waste ingredient. The dried sludge was then scraped from the filter and dissolved in $8 \mathrm{~N}$ nitric acid with hydrofluoric acid and brought to volume in de-ionized water. The quantity of the dried sludge samples was small, each weighting in the microgram range. All solutions were then measured for actinides by ICP-MS after diluting 1:10 in 5\% nitric acid. Mass spectral analysis involved monitoring the following mass to charge $(\mathrm{m} / \mathrm{z})$ regions: 235, 236, 237, 238, 239, 240, and 241 with a mass resolution of approximately 1 atomic mass unit (amu). With this mass resolution, it was not possible to resolve the slight mass differences between ${ }^{238} \mathrm{U}$ and ${ }^{238} \mathrm{Pu}$ or ${ }^{241} \mathrm{Pu}$ and ${ }^{241} \mathrm{Am}$. Thus, any measured contribution from ${ }^{238} \mathrm{Pu}$ was included in the ${ }^{238} \mathrm{U}$ concentration, and any contribution from ${ }^{241} \mathrm{Pu}$ was included in the ${ }^{241} \mathrm{Am}$ concentration.

The measured isotopic concentration for $\mathrm{U}, \mathrm{Np}, \mathrm{Pu}$, and $\mathrm{Am}$ in the filtered brine solutions and the solid sludge for each test container is shown in Table 10. The concentrations for the filtered brine solutions include both the $0.7-\mu \mathrm{m}$ and $0.005-\mu \mathrm{m}$ filtered solutions. Very small distinctions were observed between the $0.7-\mu \mathrm{m}$ - and $0.005-\mu \mathrm{m}$-filtered solutions. This indicates that the actinides found in the brine are completely soluble and were not transported into the brine as colloidal or other precipitate material as is common in lower ionic strength, aqueous systems such as ground water. Other results show high levels of uranium in the sludge and brine. No explanation is evident for the absence of ${ }^{239} \mathrm{Pu}$ in TC-167 for the filtered brine solution. It is noted, however (cf. Tables II and III), that TC-167 was the only carbon-steelbearing vessel that did not contain the inorganic sludge waste.

Measurement of the actinide distribution shows that the vast majority of the actinides were retained in the sludge with only small amounts leaching into the brine solution, as illustrated in Figure 41 . The values shown are the average actinide concentrations measured from sludge and brine collected from TC-151, $-160,-161,-162,-166$, and -167 . The standard deviation of the average concentration is shown by the error bars. The concentrations are expressed as $\mu \mathrm{g} / \mathrm{ml}$ for brine solutions and $\mu \mathrm{g} / \mathrm{g}$ for sludge samples. The densities of the brine and sludge are assumed to be similar allowing comparison of the different concentration units. 
Table 10. Actinide isotopic concentrations in the filtered Brine solutions $(0.7-\mu \mathrm{m}$ and $0.005-\mu \mathrm{m}$ filter $)$ and the solid Sludge samples (measurement uncertainty $\pm 10 \%$ relative standard deviation).

\begin{tabular}{|c|c|c|c|c|c|c|c|c|}
\hline Sample ID & ${ }^{235} \mathbf{U}$ & ${ }^{236} \mathbf{U}$ & ${ }^{238} \mathbf{U}$ & ${ }^{237} \mathbf{N p}$ & ${ }^{239} \mathrm{Pu}$ & ${ }^{240} \mathrm{Pu}$ & ${ }^{242} \mathrm{Pu}$ & ${ }^{241} \mathrm{Am}$ \\
\hline \multicolumn{9}{|c|}{ Filtered Brine Solutions $(\mu \mathrm{g} / \mathrm{ml})$} \\
\hline $\begin{array}{c}\text { TC-151 } \\
0.7 \mu \mathrm{m}\end{array}$ & $2.63 \mathrm{E}-02$ & $6.10 \mathrm{E}-04$ & $5.07 \mathrm{E}-02$ & $1.40 \mathrm{E}-04$ & $1.10 \mathrm{E}-02$ & $1.40 \mathrm{E}-04$ & $1.20 \mathrm{E}-04$ & $1.50 \mathrm{E}-04$ \\
\hline 0.005 & $2.70 \mathrm{E}-02$ & $5.27 \mathrm{E}-04$ & 5.17E-02 & $1.20 \mathrm{E}-04$ & $1.23 \mathrm{E}-02$ & $2.30 \mathrm{E}-04$ & $1.00 \mathrm{E}-04$ & $1.30 \mathrm{E}-04$ \\
\hline $\begin{array}{c}\text { TC-160 } \\
0.7 \mu \mathrm{m}\end{array}$ & $3.00 \mathrm{E}-01$ & 8.47E-03 & $4.32 \mathrm{E}+01$ & 7.00E-05 & $4.85 \mathrm{E}-02$ & 2.60E-04 & $6.00 \mathrm{E}-05$ & $1.60 \mathrm{E}-04$ \\
\hline 0.005 & $3.05 \mathrm{E}-01$ & $8.26 \mathrm{E}-03$ & $4.42 \mathrm{E}+01$ & $1.60 \mathrm{E}-04$ & 3.89E-02 & $1.40 \mathrm{E}-04$ & $1.90 \mathrm{E}-04$ & $1.40 \mathrm{E}-04$ \\
\hline $\begin{array}{c}\text { TC-161 } \\
0.7 \mu \mathrm{m}\end{array}$ & 3.01E-01 & 5.82E-03 & $3.22 \mathrm{E}+01$ & $1.70 \mathrm{E}-04$ & $2.36 \mathrm{E}-02$ & $3.10 \mathrm{E}-04$ & $1.30 \mathrm{E}-04$ & $3.40 \mathrm{E}-04$ \\
\hline 0.005 & $2.60 \mathrm{E}-01$ & 5.01E-03 & $2.86 \mathrm{E}+01$ & $1.30 \mathrm{E}-04$ & $2.30 \mathrm{E}-02$ & $1.60 \mathrm{E}-04$ & $1.50 \mathrm{E}-04$ & $2.40 \mathrm{E}-04$ \\
\hline $\begin{array}{c}\text { TC-162 } \\
0.7 \mu \mathrm{m}\end{array}$ & $1.38 \mathrm{E}-01$ & $3.46 \mathrm{E}-03$ & $3.37 \mathrm{E}+01$ & $2.60 \mathrm{E}-04$ & 3.79E-02 & $2.80 \mathrm{E}-04$ & $2.50 \mathrm{E}-04$ & $4.00 \mathrm{E}-04$ \\
\hline 0.005 & $1.44 \mathrm{E}-01$ & $3.52 \mathrm{E}-03$ & $3.57 \mathrm{E}+01$ & 2.70E-04 & 3.74E-02 & $3.00 \mathrm{E}-04$ & $3.10 \mathrm{E}-04$ & $2.30 \mathrm{E}-04$ \\
\hline $\begin{array}{c}\text { TC-166 } \\
0.7 \mu \mathrm{m}\end{array}$ & 4.19E-02 & $3.16 \mathrm{E}-03$ & $2.06 \mathrm{E}+01$ & $2.50 \mathrm{E}-04$ & 2.49E-02 & 2.80E-04 & $3.50 \mathrm{E}-04$ & $2.90 \mathrm{E}-04$ \\
\hline 0.005 & 4.67E-02 & $2.88 \mathrm{E}-03$ & $2.24 \mathrm{E}+01$ & $1.60 \mathrm{E}-04$ & $4.33 \mathrm{E}-02$ & $3.50 \mathrm{E}-04$ & $<0.00001$ & $2.10 \mathrm{E}-04$ \\
\hline $\begin{array}{c}\text { TC-167 } \\
0.7 \mu \mathrm{m}\end{array}$ & 4.64E-02 & 7.30E-04 & $3.03 \mathrm{E}-02$ & $2.30 \mathrm{E}-04$ & $<0.00001$ & 2.80E-04 & $2.70 \mathrm{E}-04$ & $3.70 \mathrm{E}-04$ \\
\hline 0.005 & $4.66 \mathrm{E}-02$ & 6.17E-04 & 2.32E-02 & 2.30E-04 & $<0.00001$ & 2.30E-04 & $1.70 \mathrm{E}-04$ & $1.90 \mathrm{E}-04$ \\
\hline \multicolumn{9}{|c|}{ Remnant Sludge Samples $(\mu \mathrm{g} / \mathrm{g})$} \\
\hline Sample ID & ${ }^{235} \mathbf{U}$ & ${ }^{236} \mathbf{U}$ & ${ }^{238} \mathrm{U}$ & ${ }^{237} \mathbf{N p}$ & ${ }^{239} \mathrm{Pu}$ & ${ }^{240} \mathrm{Pu}$ & ${ }^{242} \mathrm{Pu}$ & ${ }^{241} \mathrm{Am}$ \\
\hline TC-151 & $6.06 \mathrm{E}+00$ & $<0.05$ & $5.69 \mathrm{E}+01$ & 9.28E-01 & $1.32 \mathrm{E}+03$ & $8.20 \mathrm{E}+01$ & $1.28 \mathrm{E}+00$ & $1.11 \mathrm{E}+01$ \\
\hline TC-160 & $2.23 \mathrm{E}+01$ & 3.82E-01 & $2.13 \mathrm{E}+03$ & $5.00 \mathrm{E}-01$ & $4.39 \mathrm{E}+02$ & $2.65 \mathrm{E}+01$ & 4.41E-01 & $5.17 \mathrm{E}+00$ \\
\hline TC-161 & $2.59 \mathrm{E}+01$ & $6.66 \mathrm{E}-01$ & $2.22 \mathrm{E}+03$ & 3.67E-01 & $4.00 \mathrm{E}+02$ & $2.57 \mathrm{E}+01$ & 7.75E-01 & $5.26 \mathrm{E}+00$ \\
\hline TC-162 & $1.13 \mathrm{E}+01$ & 7.68E-01 & $1.12 \mathrm{E}+03$ & $2.93 \mathrm{E}-01$ & $2.51 \mathrm{E}+02$ & $1.57 \mathrm{E}+01$ & $8.78 \mathrm{E}-01$ & $3.26 \mathrm{E}+00$ \\
\hline TC-166 & $5.72 \mathrm{E}+00$ & 4.17E-01 & $2.85 \mathrm{E}+03$ & $2.05 \mathrm{E}-01$ & $1.08 \mathrm{E}+01$ & $9.16 \mathrm{E}-01$ & $2.16 \mathrm{E}-01$ & $1.03 \mathrm{E}+00$ \\
\hline TC-167 & $2.39 \mathrm{E}+01$ & $<0.05$ & $6.56 \mathrm{E}+01$ & $9.17 \mathrm{E}-01$ & $2.57 \mathrm{E}+02$ & $1.60 \mathrm{E}+01$ & 7.06E-01 & $2.68 \mathrm{E}+00$ \\
\hline
\end{tabular}




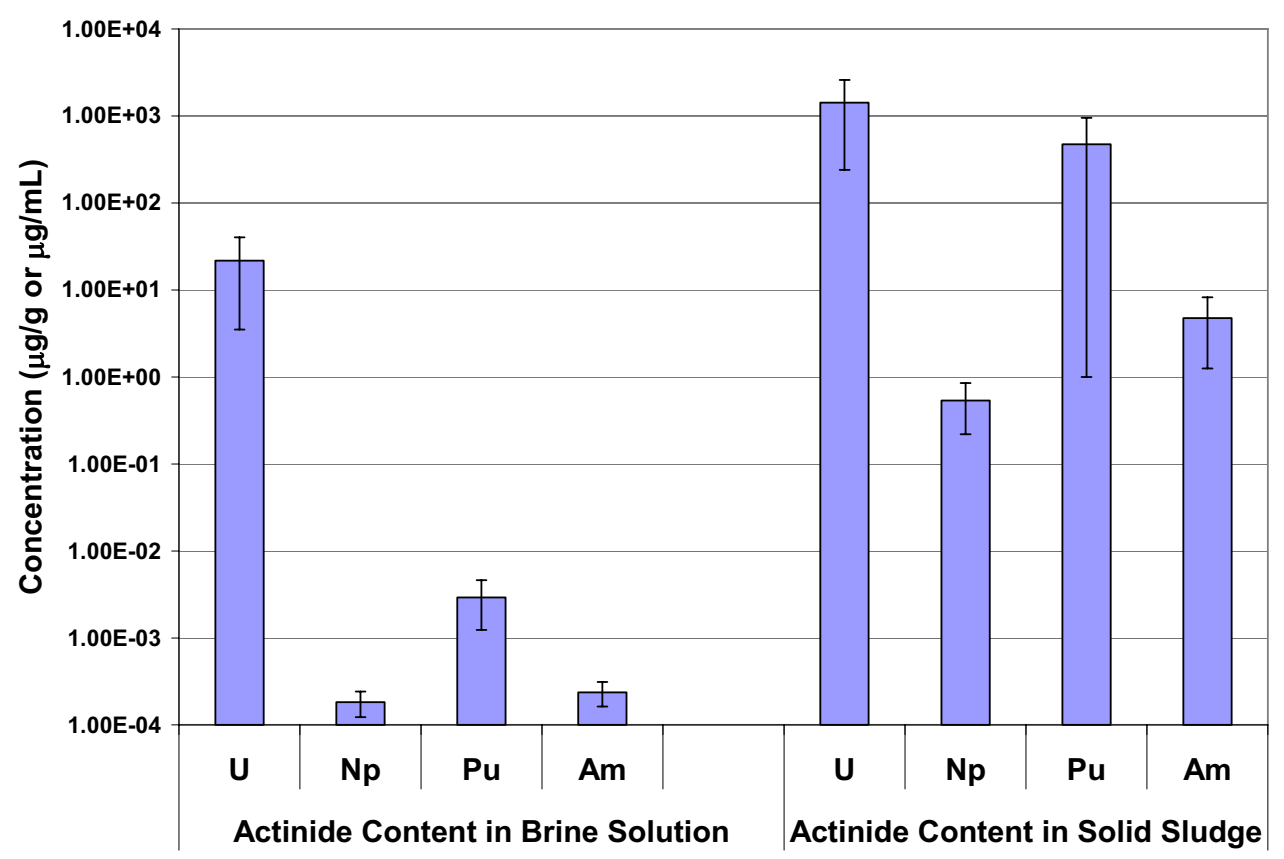

Figure 41. Comparison of the Uranium, Neptunium, Plutonium, and Americium distributions in the Brine and the solid Sludge.

\subsection{Summary of Laboratory Analyses}

Corrosion products were observed on the metal coupons after termination of the GGE project. Possible corrosion products produced during the GGE test period observed by XRD included two species of iron chloride. It is most likely that the iron oxide species observed in the XRD analysis resulted from oxidation after the coupons were removed from the test containers.

Analysis by SEM confirmed the visual inspection that the coupon from TC-166 had corroded much more than the coupon from TC-160. Furthermore, microscopy of coupon TC-166 indicates possibility of significant localized corrosion. Most of the corrosion products formed as uniform layers, however, some discrete phases were also observed. All the corrosion products appeared to contain $\mathrm{Fe}$ and $\mathrm{O}$ in varying concentrations. Some of the corrosion products also contained $\mathrm{U}, \mathrm{Mg}, \mathrm{Al}, \mathrm{Ca}, \mathrm{Cl}$, and/or Si.

The actinide elements $\mathrm{U}, \mathrm{Np}, \mathrm{Pu}$ and $\mathrm{Am}$ were measured in both the brine solution and sludge material, however, the actinide content was greater in the sludge by several orders of magnitude. The results suggest that the actinides that did migrate into the brine solution are of a soluble form. There is no indication of actinide migration into the brine due to the formation of colloidal or other precipitate material. 


\section{CONCLUSIONS}

1. No measurable gas generation was observed in either of the two non-waste-bearing experimentcontrol vessels.

2. Replicated test vessels generally showed very good consistency.

3. Significant rates of hydrogen generation were measured in the carbon-steel-bearing waste compositions.

4. Corrosion of carbon steel was found to be the predominant generator of hydrogen gas.

5. Post-test visual observations of steel coupon corrosion corroborated the headspace gas measurements.

6. A considerable variation was noted in the rates of hydrogen generation over the first 1 to $2 \mathrm{yr}$ as compared to the trends discernable over the entire test. Some vessels displayed a decaying rate, some a constant rate, and some an increasing rate. This could cast some question on results previously obtained on the basis of comparatively short-term testing.

7. The largest concentration of hydrogen, by far, was in a carbon-steel and sludge waste composition. For this vessel no reduction in the rate of hydrogen production occurred over the $6-1 / 2 \mathrm{yr}$ of the test.

8. Small quantities of carbon dioxide were observed with most waste compositions, but the variation in the quantity was quite modest among the different waste compositions.

9. When observed, carbon dioxide generation was initially rapid, but headspace concentrations generally leveled off after 1 to 2 years.

10. Carbon monoxide and methane were only detected in one waste composition, and only at levels barely above detection limits.

11. No hydrogen sulfide was ever detected.

12. Interactions among several of the constituents apparently reduce the rate of steel corrosion.

13. Except for corrosion of the carbon-steel coupons, no changes were observed in the appearance of the waste constituents.

14. Brine extracted from the surface appeared clear, but appeared dark when the entire brine inventory from a test vessel was homogenized. This indicates that particulate matter was transported to the brine.

15. X-ray diffraction analyses of the carbon-steel coupons showed that the corrosion products generally consisted of various iron chlorides and iron oxides, but the latter may have resulted from the post-test exposure to air. 
16. Scanning electron microscopy examinations of the carbon-steel coupons with energy-dispersive and wavelength-dispersive spectrometers confirmed the presence of iron, chlorine, and oxygen. In addition, uranium, magnesium, calcium, aluminum, and silicon were observed among the corrosion products. Neither americium nor neptunium was observed.

17. $\mathrm{pH}$ measurements in the brine from carbon-steel-bearing test vessels were slightly acidic, varying between 5.0 and $6.0, \pm 1.0$.

18. All actinide activity in the brine was determined to be fully solubilized. No actinide colloids or particulates appear to have been transported to the brine. 


\section{REFERENCES}

1. M. R. Telander and R. E. Westerman, "Hydrogen Generation by Metal Corrosion in Simulated Waste Isolation Pilot Plant Environments." SAND96-2538, UC-721 (1997).

2. A. J. Francis and J. B. Gillow, "Effects of Microbial Processes on Gas Generation Under Expected Waste Isolation Pilot Plant Repository Conditions." SAND93-7036, UC-721 (1994).

3. R. Villarreal, "The Actinide Source-Term Waste Test Program Final Report” (2001).

4. A. C. Peterson, "Technical Requirements for Gas-Generation Experiments with Contact-Handled Transuranic Waste Materials.” SAND93-3977, UC-721 (1993).

5. M. L. F. Phillips and M. A. Molecke, "Technical Requirements for the Actinide Source-Term Waste Test Program.” SAND91-2111, UC-721 (1993).

6. Waste Isolation Pilot Plant Transuranic Waste Baseline Inventory Report, CAO-94-1005, U.S. Department of Energy, Carlsbad, NM (1994).

7. Jim Brown, Technical Representative, North Safety Products, Cranston, RI, personal communication, Jan. 5, 2003.

8. F. S. Felicione, Development and Application of an Analysis Methodology for Interpreting Ambiguous Historical Pressure Data in the WIPP Gas-Generation Experiments, Argonne National Laboratory Report. ANL-NT-231 (2006).

9. E. R. Dougherty, Probability and Statistics for the Engineering, Computing, and Physical Sciences, Prentice Hall, 1990, p. 690.

10. J. S. Hunter, Design of Experiments, Westinghouse Learning Corporation, vol. 4, 1968.

The submitted manuscript has been created by The University of Chicago as Operator of Argonne National Laboratory (Argonne) under Contract No. W-31-109-Eng-38 with the U.S. Department of Energy. The U.S. Government retains for itself, and others acting on its behalf, a paid-up nonexclusive, irrevocable worldwide license in said article to reproduce, prepare derivative works, distribute copies to the public, and perform publicly and display publicly, by or on behalf of the Government. 
Appendix A

Statistical Analysis of the GGE 
Table A1. Statistical analysis.

\begin{tabular}{|c|c|c|c|c|c|c|c|c|c|c|c|c|}
\hline \multicolumn{13}{|c|}{ Analysis of the GGE as a $2^{5-2}$ Fractional Factorial Experiment Design } \\
\hline \multicolumn{2}{|c|}{ Variables Definitions: } & & & & & & & & & & & \\
\hline & A & \multicolumn{2}{|c|}{ Leaded Rubber } & & & & & & & & & \\
\hline & B & Steel & & & & & & & & & & \\
\hline & C & Cellulose & & & & & & & & & & \\
\hline & D & Sludge & & & & & & & & & & \\
\hline \multirow{2}{*}{\multicolumn{2}{|c|}{$\mathrm{E}$}} & \multicolumn{2}{|c|}{ Plastic/Rubber } & & & & & & & & & \\
\hline \multirow{2}{*}{\multicolumn{13}{|c|}{ Experiment Design Table (Standard Order) }} \\
\hline & & & & & & & & & & & & \\
\hline \multirow{2}{*}{\multicolumn{2}{|c|}{ Treatments }} & \multirow{2}{*}{\multicolumn{5}{|c|}{ Variable Settings }} & & & & & & \\
\hline & & & & & & & & & & & & \\
\hline \multicolumn{2}{|c|}{ No. Identifier(s) } & A & B & C I & $\mathrm{D}(\sim \mathrm{AC})$ & $\mathrm{E}(\sim \mathrm{BC})$ & & Legend: & & + High Value & & \\
\hline & & & & & & & & & & - Low Value & & \\
\hline 1 & TC-165 & - & - & - & + & + & & & & & & \\
\hline 2 & TC-170 & + & - & - & - & + & & \multicolumn{2}{|l|}{ Generators: } & D: ACD & & \\
\hline 3 & TC-166 & - & + & - & + & - & & & & E: BCE & & \\
\hline 4 & TC-151 & + & + & - & - & - & & \multirow{2}{*}{\multicolumn{2}{|c|}{ Resolution, r: }} & & & \\
\hline 5 & TC-168, -169 & - & - & 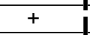 & - & - & & & & 3 & & \\
\hline 6 & TC-163, -164 & + & - & + & + & - & & \multirow{2}{*}{\multicolumn{2}{|c|}{ Defining Relation: }} & & & \\
\hline 7 & TC-167 & - & + & + & - & + & & & & I+ACD+BCE+ABDE & & \\
\hline \multirow[t]{2}{*}{8} & TC-160, -161, -162 & + & + & + & + & + & & & & & & \\
\hline & & & & & & & & No. Runs: & & 8 & & \\
\hline & & & & & & & & & & & & \\
\hline \multicolumn{13}{|c|}{ Yate's Algorithm } \\
\hline & & & & & & & & & & & & \\
\hline & Treatments & Resp & onses $(g-n$ & $\mathrm{H}_{2}$ by $\mathrm{F}$ & all '02) & & 's Column & & Naïve & Actual Estimate & w/o 3- \& 4-fact & Estimated \\
\hline \multicolumn{2}{|c|}{ No. Identifier(s) } & \begin{tabular}{l|l}
1 \\
\end{tabular} & 2 & 3 & Resp. Ave. & \begin{tabular}{|l|l} 
No. 1 \\
\end{tabular} & No. 2 & No. 3 & Estimate & per Defining Relation & interactions & Effects \\
\hline & & & & & & & & & & & & \\
\hline 1 & TC-165 & 0.0077 & & & 0.0077 & 0.0160 & 0.2057 & 0.3213 & Y-ave & Y-ave & Y-ave & 0.0402 \\
\hline 2 & TC-170 & 0.0083 & & & 0.0083 & 0.1897 & 0.1156 & $\begin{array}{ll}-0.1635 \\
\end{array}$ & A & $A+C D+A B C E+B D E$ & $A+C D$ & -0.0409 \\
\hline 3 & TC-166 & 0.1661 & & & 0.1661 & 0.0052 & -0.1419 & 0.2791 & $\mathrm{~B}$ & $B+A B C D+C D+A D E$ & $\mathrm{~B}+\mathrm{CE}$ & 0.0698 \\
\hline 4 & TC-151 & 0.0236 & & & 0.0236 & 0.1105 & -0.0215 & -0.1750 & $A B$ & $A B+B C D+A C+D E$ & $A B+D E$ & -0.0437 \\
\hline 5 & TC-168, -169 & 0.0000 & & & 0.0000 & 0.0006 & 0.1737 & -0.0901 & $\mathrm{C}$ & $C+A D+B E+A B C D E$ & $C+A D+B E$ & -0.0225 \\
\hline 6 & TC-163, -164 & 0.0056 & 0.0047 & & 0.0052 & -0.1425 & 0.1053 & 0.1204 & $A C$ & $A C+D+A B E+B C D E$ & $A C+D$ & 0.0301 \\
\hline 7 & TC-167 & 0.0686 & & & 0.0686 & 0.0052 & -0.1431 & -0.0684 & $\mathrm{BC}$ & $B C+A B D+E+A C D E$ & $\mathrm{BC}+\mathrm{E}$ & -0.0171 \\
\hline \multirow[t]{4}{*}{8} & TC-160, -161, -162 & 0.0548 & 0.0562 & 0.0147 & 0.0419 & \begin{tabular}{|l|}
-0.0267 \\
\end{tabular} & -0.0318 & 0.1113 & $A B C$ & $A B C+B D+A E+C D E$ & $B D+A E$ & 0.0278 \\
\hline & & & & & & & & & & & & \\
\hline & & & Sum & & 0.3213 & & & & & & & \\
\hline & & & Overall Av & Check & 0.0402 & & & & & & & \\
\hline
\end{tabular}


Table A2. ANOVA analysis.

\begin{tabular}{|c|c|c|c|c|c|c|c|c|}
\hline \multicolumn{9}{|c|}{ Analysis of Variance (ANOVA) } \\
\hline & & & & & & & & \\
\hline Sum of responses & $2 y_{\mathrm{i}}$ & $3.213 \mathrm{E}-01$ & & & & & & \\
\hline Number of runs & $\mathrm{N}$ & 8 & & & & & & \\
\hline Student's t-statistic ( 95\%) & $t_{4,0.025}$ & 2.776 & & & & & & \\
\hline Student's t-statistic ( $80 \%)$ & $t_{4,0.10}$ & 1.533 & & & & & & \\
\hline \multirow[t]{2}{*}{ Critical F-Statistics ( 95\%) } & $\mathrm{F}_{1,4,0.05}$ & 7.71 & & & & & & \\
\hline & $\mathrm{F}_{3,4,0.05}$ & 6.59 & & & & & & \\
\hline Error limits for effects & \multicolumn{2}{|c|}{$\pm \mathrm{t}_{\mathrm{v}, \text { critical }} \sqrt{ }\left(4 \mathrm{~s}^{2} / \mathrm{N}\right)$} & & & & & & \\
\hline \multirow[t]{2}{*}{ F-Statistic } & \multicolumn{2}{|c|}{\begin{tabular}{|l|l|}
$\mathrm{S}_{\mathrm{T}}{ }^{2} / \mathrm{s}^{2}$ & \\
\end{tabular}} & & & & & & \\
\hline & \multicolumn{2}{|c|}{ Sum of Squares SSq } & Deg. of & \multicolumn{2}{|c|}{ Estimates of the Variance } & \multicolumn{3}{|r|}{ F Test of Significance } \\
\hline Term & Definition & Value & Freedom & $\mathrm{s}^{2}=\mathrm{SSq} / \mathrm{DF}$ & Definition & $F_{v 1, v 2}$ & \multicolumn{2}{|c|}{$F_{\mathrm{v} 1, \mathrm{v} 2, \text { critical }}$} \\
\hline Crude SSq & $\Sigma y_{i}^{2}$ & $3.477 \mathrm{E}-02$ & 8 & & & & & \\
\hline Correction Factor & $\left(\Sigma y_{i}\right)^{2} / N$ & $1.291 \mathrm{E}-02$ & 1 & & & & & \\
\hline & & & & & & & & \\
\hline \multicolumn{9}{|c|}{ Treatment Effects Apparently NOT Random Errors } \\
\hline$A+C D$-effect SSq & $\mathrm{N} / 4^{*}(\text { effect })^{2}$ & $3.340 \mathrm{E}-03$ & 1 & $3.340 \mathrm{E}-03$ & $\mathrm{~s}_{\mathrm{T}}{ }^{2}$, est. $\sigma^{2}$ if no treatment effect & 2.694 & 7.71 & 'No treatment effect' NOT contradicted by the data \\
\hline B+CE-effect SSq & $\mathrm{N} / 4^{*}(\text { effect })^{2}$ & $9.734 \mathrm{E}-03$ & 1 & 9.734E-03 & $\mathrm{s}_{\mathrm{T}}^{2}$, est. $\sigma^{2}$ if no treatment effect & 7.850 & 7.71 & 'No treatment effect' IS NOT SUPPORTED by the data \\
\hline$A B+D E-$ effect SSq & $\mathrm{N} / 4^{*}(\text { effect })^{2}$ & $3.826 \mathrm{E}-03$ & 1 & 3.826E-03 & $\mathrm{s}_{\mathrm{T}}^{2}$, est. $\sigma^{2}$ if no treatment effect & 3.086 & 7.71 & 'No treatment effect' NOT contradicted by the data \\
\hline \multicolumn{2}{|c|}{ Sum of Real Treatment Effects } & $1.690 \mathrm{E}-02$ & 3 & 5.634E-03 & $\mathrm{s}_{\mathrm{T}}^{2}$, est. $\sigma^{2}$ if no treatment effects & 4.543 & 6.59 & 'No treatment effect' NOT contradicted by the data \\
\hline \multicolumn{9}{|c|}{ Treatment Effects Apparently Result Only of Random Errors } \\
\hline$C+A D+B E-e f f e c t S S q$ & $\mathrm{~N} / 4^{*}(\mathrm{effect})^{2}$ & $1.015 \mathrm{E}-03$ & 1 & & & & & \\
\hline$A C+D$-effect SSq & $\mathrm{N} / 4^{*}(\text { effect })^{2}$ & $1.812 \mathrm{E}-03$ & 1 & & & & & \\
\hline BC+E-effect SSq & $\mathrm{N} / 4^{*}(\text { effect })^{2}$ & $5.852 \mathrm{E}-04$ & 1 & & & & & \\
\hline BD+AE-effect SSq & $\mathrm{N} / 4^{*}(\text { effect })^{2}$ & $1.548 \mathrm{E}-03$ & 1 & & & & & \\
\hline & & & & & & & & \\
\hline Overall ANOVA Residuals & & $0.000 \mathrm{E}+00$ & 0 & Insuff. Data & $\mathrm{s}^{2}$ estimates $\sigma^{2}$ & & & \\
\hline \multicolumn{2}{|c|}{ Apparent Random Error Effects } & $4.960 \mathrm{E}-03$ & 4 & $1.240 \mathrm{E}-03$ & $\mathrm{~s}^{2}$ estimates $\sigma^{2}$ & & & \\
\hline & & & & & & & & \\
\hline \multicolumn{9}{|l|}{ Error Limits for Treatments } \\
\hline & & \multicolumn{2}{|c|}{ Limit Bar Placement } & & & & & \\
\hline Confidence Level, \% & Limits, \pm & Horz. & Vert. & & & & & \\
\hline 95 & $6.912 \mathrm{E}-02$ & 0 & 0.667 & & & & & \\
\hline 80 & $3.817 \mathrm{E}-02$ & 0 & 0.333 & & & & & \\
\hline
\end{tabular}




\section{Appendix B}

\section{Photographs of the Vessel Unloading Operations}

$$
\text { Vessels TC-151, }-160,-162 \text {, and }-166
$$


Vessel TC-151
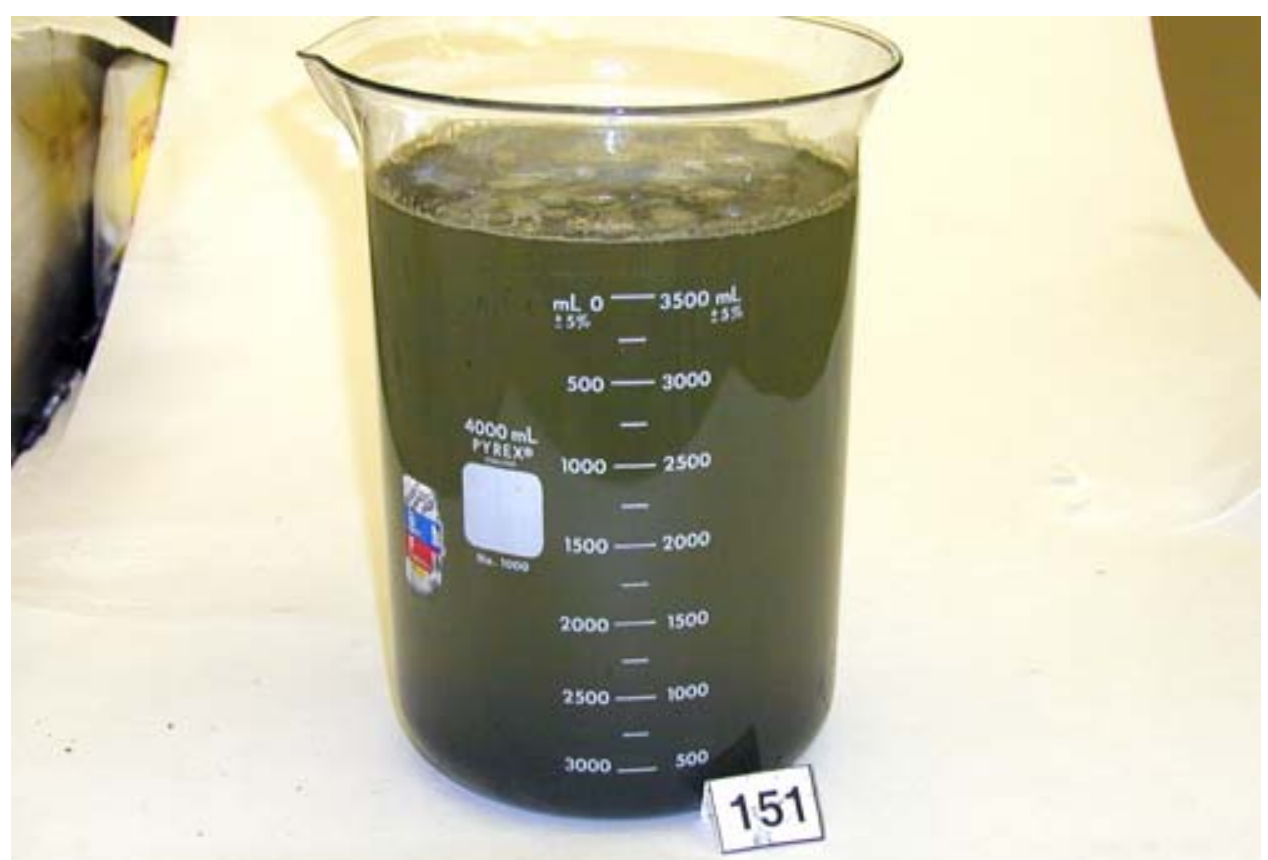

09819.

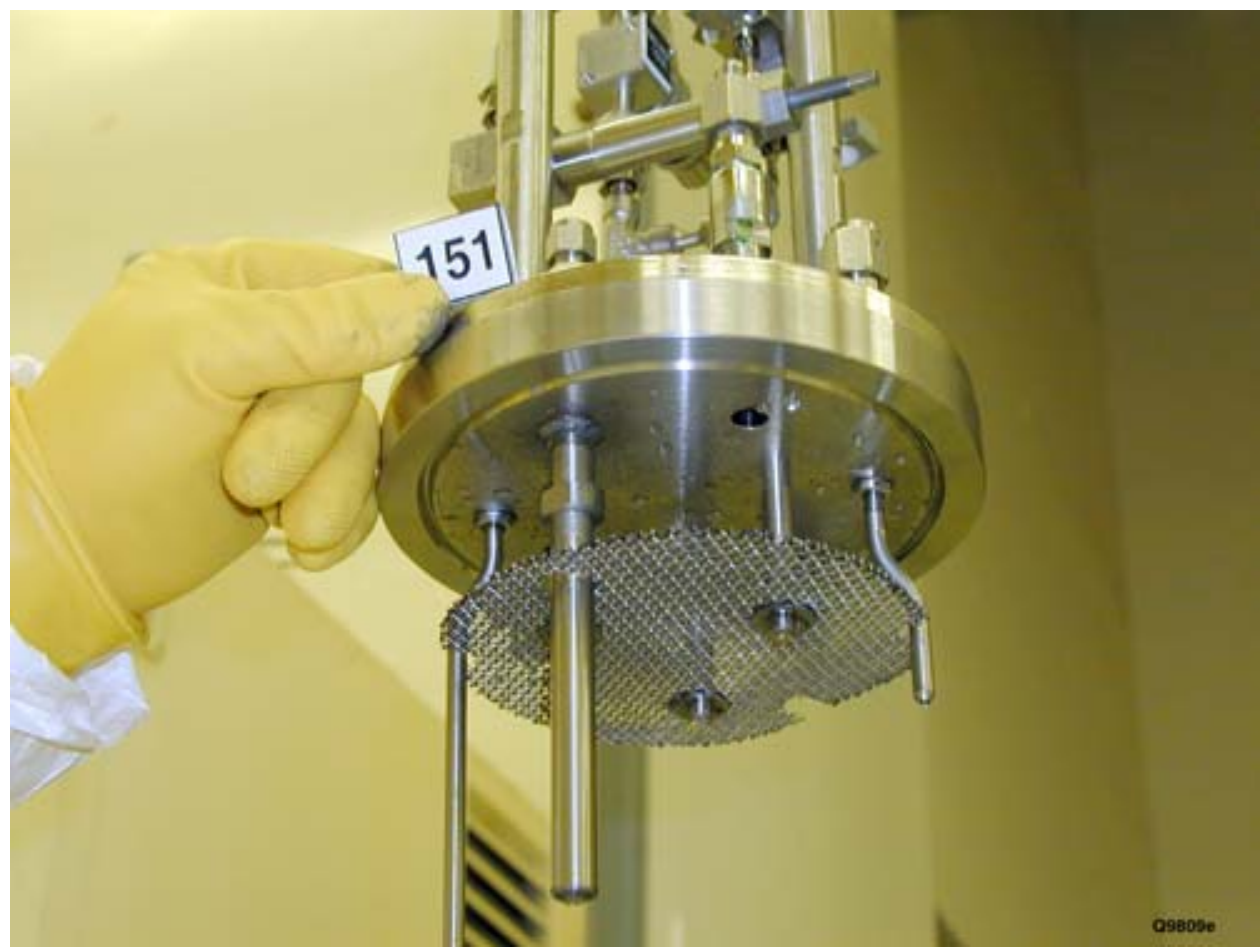



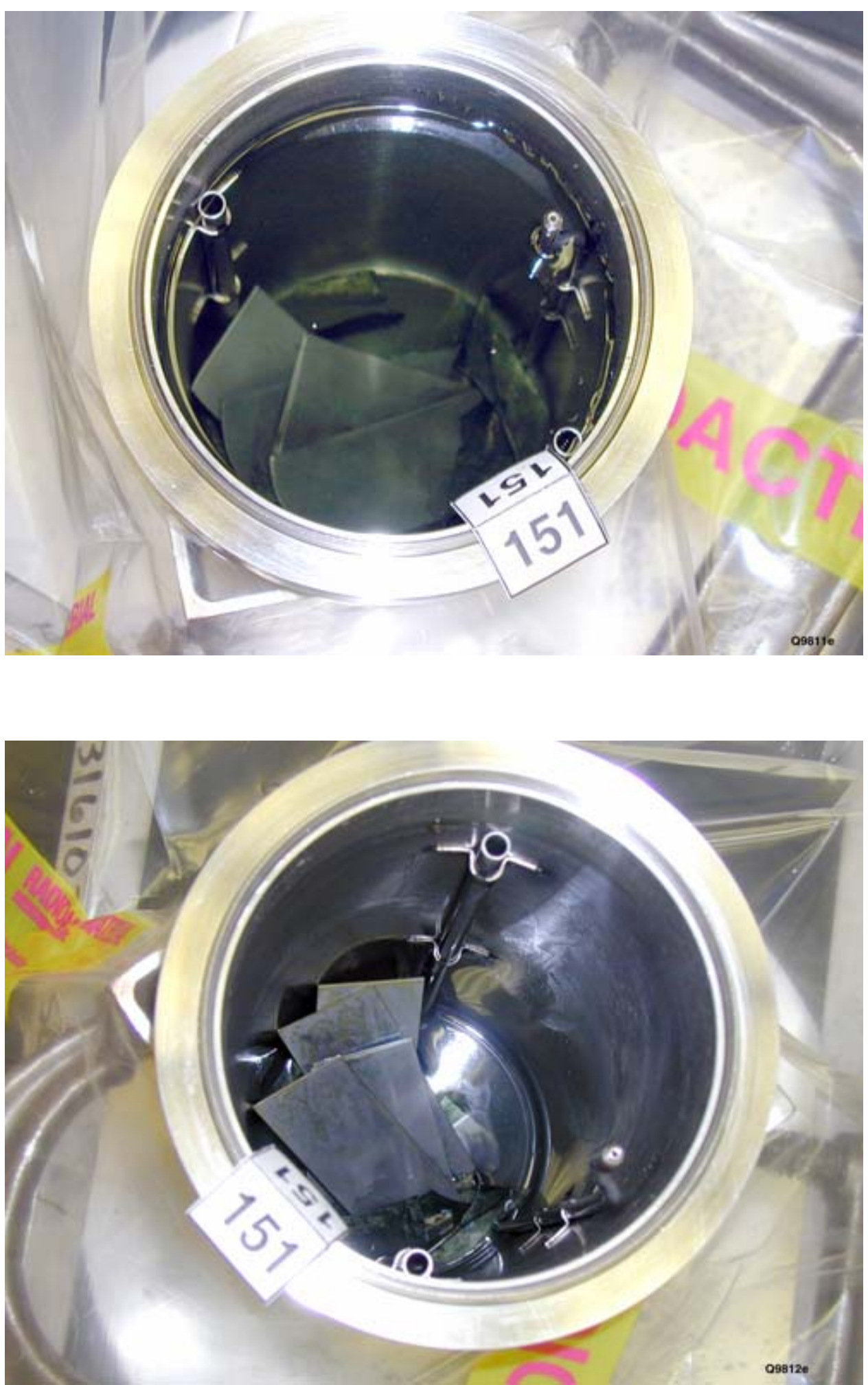

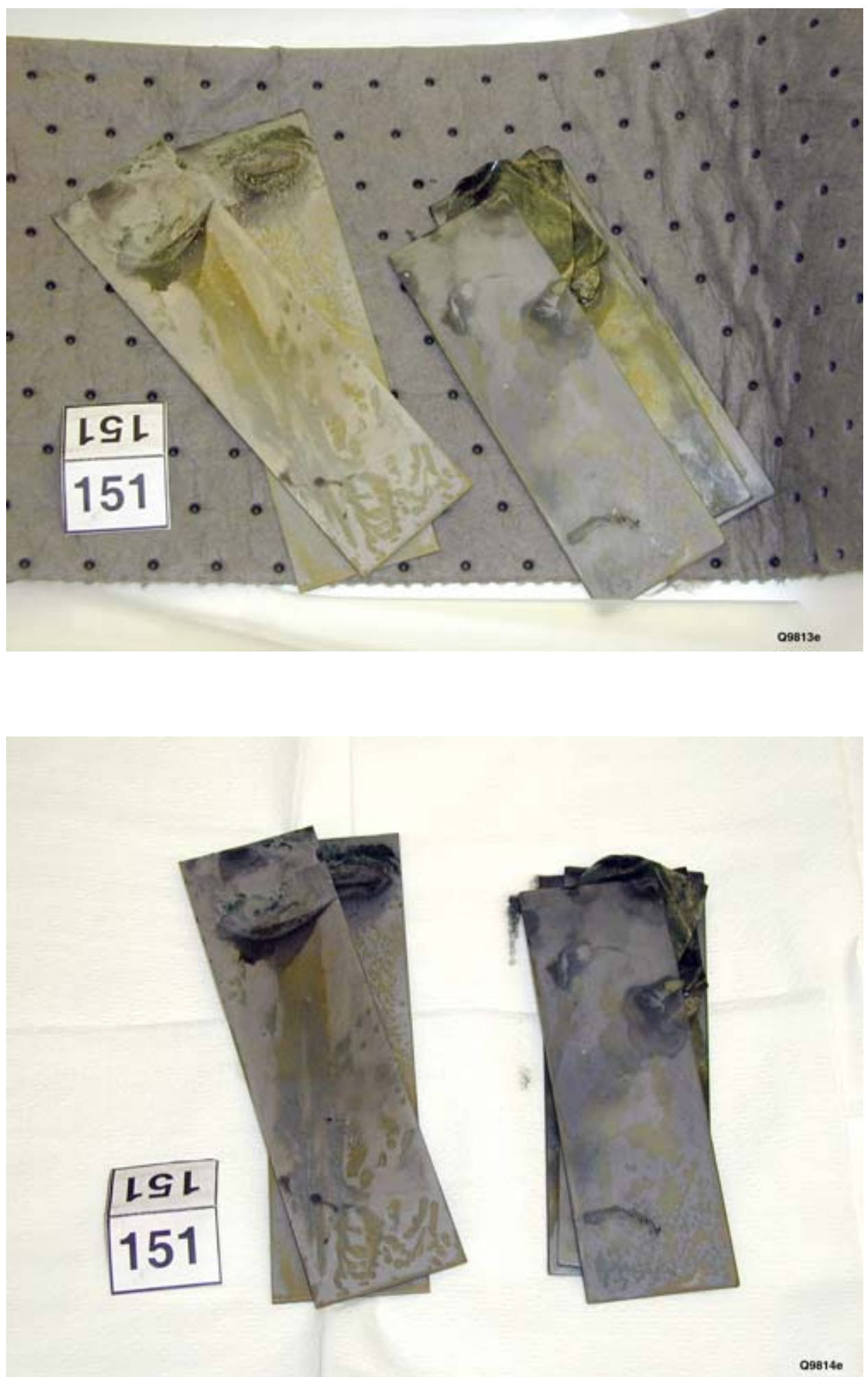

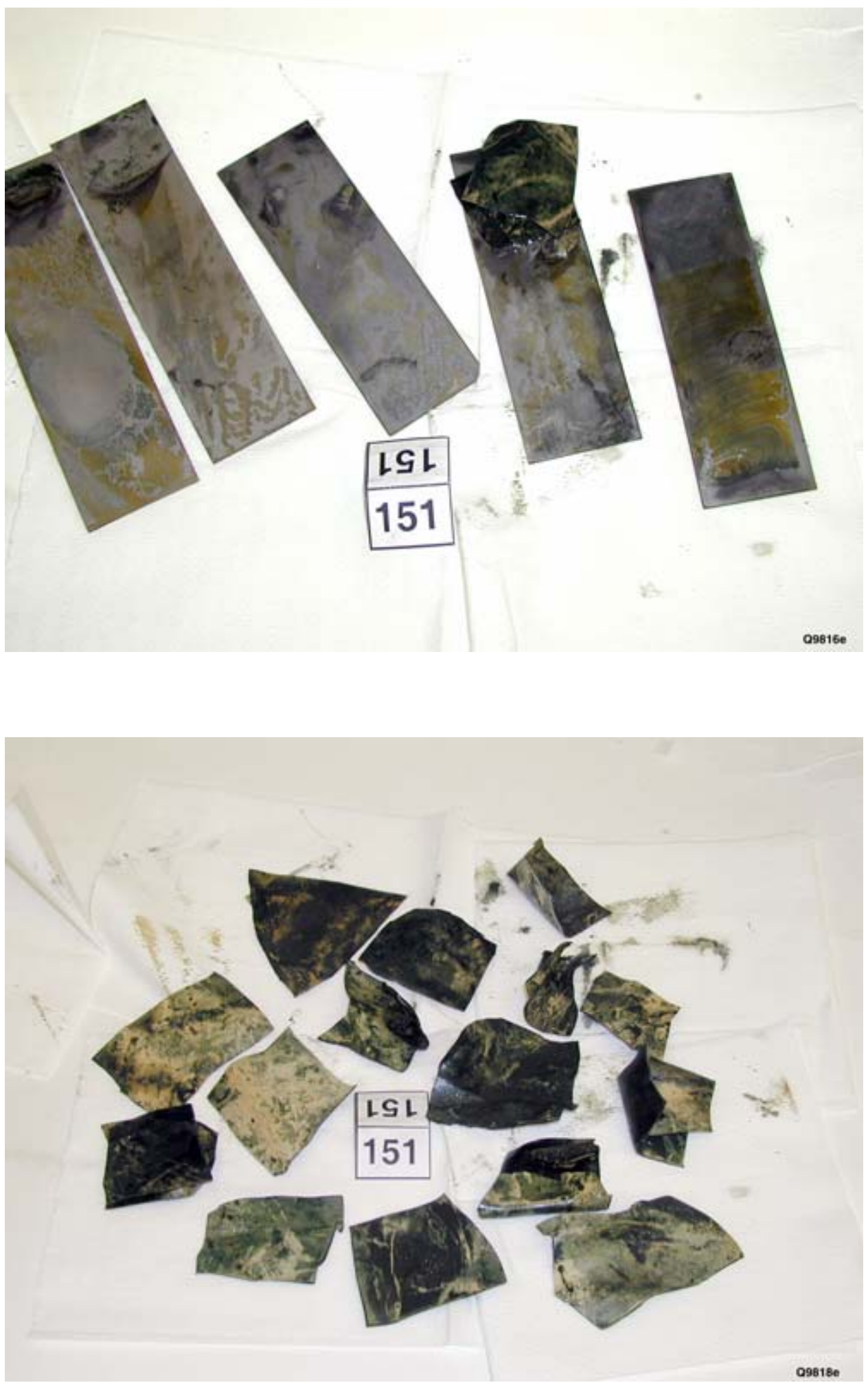


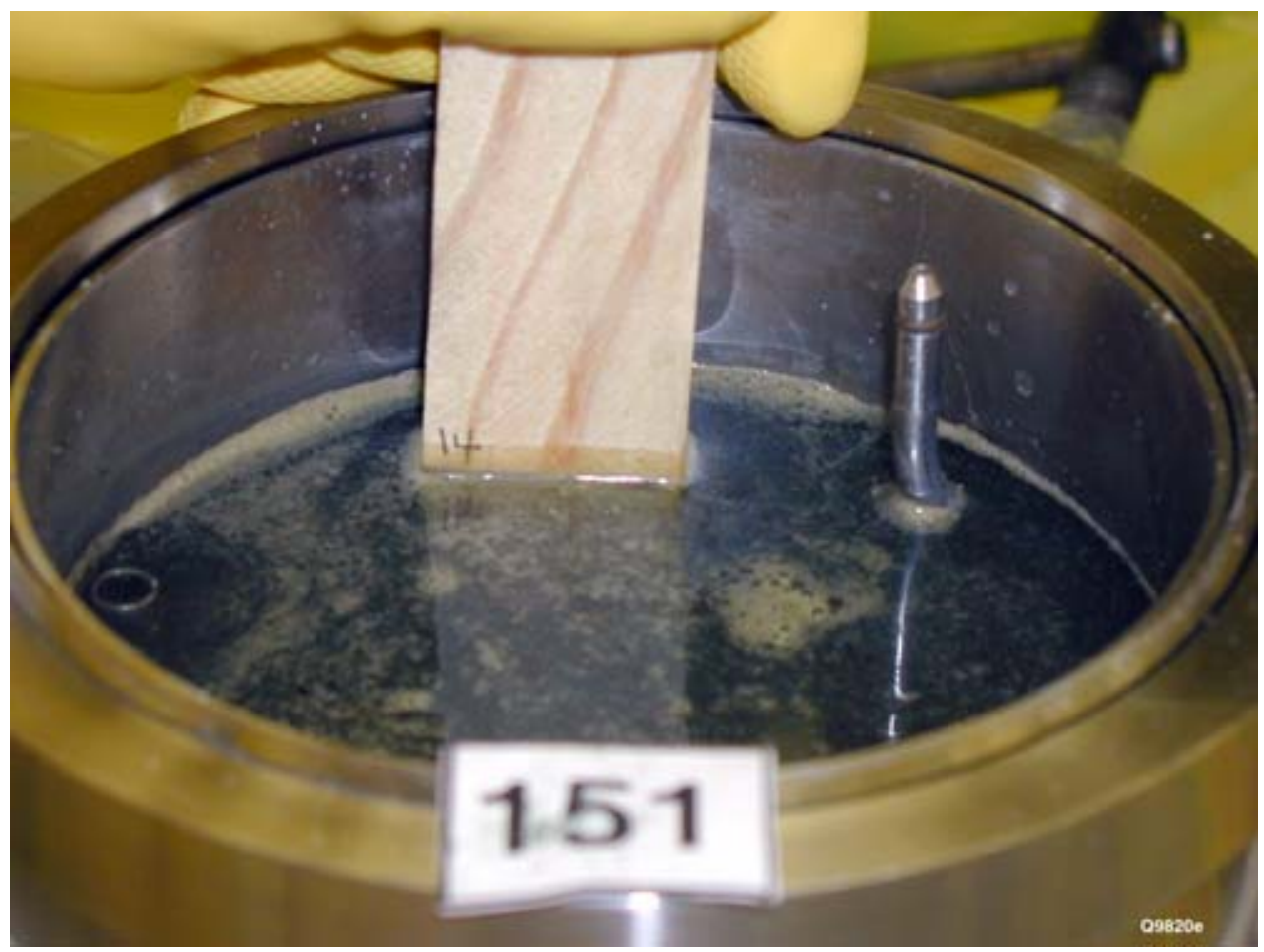


Vessel TC-160

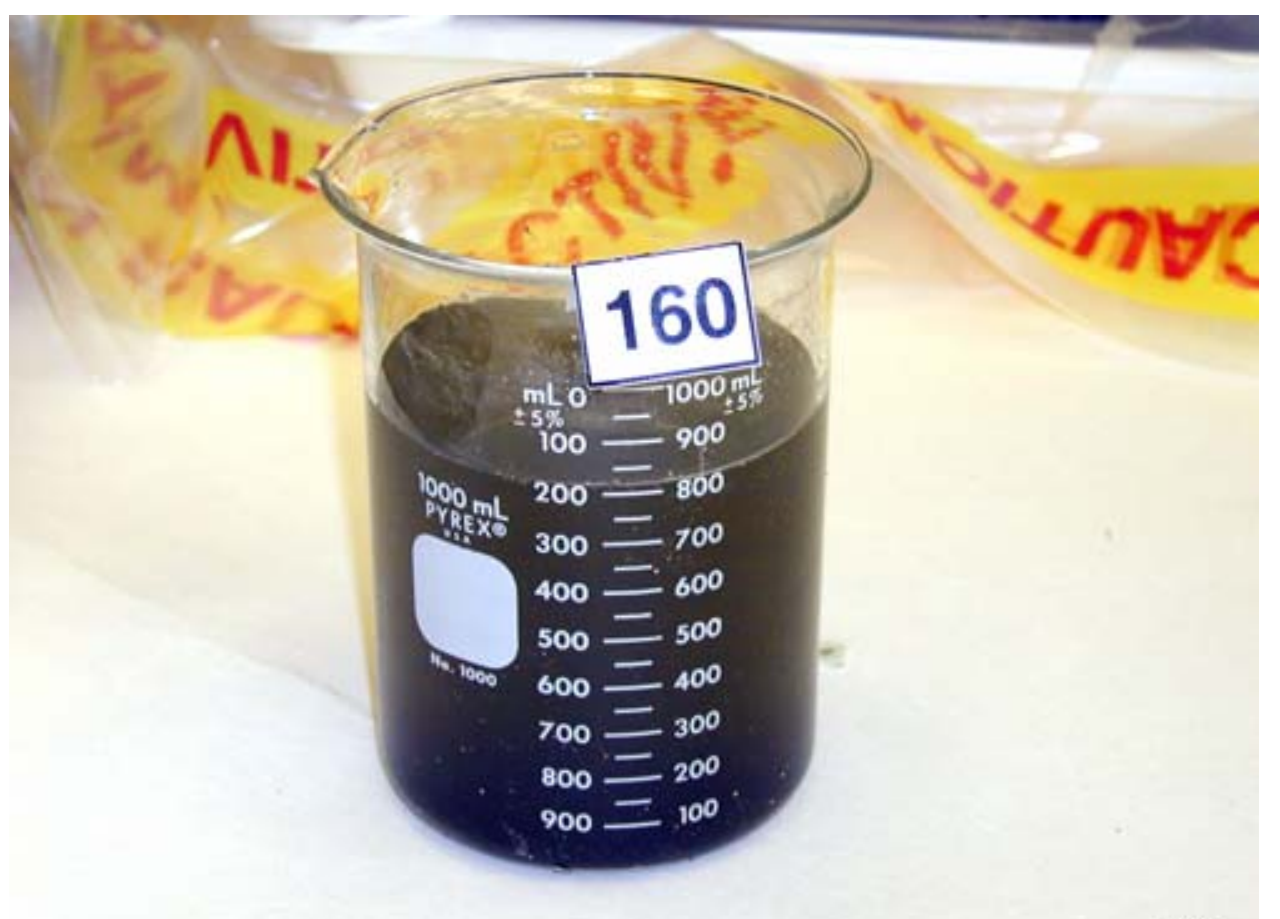

Q9844e

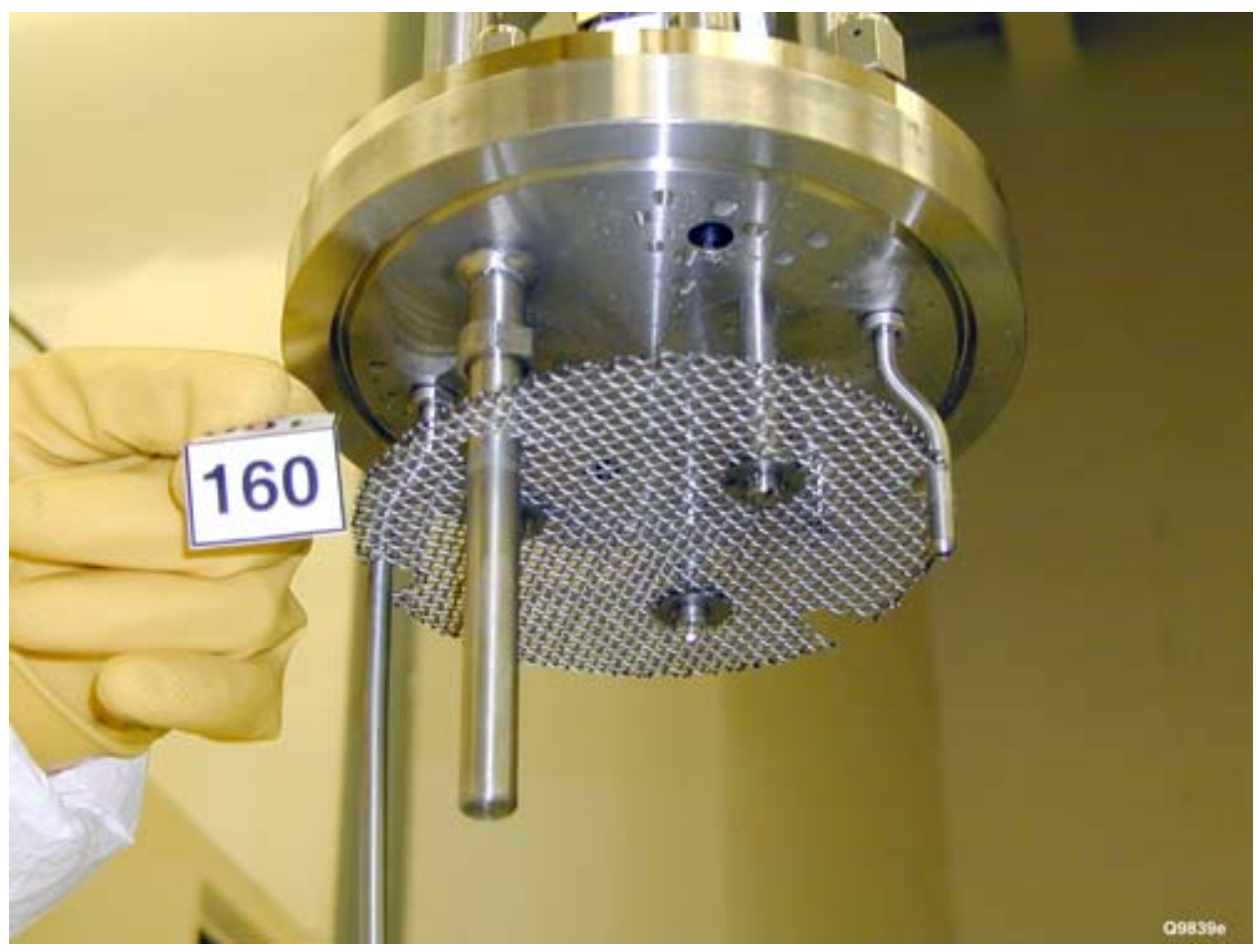



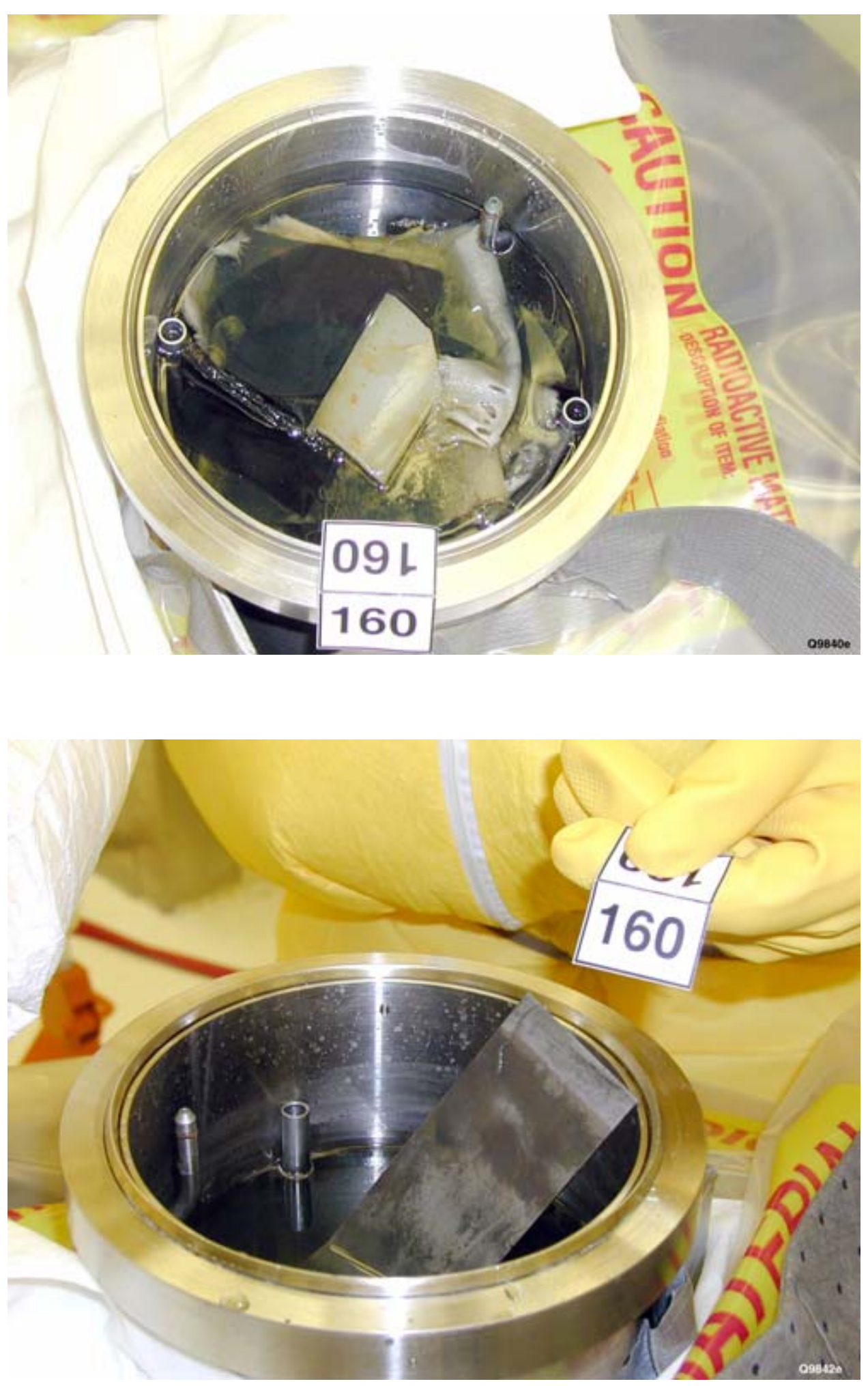

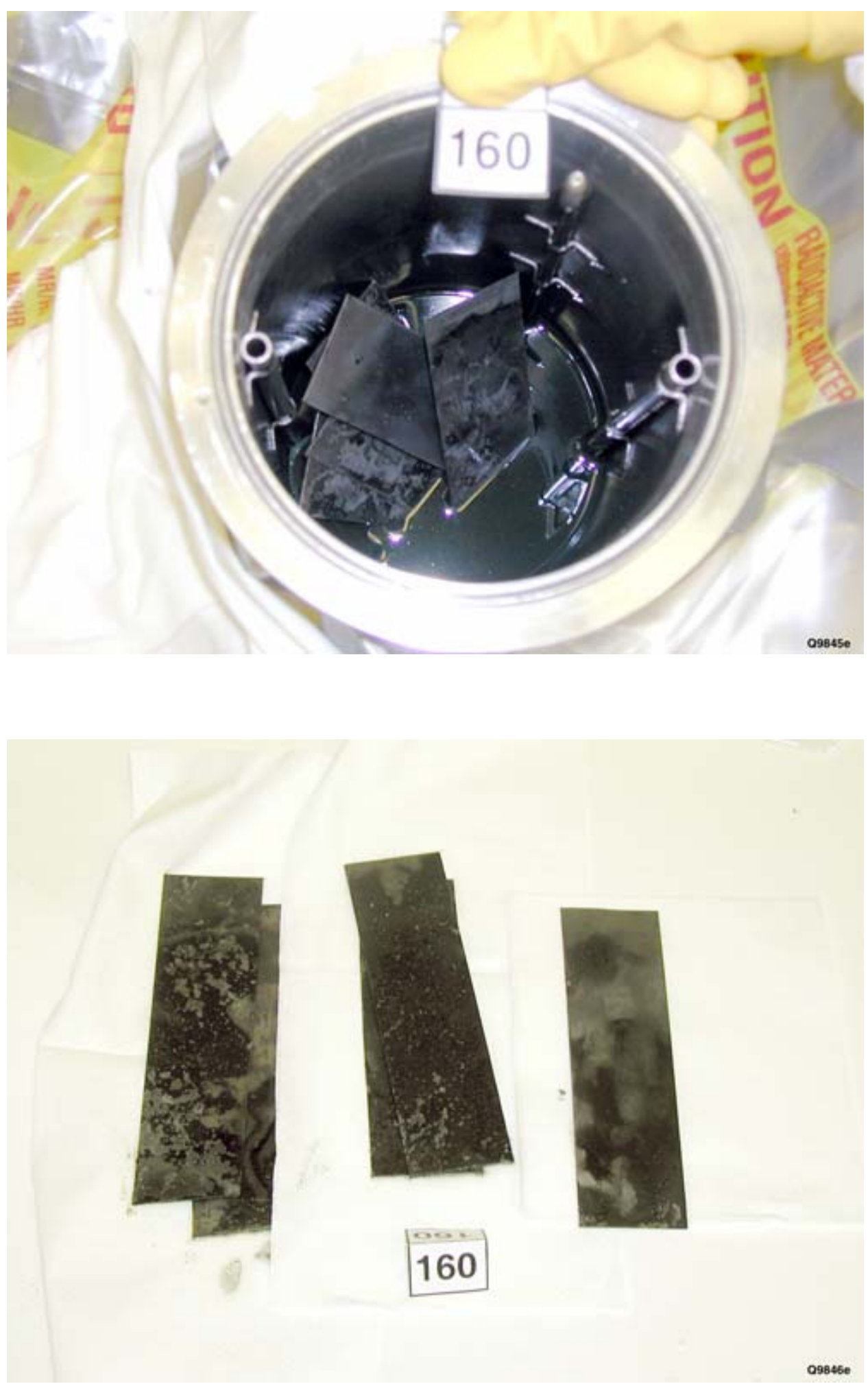

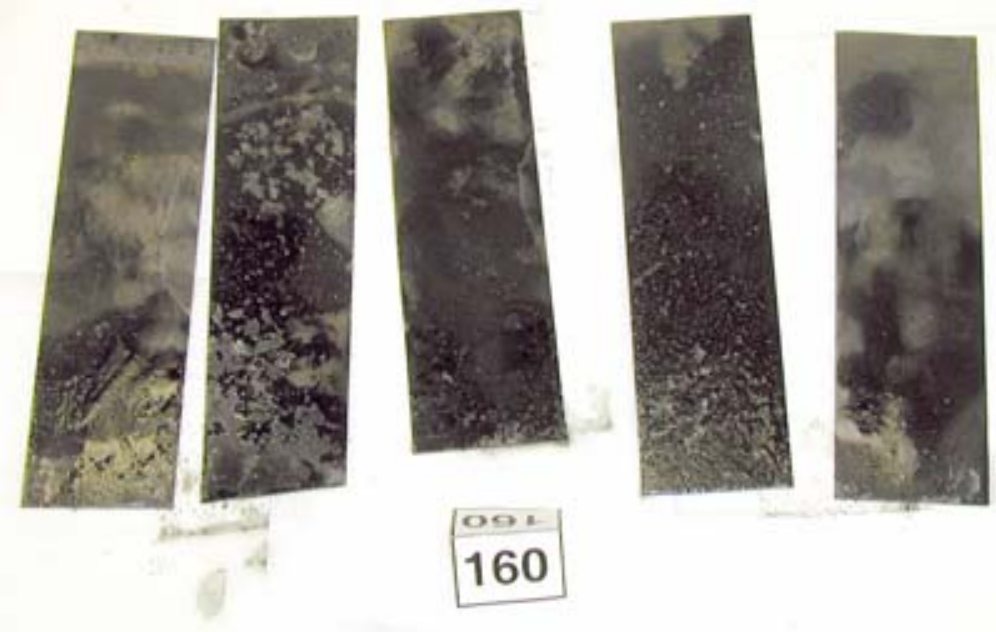

09847.

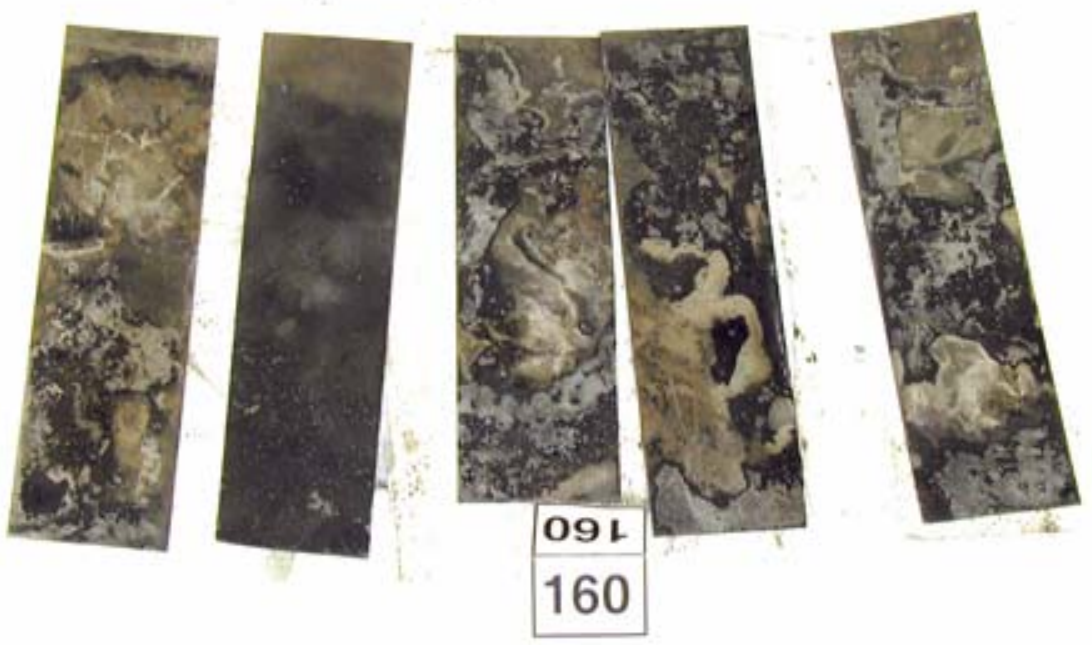

Q984Be 


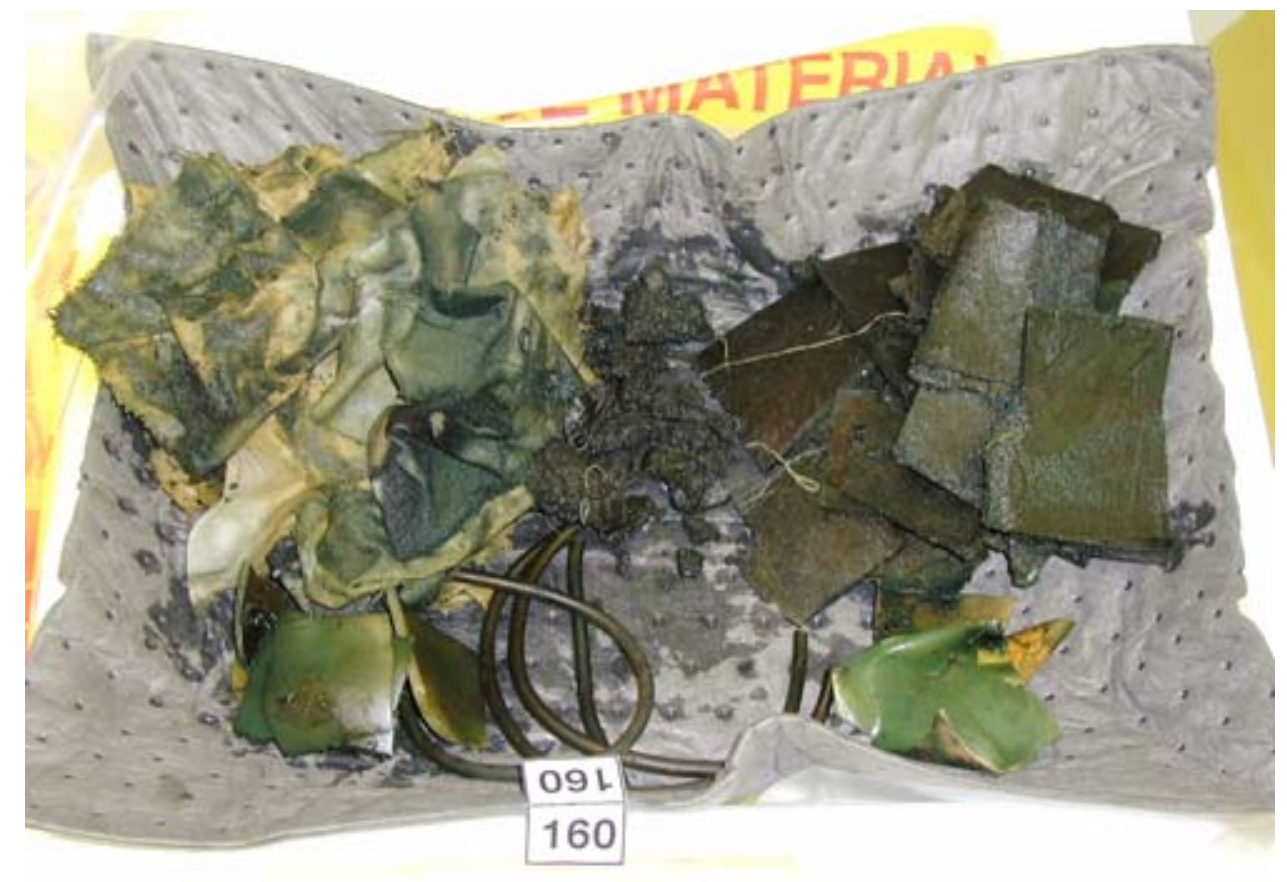

- xwhal hy

Q9843e

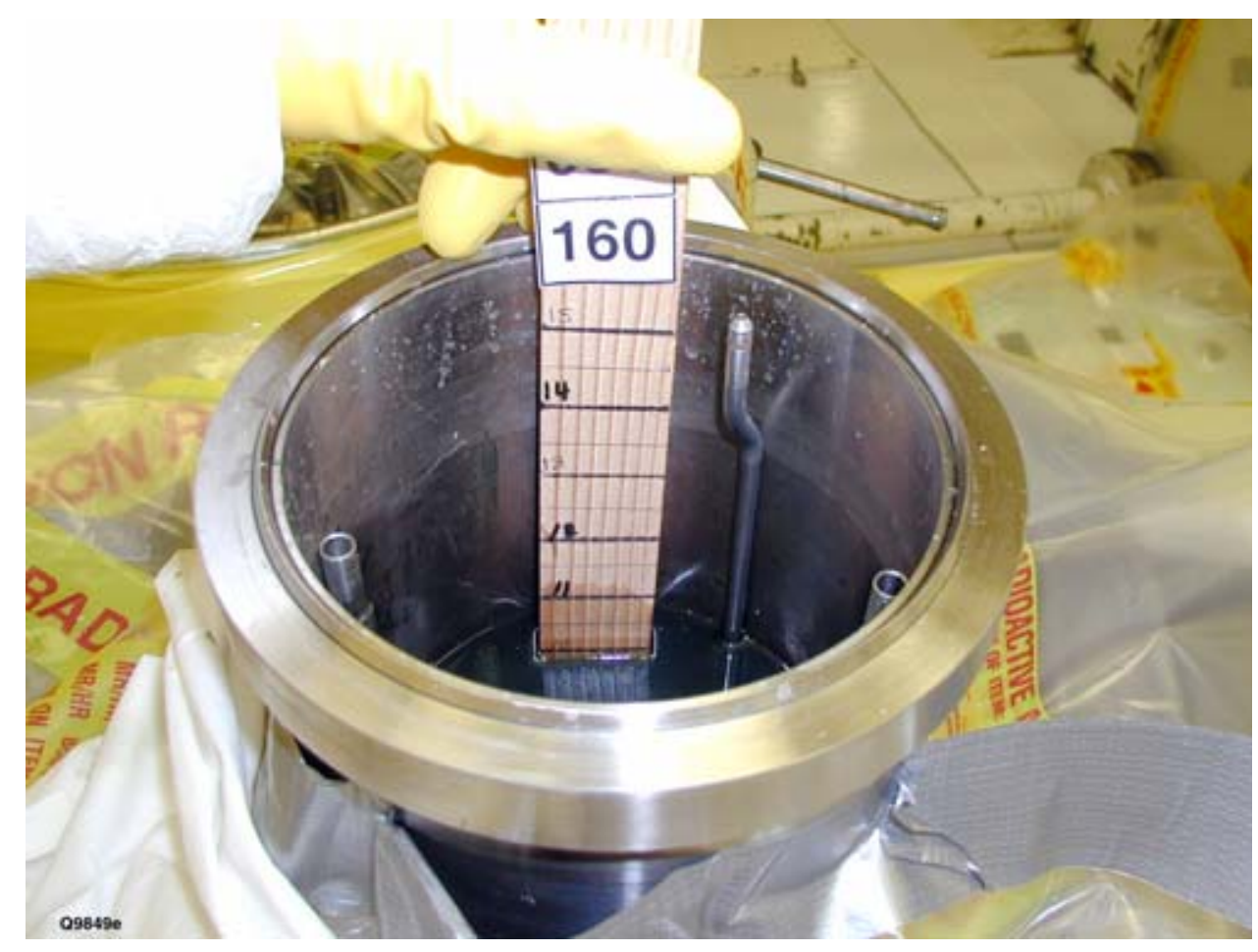


Vessel TC-161
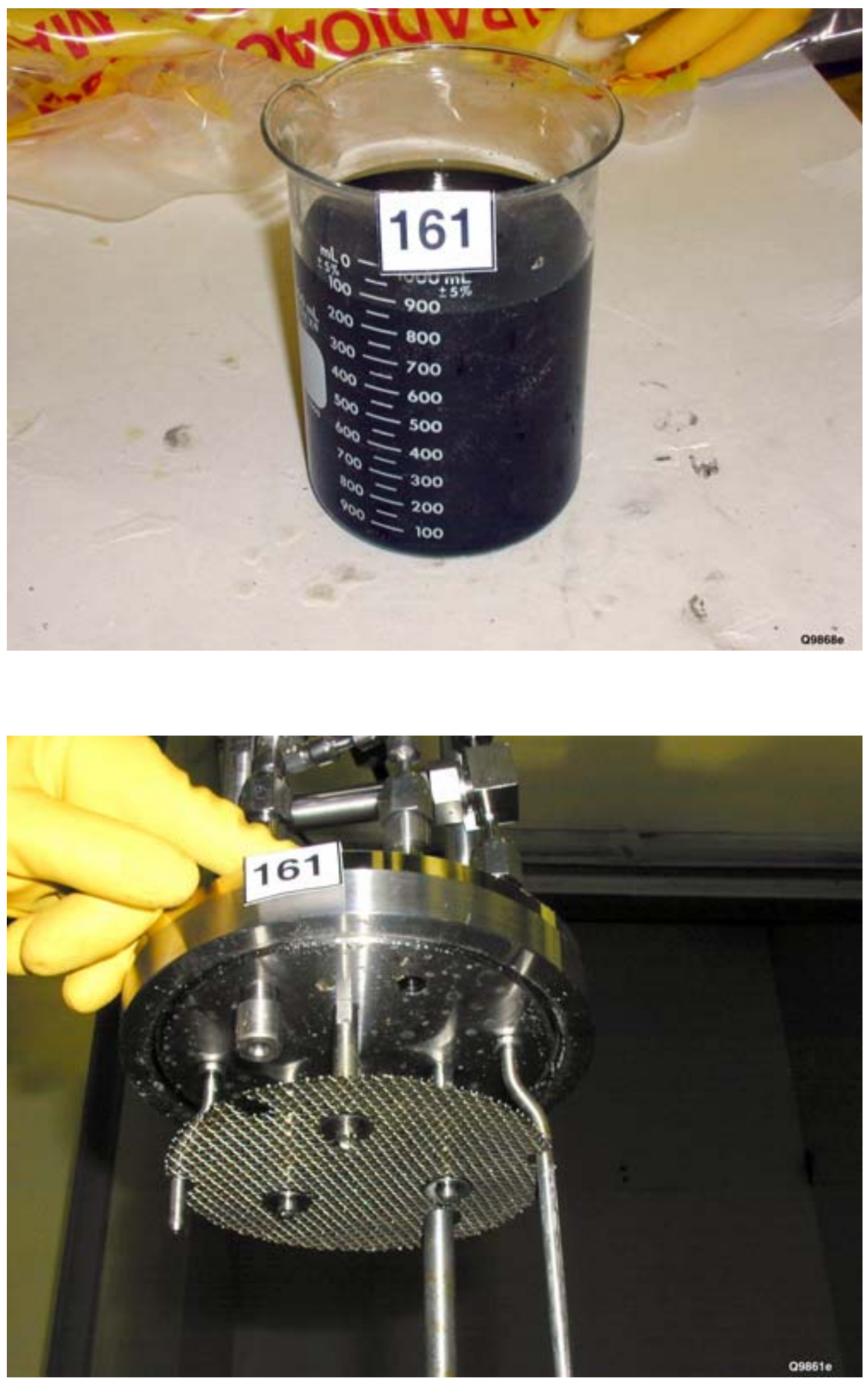

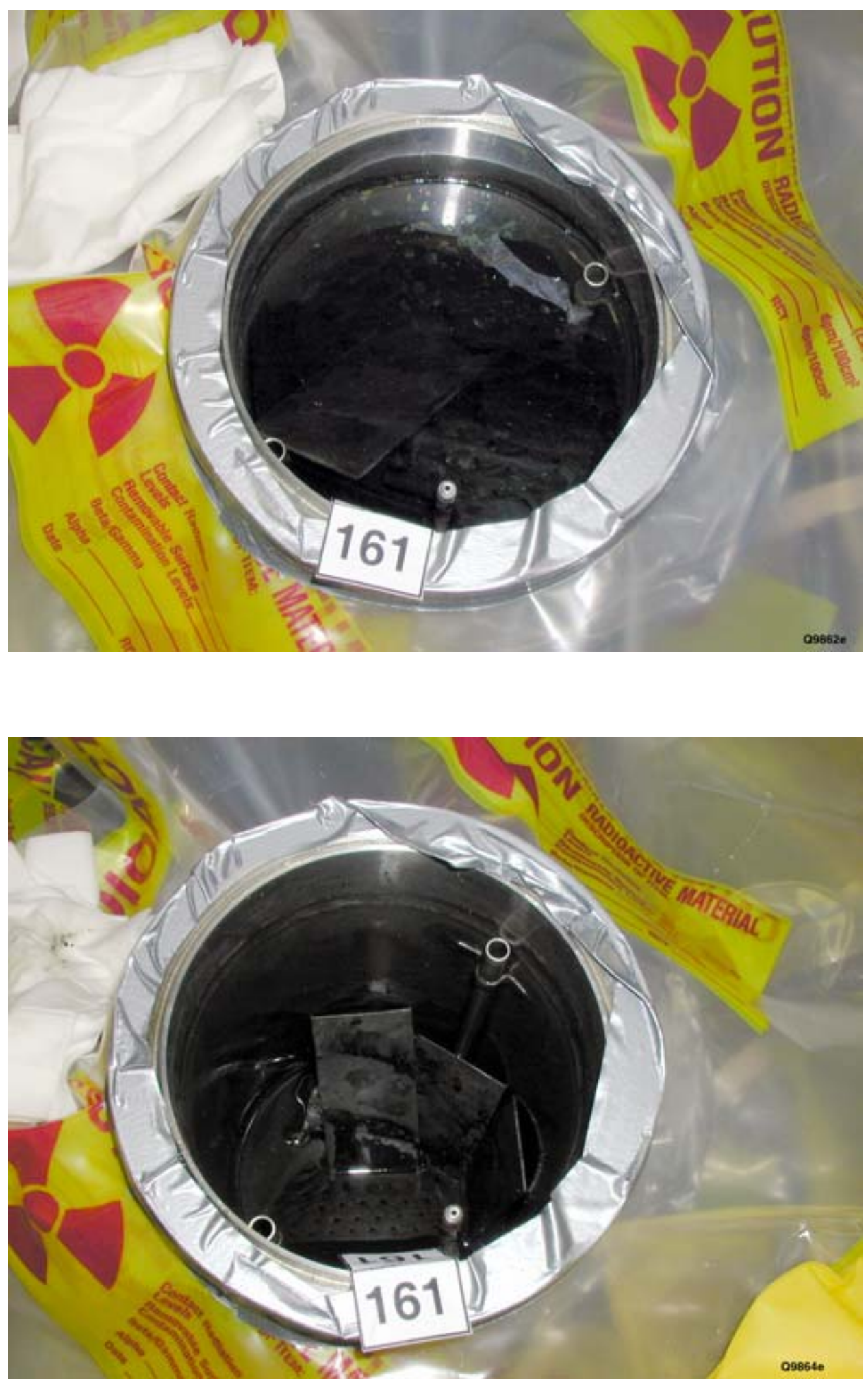

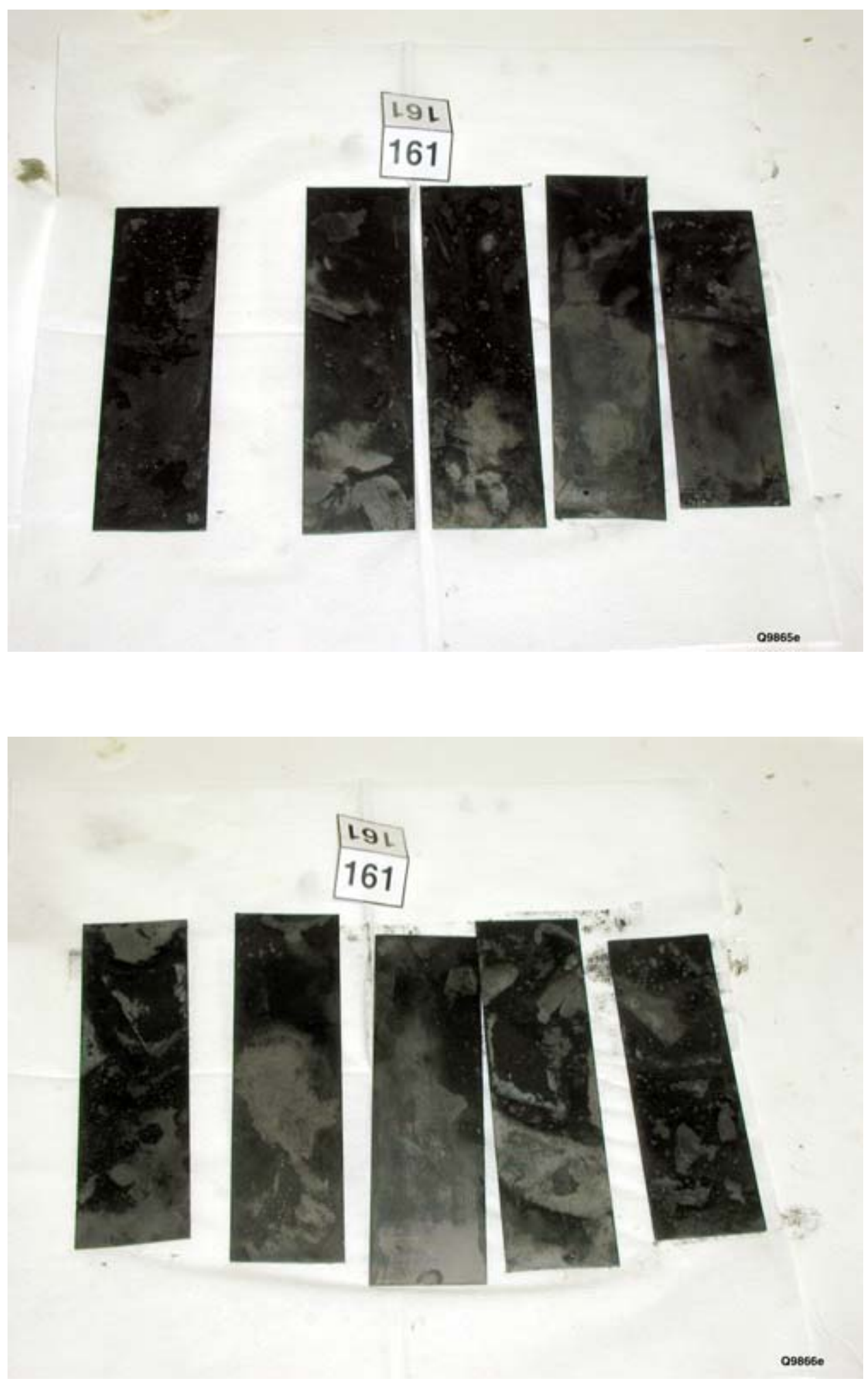

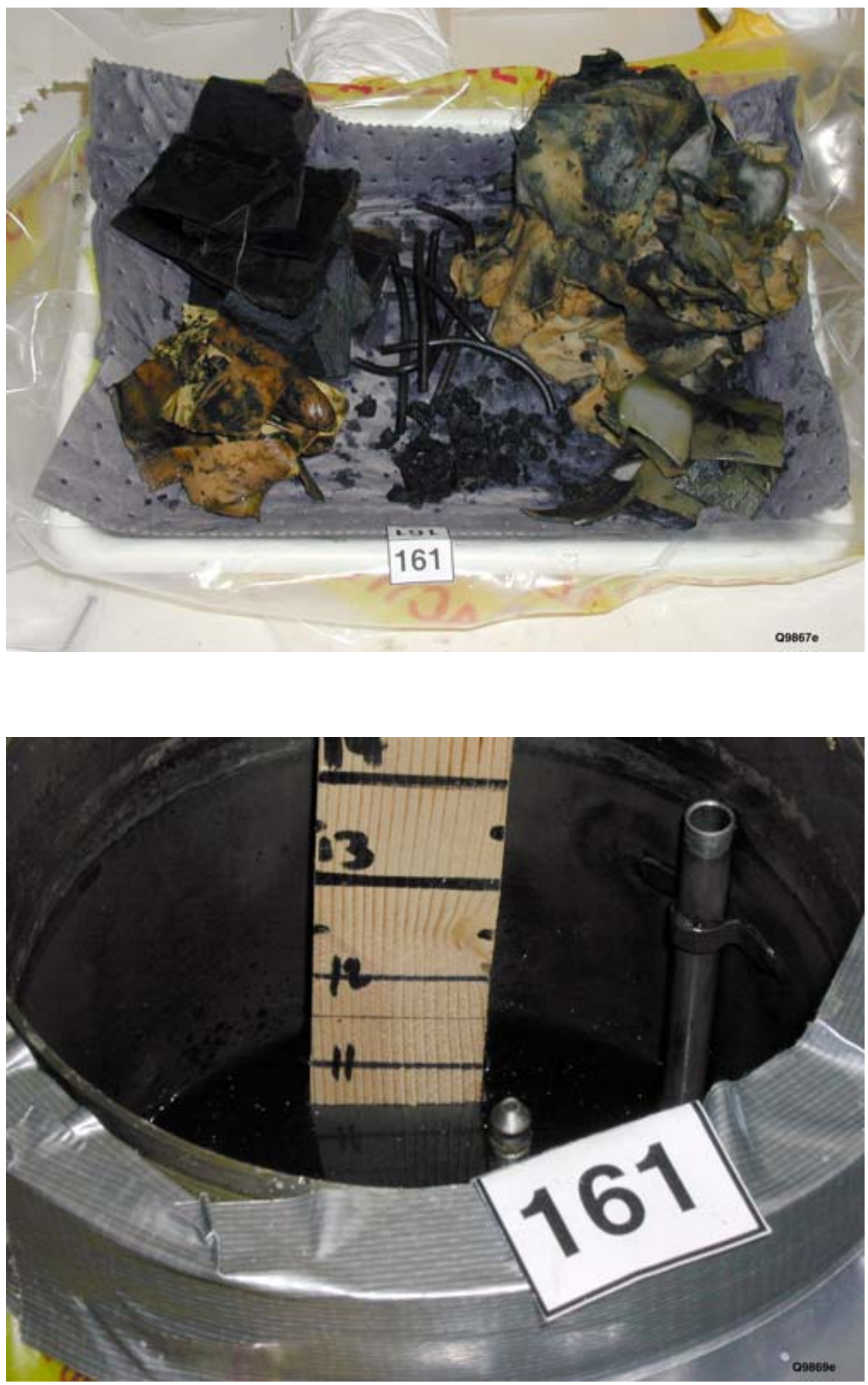
Vessel TC-162
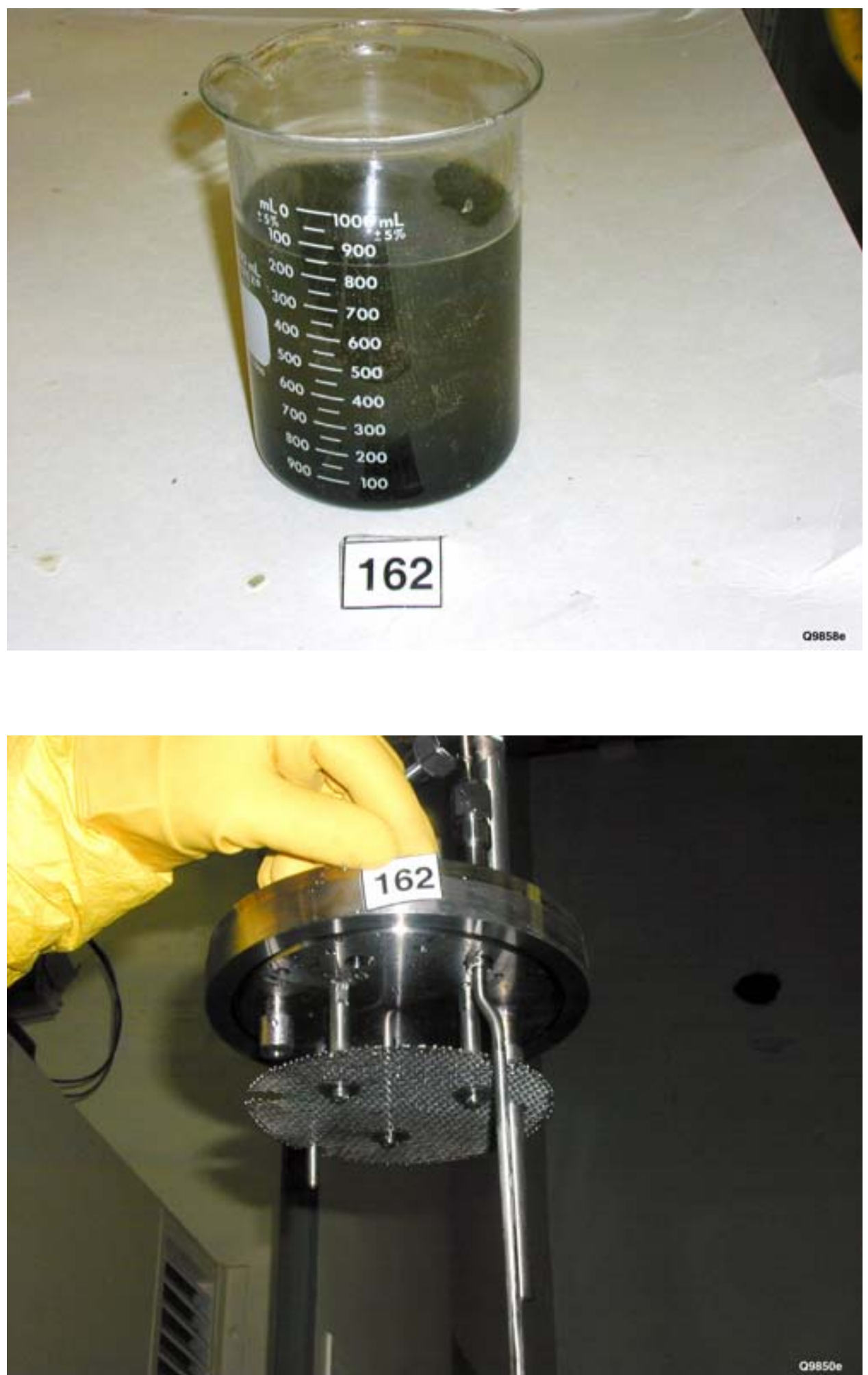

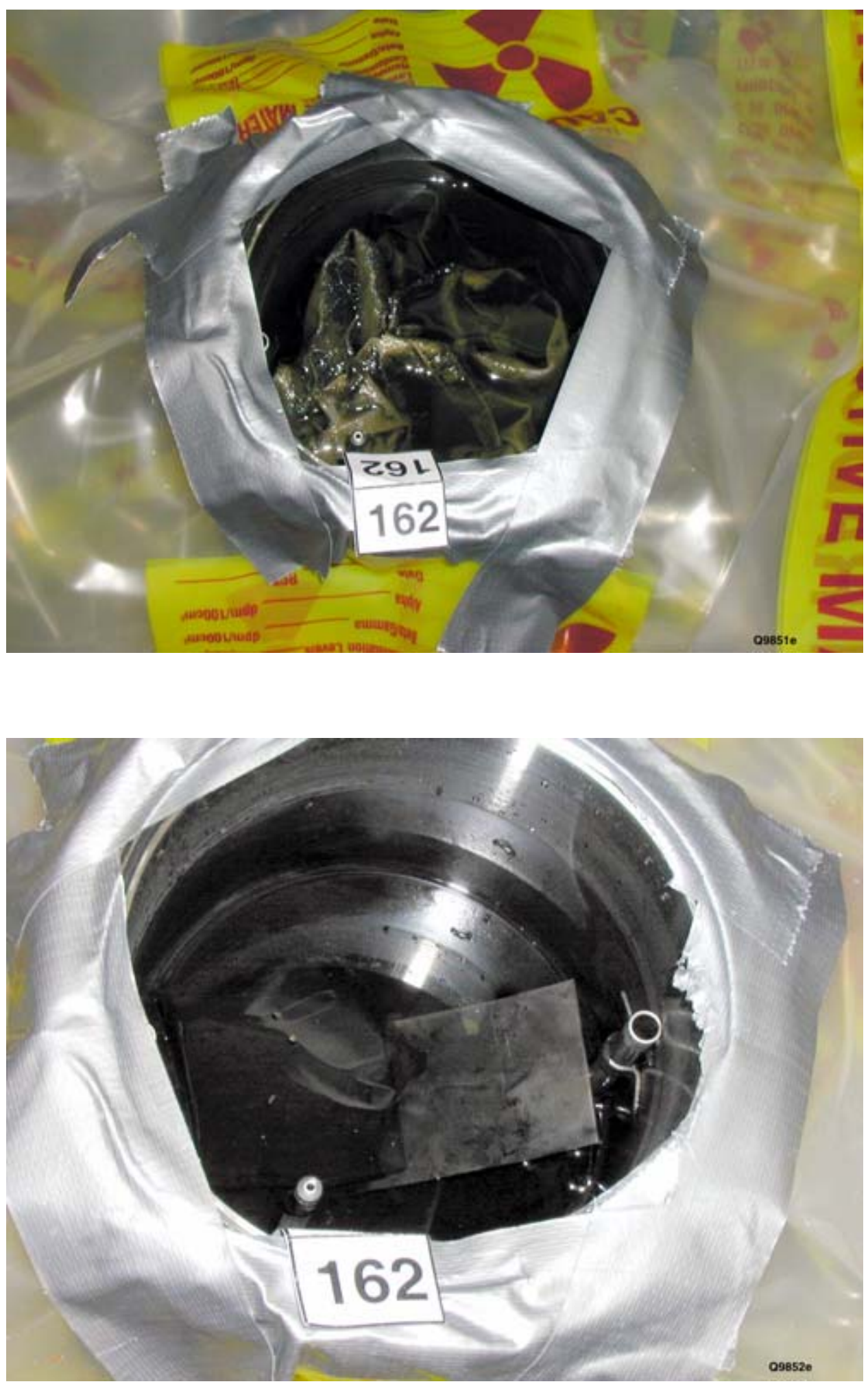

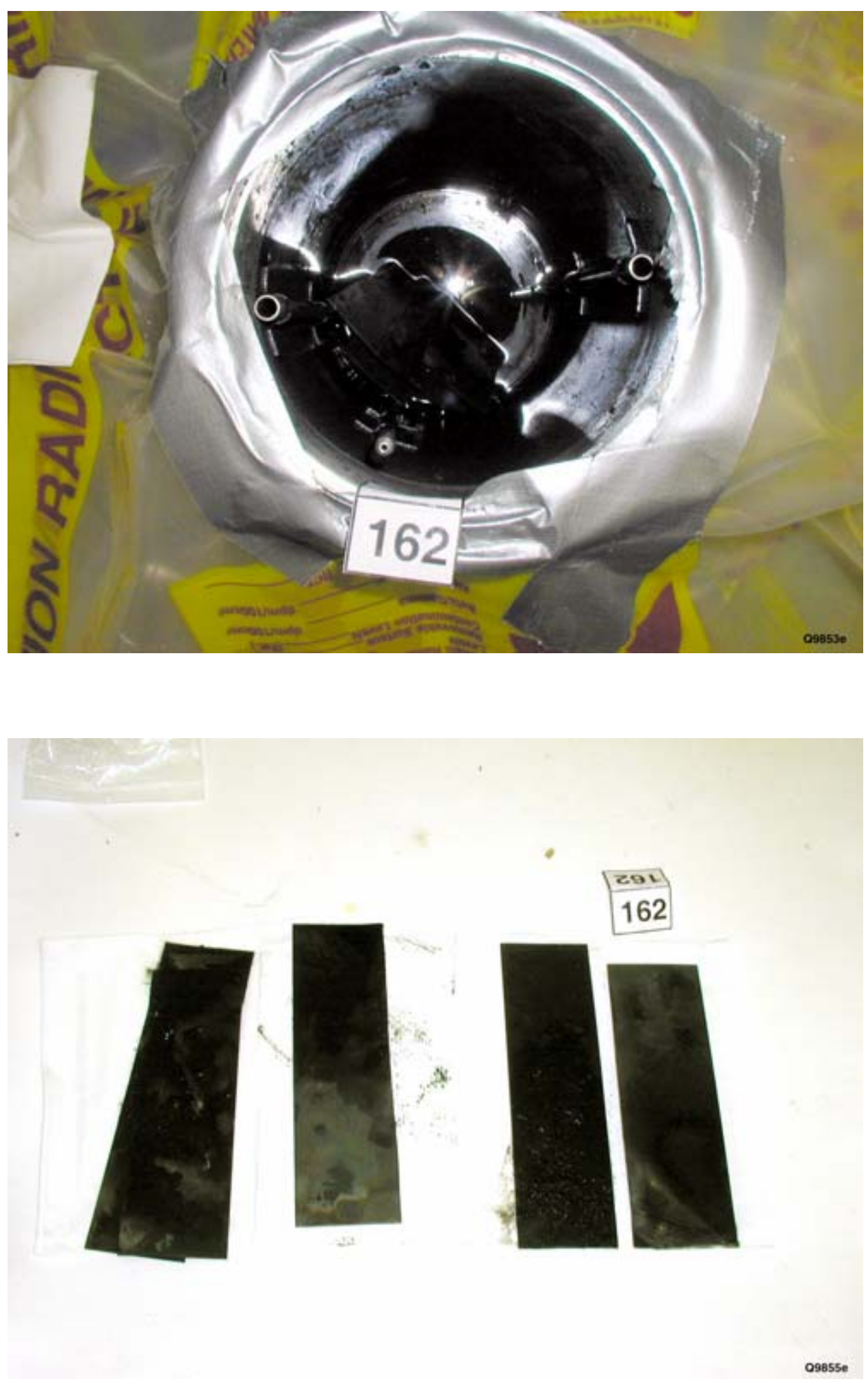

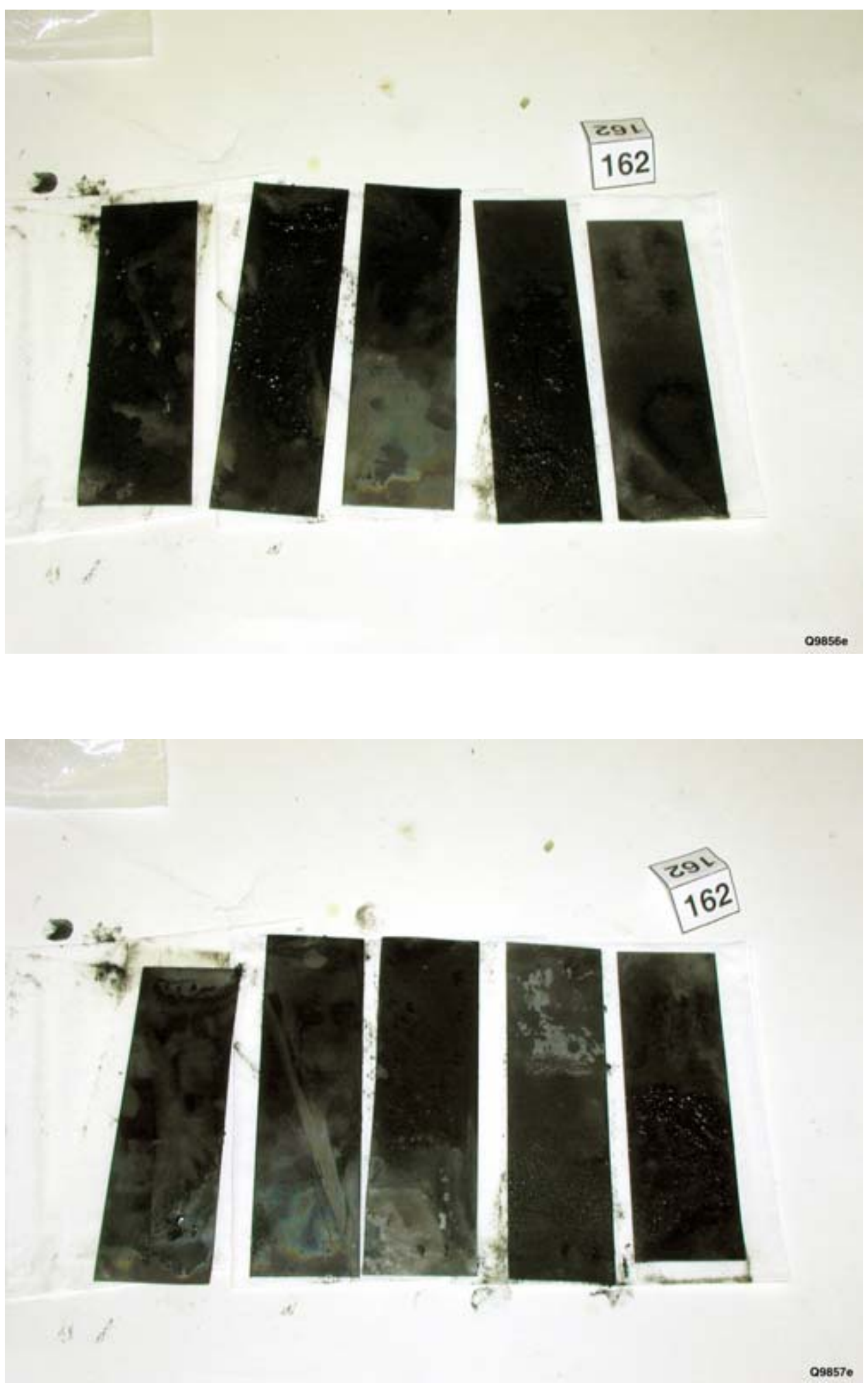

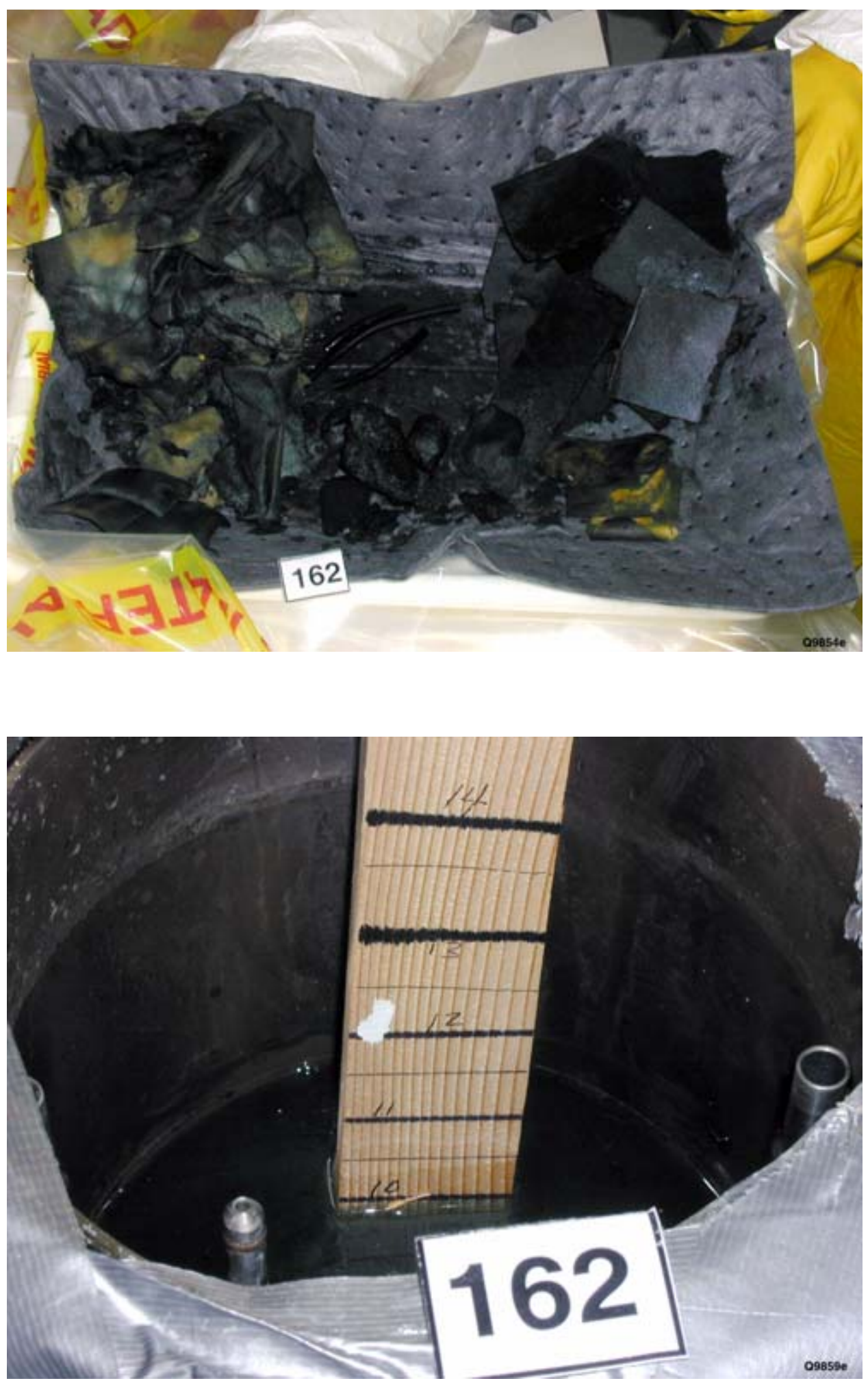
Vessel TC-166
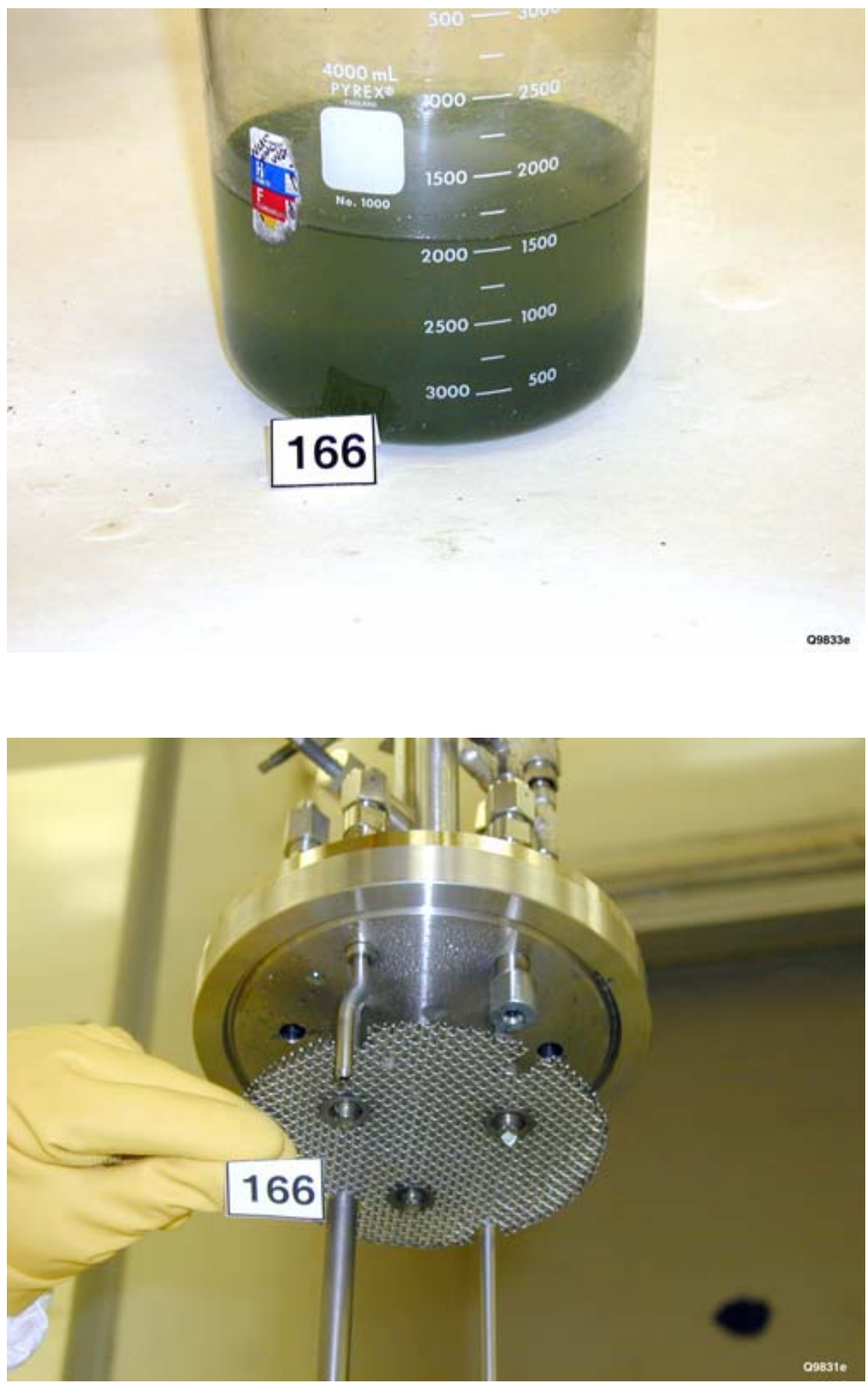

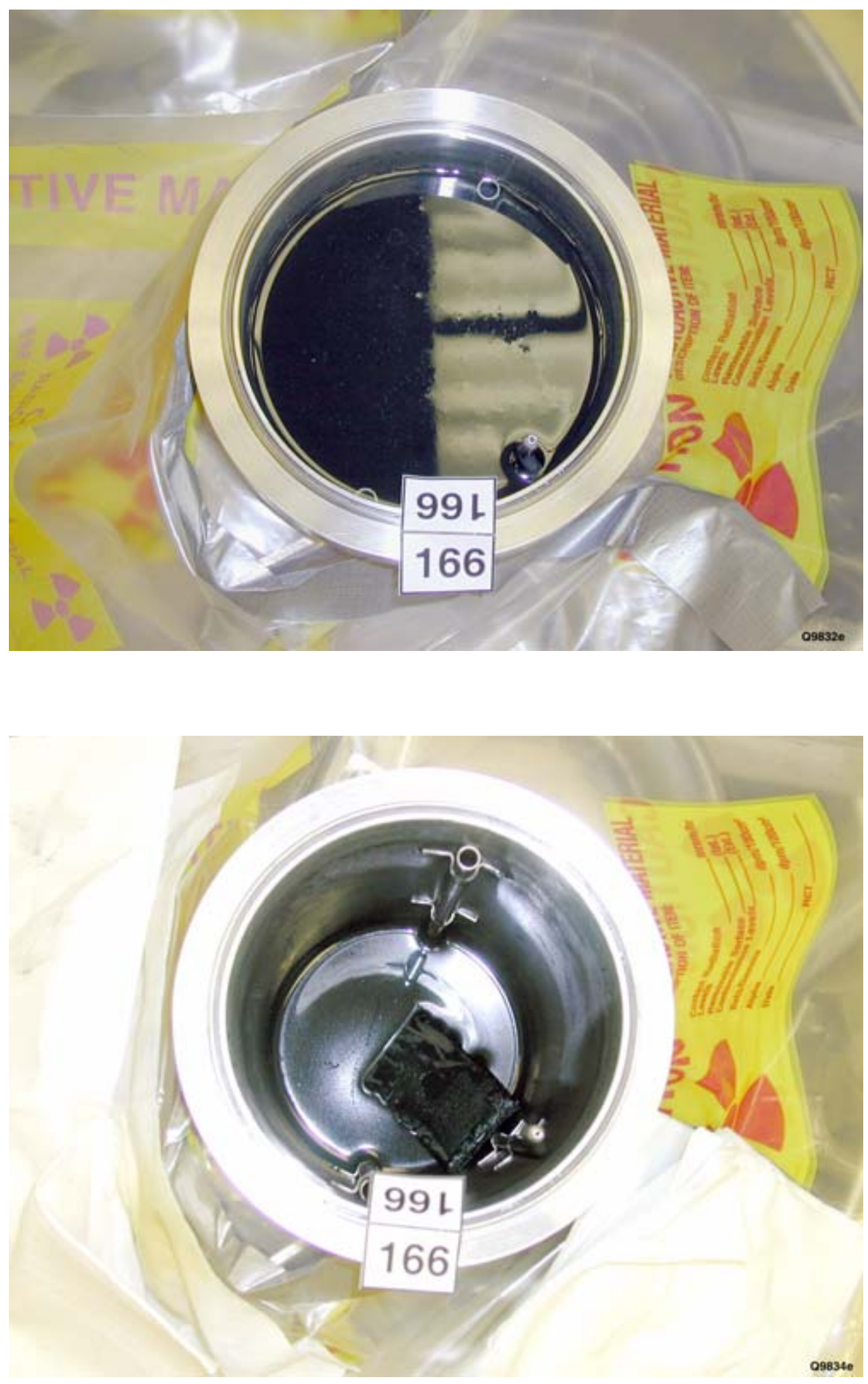
\begin{tabular}{|l|}
991 \\
\hline 166 \\
\hline
\end{tabular}

$$
\begin{array}{|l|}
\hline 994 \\
\hline 166 \\
\hline
\end{array}
$$

86 


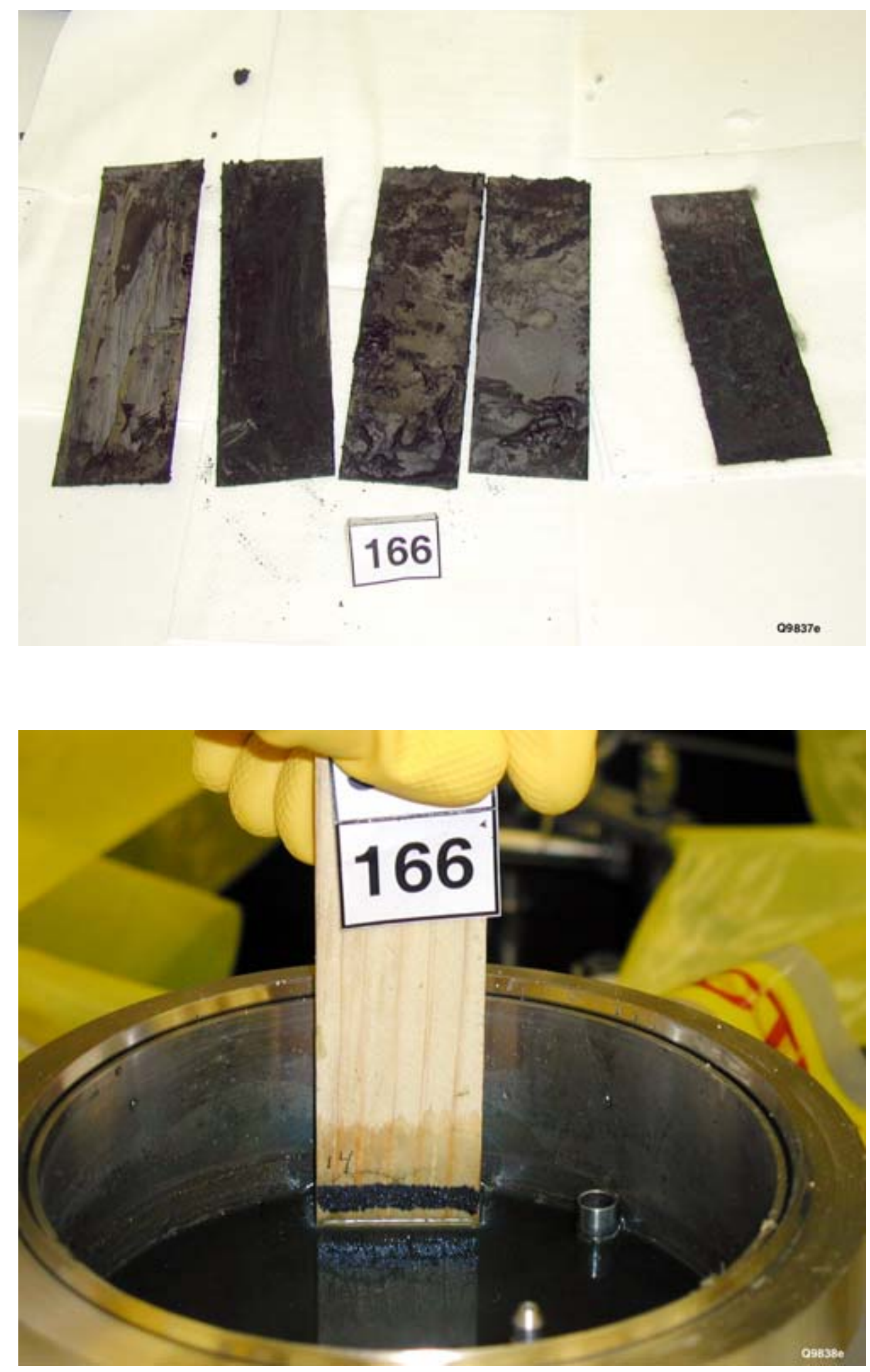

